\title{
A review on electrospun bio-based polymers for water treatment
}

\author{
T. C. Mokhena ${ }^{1,3}$, V. Jacobs ${ }^{1,2 *}$, A. S. Luyt $t^{3,4}$ \\ ${ }^{1}$ CSIR Materials Science and Manufacturing, Polymer and Composites, Port Elizabeth, South Africa \\ ${ }^{2}$ Department of Chemistry, Faculty of Science, Nelson Mandela Metropolitan University, Port Elizabeth, South Africa \\ ${ }^{3}$ Department of Chemistry, Faculty of Natural and Agricultural Sciences, University of the Free State (Qwaqwa Campus), \\ Phuthaditjhaba, South Africa \\ ${ }^{4}$ Center for Advanced Materials, Qatar University, Doha, Qatar
}

Received 28 January 2015; accepted in revised form 5 May 2015

\begin{abstract}
Over the past decades, electrospinning of biopolymers down to nanoscale garnered much interest to address most of the millennia issues related to water treatment. The fabrication of these nanostructured membranes added a new dimension to the current nanotechnologies where a wide range of materials can be processed to their nanosize. Electrospinning is a simple and versatile technique to fabricate unique nanostructured membranes with fascinating properties for a wide spectrum of applications such as filtration and others. These nanostructured membranes, fabricated by electrospinning, were found to be of a paramount importance because of their advanced inherited properties such as large surface-to-volume ratio, as well as tuneable porosity, stability, and high permeability. The extensive research conducted on these materials extended the success of electrospinning not only to bio-based polymer nanofibres, but to their hybrids and their derivatives. The technique also created avenues for advanced and massive production of nanofibres. This paper reviews the recent developments in the electrospinning technique. Electrospinning of biopolymers, their blends and functionalization using metals/metal oxides, and the potential applications of electrospun nanofibrous membranes in water filtration are discussed.
\end{abstract}

Keywords: nanomaterials, electrospinning, nanofibre materials, biopolymers, biocomposites

\section{Introduction}

The exponential growth of the population, water scarcity, and man undesirable practices have spurred efforts to develop innovative technologies to produce high quality water at relatively low cost and energy $[1,2]$. Urbanization, industrial activities, waste dumping, and alien plants are common practices contributing to the current environmental crisis [3, 4]. For example, the mining industries, although serving as a one of the driving forces of many countries' economy, dump billions of tons of hazardous materials into the environment. The emissions of such pollutants into the air and water are seriously considered as primary factors to the common respiratory, neural and intestinal diseases. A safe and healthy environment is a priority that needs immediate intervention in both developing and well-developed countries [5, 6]. These challenges call upon novel and effective technologies to address the current environmental issues, either by protecting the environment and current water sources or by producing high quality water from available sources (oceans and wastewater) without harmful by-products $[5,6]$.

Over the past decades, the production of nanofibres gained much interest and attention to develop innovative materials with properties that are suitable to address the challenges related to water treatment. Nanofibres are a new class of nanomaterials with

\footnotetext{
*Corresponding author, e-mail: VJacobs@csir.co.za

(C) BME-PT
} 
inherited properties such as the large surface-to-area ratio, high porosity, flexibility, stability, and permeability. Several routes have been utilized to fabricate these nanostructured materials from different materials such as drawing, templates synthesis, phase separation, self-assembly, electrospinning etc. [8-10]. Amongst them, electrospinning technique received a considerable interest due to its simplicity, efficiency and versatility in producing nanofibres [8-10].

In the electrospinning process, an electric field is introduced to the solution (or melt) to produce extremely long fibres with diameters down to a few nanometers. Almost all soluble materials can be electrospun into nanofibres. These include synthetic and natural polymers, polymer alloys and polymers loaded with chromophores, nanoparticles, or active agents, as well as metals and ceramics [8]. This technique gained much interest in the past two decades not only because of its simplicity, but also due to its feasibility to produce consistent long nanofibres with desirable properties which cannot be fabricated through other techniques. The resulting nanostructured materials with an extremely large surface to volume ratio, and engineered porosity, malleability, stability and functionality, have been applied in a wide variety of fields $[8,10]$.

Research has escalated in electrospinning of biopolymers, their hybrids and derivatives, for various applications because of their unique properties such as renewability, biodegradability and their abundant availability [7, 11]. Generally, biopolymers are defined as polymeric biomolecules generated by living organisms. They are categorized according to the monomeric units that build up the complex polymeric structure, namely polynucleids (ribonucleic acid (RNA) and deoxyribonucleic acid (DNA)), polypeptides (proteins), and polysaccharides (cellulose, and chitosan). The electrospinnability of most biopolymers is still a challenge because of numerous factors [11-15]. These include their rigid structure, high conductivity, high surface tension, and their gelation at fairly low concentrations. Several routes have been proposed to improve their electrospinnability such as the use of copolymers [16] and the modification of the processing device $[13,15]$.

A number of biopolymers, such as DNA [17], silk [18], chitosan [19], collagen [20], fibrinogen [21], gelatin [22], hyaluronic [13, 15], cellulose [23], and alginate [24] were successfully electrospun into nanofibres for their application in various fields such as filtration, biomedical and tissue engineering. Only few of them were, however, applied in air and water treatment [25-27]. Their readily water solubility and biodegradation are common factors that disrupt the success of electrospun bio-based nanofibrous membranes, especially in water filtration. The addition of nanoparticles [28, 29], functionalization and the use of co-polymers [30] to enhance stability and biocidal activity have been the major object of research in electrospun nanofibrous membranes (ENM).

Even though there is some success in electrospinning a broad spectrum of materials since its invention a century ago, the throughput of nanofibres is still a limiting factor in the industrial production for commercial practice. However, there were several modifications on the classical laboratory electrospinning setup and new technological innovations to increase the production rate of the electrospun nanofibres. These technologies include bubble electrospinning [31], multi-jet [32] and bowl electrospinning [33].

In this review we discuss the fabrication of electrospun biobased nanofibres, their hybrids and derivatives using electrospinning technique. The factors that influence the properties of the electrospun nanofibres, and their functionalization using various methods, to enhance their performance in water and wastewater treatment, are discussed. We also look at other innovative technologies to modify classic electrospinning and to improve the properties and production of electrospun nanofibres.

\section{Electrospinning process}

\subsection{Historical background on electrospinning}

Electrospinning was initially not considered a viable technique because of difficulties with drying and collection of the nanofibres during its execution. However, it gained scientific and commercial publicity in the past two decades. Raleigh was the first to discover electrospinning in 1897, and a thorough study on electrospraying was done by Zeleny in 1914 [34, 35]. Cooley [36] was one of the scientists that patented the electrospinning technique about 100 years ago. However, the electrospinning technique gained enormous interest later in the early 1990s, thanks to the Reneker group. The group studied the mechanisms involved during electrospinning which spurred much interest in the nanotechnology arena because of the size of the resulting nanofibres. In Germany (in the early 1930 s to 1940 s), Formhals published a series 
of patents based on the process and apparatus to execute this simple and versatile technique [37-39]. Later in the 1960s, Taylor studied the initiation of the jet from the drop on the apex of the needle when an electric field was applied. The conical shape formed because of the electric forces surmounting the solution surface tension was later named after him, 'Taylor cone' [10, 40]. By that time the technique was called 'electrostatic spinning'. The considerable interest in the electrospinning technique in the 1990s resulted in the new name 'electrospinning' [40, 41]. The name 'electrospinning' was then accepted and is now widely used in the literature as a description of this viable technique to produce ultrathin fibres from a polymer solution or melt through application of electrical forces. The success of this technique is evidenced by the number of publications each year by universities, research institutes, and about 20 commercial enterprises, who are involved in the application of electrospun nanofibres (Donalson company Inc., Espin technologies Inc., and Elmarco etc.) [31].

\subsection{Fundamentals of electrospinning}

Almost all soluble materials can be electrospun into nanofibres, with diameters ranging from several micrometres down to tens of nanometres. Over 200 polymers were successfully electrospun into long ultrathin fibres for a wide variety of applications, mostly from polymer solutions [40, 42]. A classical setup of the electrospinning technique is shown in Figure 1. It consists of a spinneret with a metallic needle, a syringe pump, a high voltage power supply, and a grounded collector $[8,40,43]$. Horizontal and vertical setups are commonly adapted configurations, but in some cases upward electrospinning was also utilized [44].

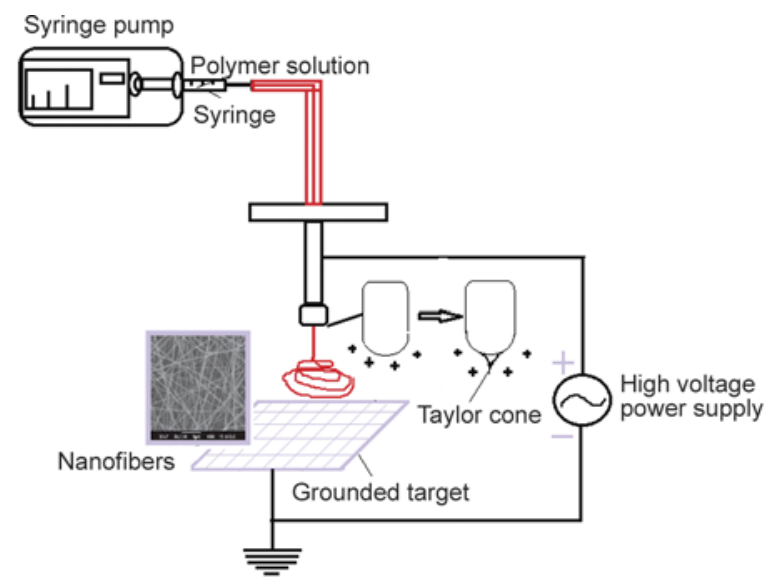

Figure 1. Schematic representation of electrospinning apparatus

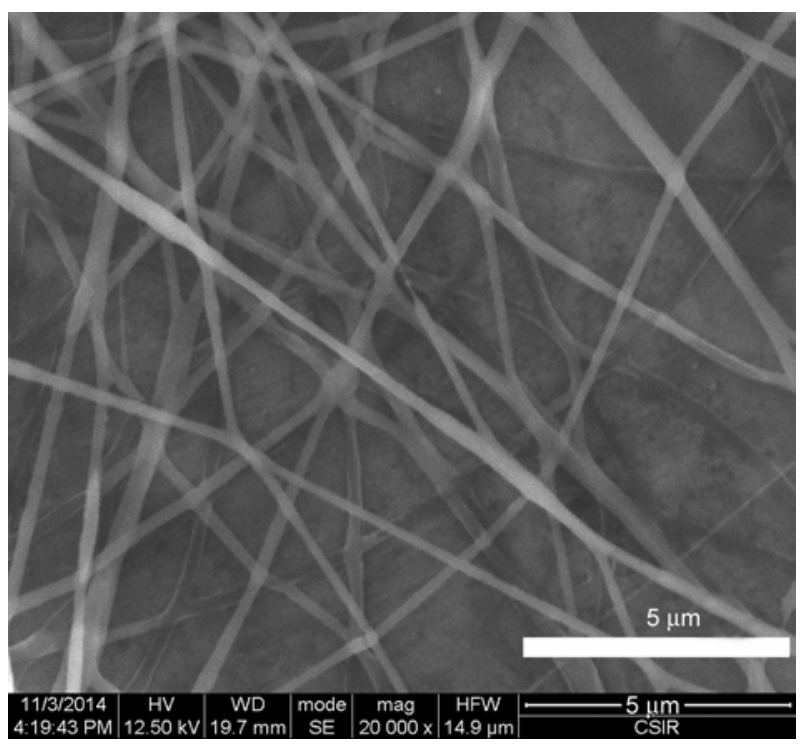

Figure 2. SEM micrograph of alginate nanofibres

Basically, the sol-gel, blend, composite, or polymer solution/melt is loaded in the syringe is driven to the needle tip by a syringe pump, forming a hemispherical droplet at the tip. A voltage $(5-40 \mathrm{kV})$ is applied to the solution on the needle which causes the drop to stretch into a conical shape (known as Taylor cone) [45]. Depending on the viscosity of the solution (which must be sufficient enough to withstand stretching and whipping to avoid any varicose breakup, which forms nanoparticles) an electrified jet is formed and moves towards to an oppositely charged collector. During this trip the solvent evaporates and the jet solidifies to form nonwoven webs on the collector. The jet is only stable from the tip of the needle, whereafter instability starts. Interestingly, this technique offers the processor a platform to control the resulting morphology and structure of the nanofibres through changing of solution properties and physical parameters. Many well-organized papers describe in detail the effect of these parameters $[8,34,43,45]$. Furthermore, the solvent and cosolvent play a significant effect in determining the resulting morphology and structure. The resulting nanofibres have high porosity, large surface to volume ratio, and good mechanical properties, which open doors for a wide variety (Figure 2) $[8,46]$.

\section{Factors affecting the electrospinning process}

Although electrospinning is a simple and straightforward technique, there are several parameters that are important (solution properties, processing parameters, and ambient conditions), that must be consid- 
ered since they significantly affect the quality of the resulting nanofibrous membranes. The solution properties include conductivity, concentration, surface tension, and molecular weight; the processing parameters include voltage, tip-to-collector distance, collector shape, diameter of the needle and feeding rate; the ambient conditions such as humidity and temperature of the surroundings are also important.

\subsection{Solution parameters}

Despite the fact that all these parameters have a significant effect on the resulting product, the solution properties serve as a more decisive parameter. The solution concentration and/or viscosity have to be sufficient enough to prevent the varicose breakup of jet to allow a continuous stream in the spinning solution. Both are directly dependent on the polymer molecular weight which defines the entanglement of the chains to withstand the Coulombic stretching force to prevent the jet breakage into droplets by surface tension [47-50]. The optimal concentration and/or viscosity are required because too high concentration/viscosity may result in larger diameter and clogging of the capillary [47-50]. Nevertheless, the gelation (highly viscous) at fairly low concentrations (below entanglement concentration) disrupts the electrospinnability of the biopolymers, resulting in collection of droplets. Moreover, most of these polymers are inherently polyelectrolytic (e.g. alginate and chitosan) which increases the solution conductivity. This also contributes to the difficulties in electrospinning of natural polymers from their aqueous solutions $[47,51]$. Several modifications have been done to improve their spinnability. The use of copolymers such as poly(vinyl alcohol) (PVA) and polyethylene oxide (PEO) was found to be suitable to reduce the conductivity of the natural polymeric spinning solutions [47, 52-54].

On the other hand, some solvents may be added either to increase $[55,56]$ or decrease the electric properties of the spinning solution $[12,19]$. The most used solvents in electrospinning are shown in Table 1.

Solvents with good volatility, moderate vapour pressure, moderate boiling point, good conductivity and good cohesion with the polymer is important in the electrospinning process [12, 56-61]. The solubility of the polymer, however, does not guarantee the solution spinnability [12]. For example, partial solubility in a solvent can result in smooth bead-free nanofibres. Some reports suggested that a single solvent system could result in beaded nanofibres, whereas the addition of partially soluble solvent could improve the nanofibre morphology $[57,59,61]$.

\subsection{Setup parameters}

Essentially, the electrospinning process begin directly at the point at which electrostatic forces overcomes the solution surface tension and viscoelastic forces. Typically, a critical voltage is required to eject the charged jet from the drop at the nozzle (Taylor cone) $[15,62]$. For instance as the concentration, or similarly, the viscosity increases, higher electrical forces are required to overcome both the surface tension and the viscoelastic forces for fibre stretching. The size of the droplet at tip of the nozzle depends on

Table 1. Properties of solvents and liquids used in electrospinning

\begin{tabular}{|c|c|c|c|c|c|c|}
\hline Solvent & $\begin{array}{l}\text { Density } \\
{\left[\mathrm{g} \cdot \mathrm{cm}^{-3}\right]}\end{array}$ & $\begin{array}{c}\text { Viscosity } \\
{[\mathrm{cP}]}\end{array}$ & $\begin{array}{c}\text { Boiling point } \\
{\left[{ }^{\circ} \mathrm{C}\right]}\end{array}$ & $\begin{array}{c}\text { Dipole moment } \\
\text { [D] }\end{array}$ & $\begin{array}{c}\text { Dielectric } \\
\text { constant }\end{array}$ & $\begin{array}{c}\text { Surface tension } \\
{\left[\mathrm{mN} \cdot \mathrm{m}^{2}\right]}\end{array}$ \\
\hline Acetic acid & 1.05 & 1.12 & 118.0 & 1.68 & 6.15 & 26.9 \\
\hline Acetone & 1.39 & 0.32 & 78.0 & 2.88 & 27.0 & 21.4 \\
\hline Chloroform & 1.50 & 0.53 & 61.6 & 1.15 & 4.80 & 26.5 \\
\hline Dichloromethane & 1.33 & 0.41 & 40.0 & 1.60 & 8.93 & 28.1 \\
\hline Dimethylacetamide & 0.94 & 1.96 & 165.0 & 3.72 & 37.8 & 36.7 \\
\hline Dimethylformamide & 0.99 & 0.80 & 153.0 & 36.70 & 38.3 & 37.1 \\
\hline Dimethyl sulfoxide & 1.10 & 2.00 & 189.0 & 3.90 & 46.7 & 43.0 \\
\hline Ethylene glycol & 1.11 & 16.13 & 197.0 & 2.20 & 37.7 & 47.0 \\
\hline Formamide & 1.13 & 3.30 & 211.0 & 3.37 & 110. & 59.1 \\
\hline Formic acid & 1.22 & 1.57 & 101.0 & 1.41 & 57.9 & 37.6 \\
\hline Glycerol & 1.26 & 950 & 290.0 & 2.62 & 42.5 & 64.0 \\
\hline Hexafluoro isopropanol & 1.60 & 1.02 & 58.2 & 1.85 & 16.7 & 16.1 \\
\hline Methanol & 0.79 & 0.54 & 65.0 & 1.70 & 33.0 & 22.7 \\
\hline Tetrahydrofuran & 0.89 & 0.46 & 66.0 & 1.75 & 7.52 & 26.4 \\
\hline Triflouroethanol & 1.38 & 1.24 & 74.0 & 2.52 & 8.55 & 43.3 \\
\hline Water & 1.00 & 1.00 & 100.0 & - & 21.0 & 25.2 \\
\hline
\end{tabular}


the feeding rate as well as the needle shape and diameter [13, 62-64]. Therefore, these factors influence the forces acting on the drop which contribute to the jet initiation and stretching. The optimal distance is required to give the electrified jet sufficient time for nanofibre dryness [65-67]. At longer tip-tocollector distance (TCD), the fibre will have sufficient time to solidify before reaching the collector, but if the distance is too long, either beaded fibres or no fibres are collected [65]. Similarly, when the distance is too short, it reduces the flight distance and solvent evaporation, and increases electric field, which results in beads.

One of the essential aspects in electrospinning is the type of collector used. These collectors act as a conductive substrate to collect the charged fibres. Aluminium foil [61] is usually used to collect the nanofibres. However, due to the difficulty to transfer the nanofibres from this collector $[13,15]$, other collectors such as liquid baths [68], metal plates [69], grids [70], parallel or gridded bars $[71,72]$, rotating disks [73], and rotating drums [74] were investigated as possible collectors. Different collectors used in electrospun nanofibres were recently reviewed in [46]. The collectors specifically used in electrospun biopolymers as well as the optimal conditions are summarized in Table 2. The collectors are often used to engineer and design the structure and morphology of the fibres. For example, Matthews et al. [75] observed that collagen nanofibres, collected at lower speeds, were random filaments, whereas collection at higher speeds resulted in deposition of the nanofibres along the rotation axis.

\subsection{Ambient conditions}

Ambient conditions, temperature and humidity, can also affect the morphology and diameter of the nanofibres [77]. It was deduced that the increase in temperature reduces the viscosity of the solution and enhances the solvent evaporation, which results in thinner nanofibres [89]. Depending on the system under investigation, two antagonistic effects are observed: (1) reduction in fibre diameters, and (2) increase in diameter which may result in fusion of the nanofibres [90]. Tripatanasuwan et al. [91] reported that an increase in relative humidity resulted in smaller diameters of the nanofibres. They stated that at the lower relative humidity the rate of solvent evaporation increased, with the opposite effect at higher humidity. Furthermore, the humidity can generate pores of different size and depth depending on the molecular weight of the polymer [92].

\section{Recent advances in electrospinning techniques}

During the past years research on various advancements and modifications on standard needle electrospinning (SNE) with the aim to scale up the nanofibres production, to enhance the stability of the electrospinning technique, and to engineer patterns and desired morphologies of the resulting nanofibres for various applications, has escalated. The production rate has been one of the inhibiting factors for the commercial implementation and industrial viability of the electrospinning processing technique. In SNE the mass production rate is approximately $0.01-0.1 \mathrm{~g} \cdot \mathrm{h}^{-1}$, where the nanofibre source is a single jet arising from a single needle apex through which the polymer solutions is ejected. Various innovative ways to produce electrospun nanofibres with enhanced functionalities were developed. These advances, namely multi-needle and needleless electrospinning, gas-jet electroblowing spinning, and coaxial electrospinning (Table 3 ) are described in the following sections. However, most of these technological advances are mostly applied in synthetic polymers as deliberated in Table 3 .

\subsection{Multi-needle electrospinning}

An increase in the number of nozzles is the most convenient way to increase the production rate of the nanofibres [100, 101]. However, there are some drawbacks associated with multi-needle electrospinning, such as complicated design and large operating space, and repulsion between the nanofibres that causes the uneven deposition of the nanofibres [102]. Furthermore, the clogging of needles discourages the industrial viability of multijet spinning. In industry the needles would require regular cleaning, which would result in complex processes and too much labour. Therefore, several modifications were suggested to overcome the nanofibre repulsions without compromising the production rate. For example, Kim and Park [103] electrospun alginate/PEO nanofibres using multi-nozzle electrospinning with an extra auxiliary electrode to alleviate the repulsion between the jets. PEO $(2 \mathrm{wt} \%)$ /alginate $(2 \mathrm{wt} \%)$ doped with lecithin $(0.7 \mathrm{wt} \%)$ as surfactant produced smooth nanofibres using SNE. The same composition was used for a comparison between nanofibres 


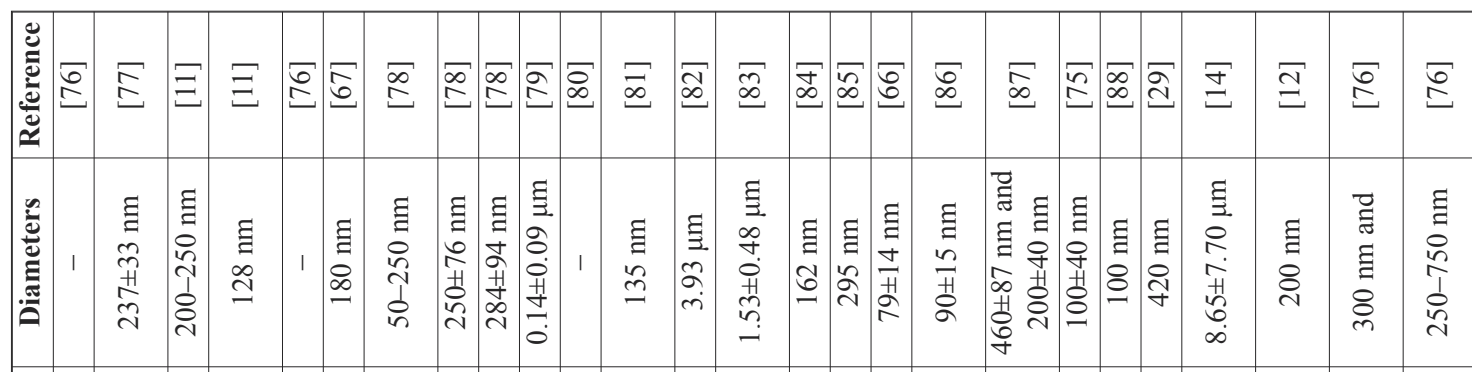

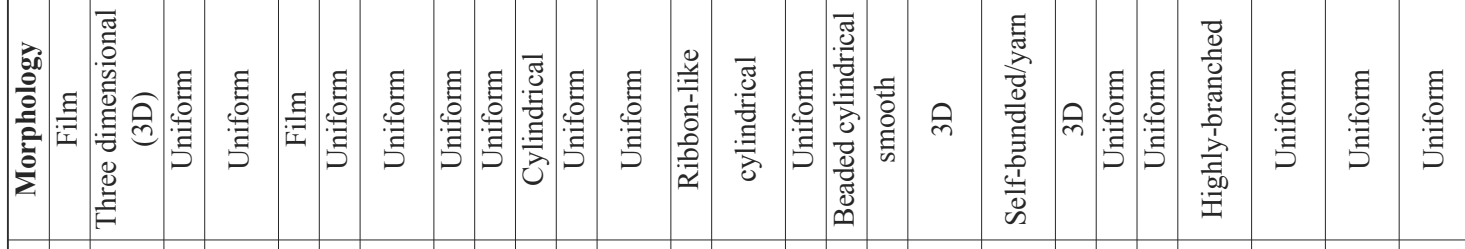

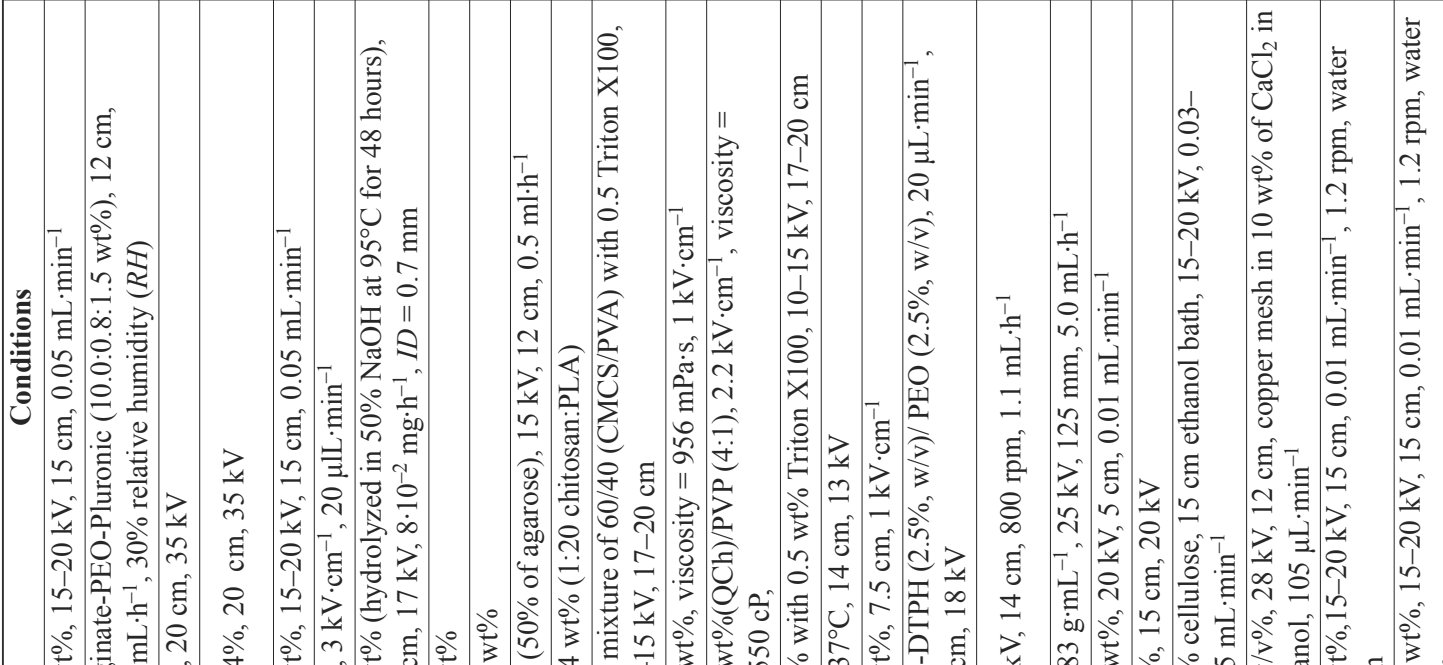

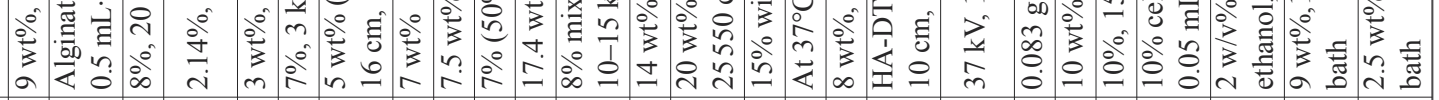

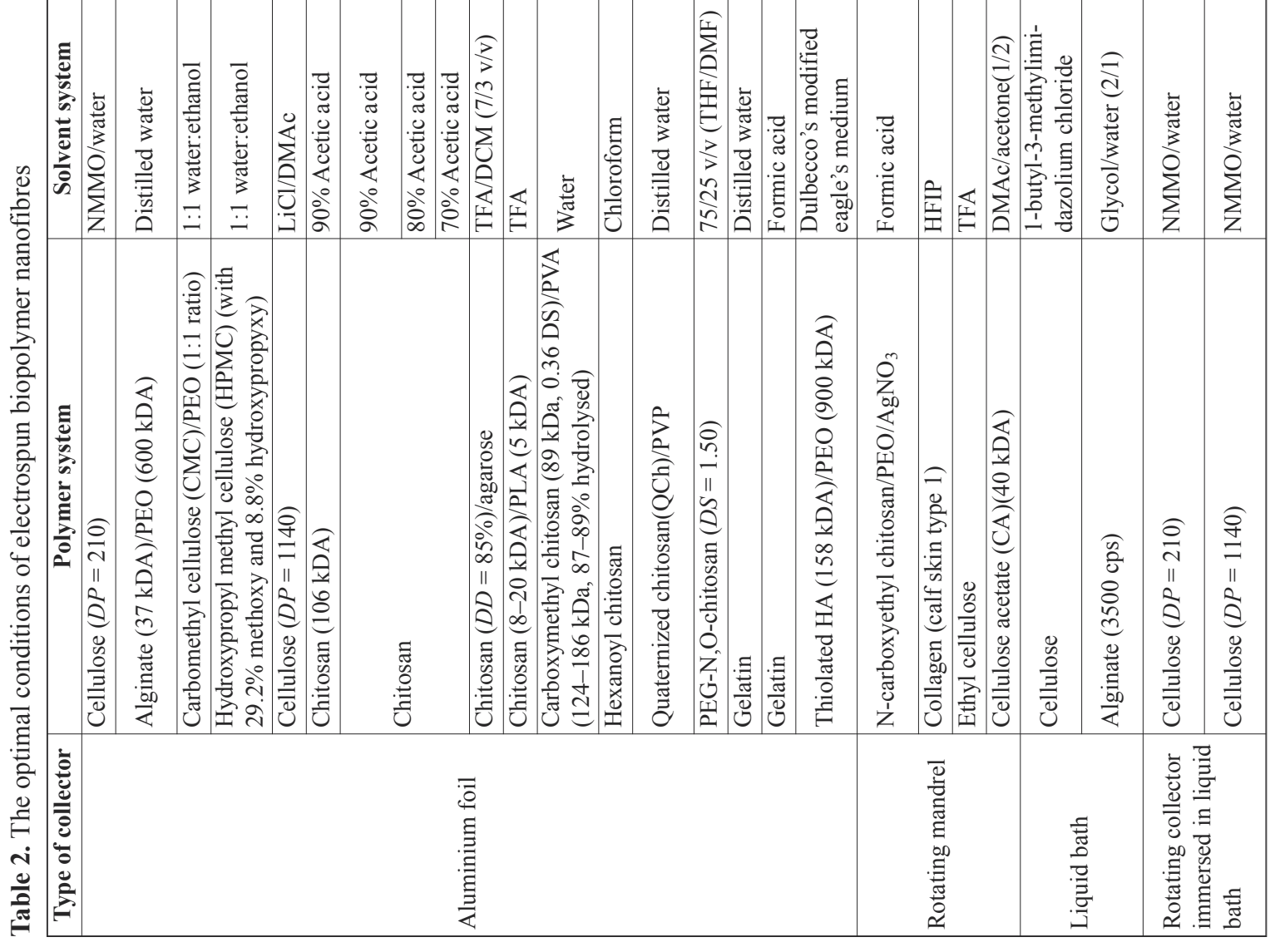


Table 3. The novel advances on standard laboratory electrospinning

\begin{tabular}{|c|c|c|c|c|}
\hline Technique & $\begin{array}{c}\text { Polymer concentration } \\
{[\mathrm{wt} \%]}\end{array}$ & $\begin{array}{l}\text { Average diameter }[\mathrm{nm}] \\
\text { and voltage }[\mathrm{kV}]\end{array}$ & $\begin{array}{c}\text { Throughput } \\
{\left[\mathbf{g}^{\left.-h^{-1}\right]}\right.}\end{array}$ & Reference \\
\hline Bowl & 6 (PEO) and 12 (PCL) & $268 \pm 25$ at 16 and $344 \pm 97$ at 30 & 7.0 & [31] \\
\hline Bubble & 10 (PVA) & $111-48.6$ at $10-30$ & - & [33] \\
\hline Conical wire coil & 9 (PVA) & $275 \pm 113$ at 50 & 2.8 & {$[93,94]$} \\
\hline Gas jet & 8 (PVA) & 220 at 25 & 1.1 & [95] \\
\hline Multi-jet & 15 (PVA) & 230000 & $0.66-0.72$ & [96] \\
\hline Nanospider & $15(\mathrm{PU})$ & 193 at 81.2 & $96.6^{\mathrm{a}}$ & [97] \\
\hline Porous tubular & 20 (nylon-6) & $170.6 \pm 5.0$ at 20 & 5.0 & [98] \\
\hline Splashing & 9 (PEO) & $368 \pm 45.37$ at 60 & 3.0 & [99] \\
\hline
\end{tabular}

produced with and without auxiliary electrodes in multi-nozzle spinning. The auxiliary supported multinozzle showed a higher production rate and smoother nanofibres with diameters of $174 \pm 62 \mathrm{~nm}$ compared to unsupported spun nanofibres that had diameters of $246 \pm 62 \mathrm{~nm}$. A wide variety of multijet electrospinning heads, namely series, elliptic, concentric, line, rectangular and matrix can be utilized to produce nanofibres [96]. The biodegradable blend of cellulose acetate and PVA was prepared by varying the ratio of the jets from 1:3 to 3:1. The average diameters of the fibres increased (220 to $290 \mathrm{~nm}$ ) with a decrease in the number ratio of PVA/CA from 3:1 to $1: 3$. The tensile strength and the modulus increased from 7.0 to $9.4 \mathrm{MPa}$ and 18.1 to $34.0 \mathrm{MPa}$ with an increasing the number ratio of the jets of PVA/CA from $1: 3$ to $3: 1$ [26].

\subsection{Needleless electrospinning}

\subsubsection{Confined needleless electrospinning}

One of the promising processes to scale-up the nanofibre production is needleless electrospinning. This technique avoids the issues of clogging and cleaning of the needles and the complexity of the multiaxial spinning setup. The needleless process is divided into two categories depending on the feeding system: confined feeding and unconfined feeding. The difference between the confined and unconfined needleless electrospinning is the fact that in confined electrospinning the electrospun fluid is enclosed in a reservoir such as an insulating tube $[98,104,105]$ or any other material in which the polymer is protruded, whereas in unconfined systems there is no reservoir for the spinning solution and the droplets are projected naturally from the surface of the solution.

The replacement of the needles in multi-jet spinning is the most convenient way to resolve the complexity and difficulties without compromising the mass throughput $[92,99]$. In this route the polymer fills a porous hollow tube $[93,104]$. The drilled holes on the surface of the tube can be made in different configurations. The positive electrode is immersed into the solution and by using a small pressure the polymer solution is driven through the holes. The production rate is 3-250 times that of the standard electrospinning (SNE), while the nanofibre diameters may range from $300 \mathrm{~nm}$ to several hundreds of microns. Dosunmu et al. [98] used a porous polyethylene tube with pore sizes $10-100 \mu \mathrm{m}$ as reservoir for a $20 \mathrm{wt} \%$ nylon 6 spinning solution. The polymer solution was pushed with air pressure to form multiple jets on the porous surface. The jets protruding from the tube surface were collected on a surrounding vertically placed grounded co-axial wire mesh. The resulting nanofibres have equivalent mean diameters to those produced by SNE, with a much broader distribution. Moreover, different polymers can be electrospun via this method and the porous tube can be made from different materials such as ceramic.

Rotary-jet spinning (RJS) is composed of a rotating motor, a reservoir and a stationary or rotating collector [106]. The polymer solution is loaded into a punched reservoir, either continuously or once in one measurement or production. The perforated reservoir has two side wall orifices which rotate vertically to the surrounding collector. Because of the centrifugal forces on the solution, the polymer jets are forced out of the reservoir through the punched side wall, and subsequent jet extension and dryness yield three dimensions of nanofibres. The advantages include the use of low voltages, the production of three dimensional (3D) morphologies, controlled porosity, independence of solution conductivity, and larger mass production than SNE. Various polymer solutions (poly(lactic acid) (PLA) in chloroform, polyethylene oxide (PEO) in water, 
poly(acrylic acid) (PAA) in water, gelatin in acetic acid were successfully electrospun to three dimensional nanofibres by Badrossamay et al. [106]. They indicated that with the control over the spinning solution concentration and rotating speed the morphology of the nanofibres can be tuned.

\subsubsection{Unconfined needleless electrospinning}

Unconfined needleless electrospinning is the electrospinning the solutions naturally from a liquid surface. Yarin and Zussman [107] prepared nanofibres by a needleless method using the ferromagnetic liquid sub-layer below the polymer solution. It was established that the nanofibres can also be produced without a ferromagnetic sub-layer, but at a much higher voltage. The disadvantage of this method is that the number of jets and their location cannot be controlled since the jets protrude naturally from the liquid surface. Nevertheless, they produced nanofibres with diameters ranging from 200 to $800 \mathrm{~nm}$.

Another technique involves the use of charged cylindrical rotators dipped in the spinning solution [108, 109]. This is the only technique that was applied industrially since research on the enhancement of the production rate started, and is known as nanospider $^{\mathrm{TM}}$ [97]. The technique involves a polymer solution in a container and a cylindrical charged metal rotating at a certain speed. The charged rotating metal is partially immersed in the solution. When the solution is electrified by the voltage supplied to the cylindrical rotators, the multiple polymer jets are launched from the circumference of the cylindrical rotators to the grounded collector. Nanofibres with average diameters between 50 and $200 \mathrm{~nm}$ are produced at a rate of $2.53 \mathrm{~g} \cdot \mathrm{h}^{-1}$, compared to conventional electrospinning with a rate of $0.01-$ $0.1 \mathrm{~g} \cdot \mathrm{h}^{-1}$. Various shapes of rotating nozzles, such as disk and spiral coils, can be used to generate narrow distribution nanofibres with a higher mass production than SNE. A rotating spiral coil made of metal wire was used by Wang et al. [94] to eject the jets from the surface of each spiral wire. Depending on the concentration and applied voltage, ultrafine nanofibres were produced. Nanofibres with narrower distribution were generated with the mass production increasing with voltage from 2.94 to $9.42 \mathrm{~g} \cdot \mathrm{h}^{-1}$ for 45 and $60 \mathrm{kV}$, respectively. The disadvantage of these nozzle processes is the uneven electric field distribution on the spiral wire. Niu et al. [110] com- pared a rotating disk and cylinder to envisage the effect of the shape on the resulting nanofibre production. They indicated that the disk nozzle requires a lower voltage to initiate the fibre production than the cylinder nozzle, with finer nanofibre than those from the cylinder at similar conditions. The mass production was equivalent for both the rotating disk and cylinder, but higher than that of SNE.

Another approach is the polymer solution dripping from the reservoir onto a rotating cylinder, known as splashing electrospinning. In this case the reservoir is held horizontal to a charged cylinder rotating at a certain speed. With a controlled speed, gap distance, and solution parameters the nanofibre structure can be tuned with enhanced production (2445 times) compared to SNE [99] (Table 3). The influence of processing and solution properties on the resulting nanofibres via splashing was studied by Tang et al. [111]. Increased concentration was found to increase the mean diameter of the fibre, whereas an increase in the voltage decreased it. A decrease in mean diameter was reported with an increase in both rotating speed and gap distance. They found that using statistical analysis (analysis of variance (ANOVA)), the optimal conditions for fine nanofibres with narrower distribution (PEO in water) were as follows: concentration (6.94 wt\%), voltage $(12.38 \mathrm{kV})$, gap distance $(3.5 \mathrm{~cm})$, and rotational speed $(0.76 \mathrm{rpm})$. Also, nanofibres with mean diameters ranging from 100 to $400 \mathrm{~nm}$, were obtained. In the bowl-edge unconfined process, the primary interaction between the electric field and the polymer solution caused fluid perturbations within the bath reservoir filled with polymer solution [31, 41]. These fluid perturbations were responsible for Raleigh-Taylor instabilities formed by gravity forces in the polymer solution. The polymer solutions, due to the instabilities, produced jets protruding from the edge of the bowl which are similar to the jets ejected from the SNE. The bowl has a thin-lipped edged structure where the droplets are ejected to the concentric collector. At the beginning, a high voltage is supplied and then the voltage to initiate the jet formation is reduced to a lower operational value. Stable nanofibres are formed on the collector with high quality nanofibres similar to the optimal nanofibres from SNE, with 40 times faster production. Bubble electrospinning is primarily based on the bubbles on the surfaces of polymer solutions [28]. These bubbles serve as the droplets in which the 
Taylor cone is formed. The gas tube and metal electrode are inserted in the solution to produce the bubbles. When the gas is blown into the solution, the bubbles are formed (in a spherical shape) on the surface of the solution, and when the voltage is applied the bubble shape changes into a conical shape. When the voltage is above a critical value, multiple jets are ejected from the bursting bubble to the collector, while new bubbles are formed and broken again - the process repeats itself until the solution is depleted.

Another process necessitates the drops of a polymer solution dripped onto a standard spin coater followed by rotation of the chuck [112]. The fibres are produced by the instability of the spin-coated liquid that results from the competition of the centrifugal force and the Laplace force induced by the surface curvature. By adjusting the solution parameters (concentration, spinning speed, surface tension) and solvent evaporation rate, different polymers can be processed to their nanofibres. Dabirian et al. [113] modified the centrifugal spinning method by enclosing a nozzle to avoid the influence of the surrounding air on the dryness of the protruding polymer solution. They also applied a voltage which was not applied in the centrifugal spinning proposed by Weitz et al. [112]. They obtained uniform aligned nanofibres with an average diameter of $440 \pm 11.3 \mathrm{~nm}$. The mechanical properties of the resulting nanofibres were significantly improved compared to those of the electrospun nanofibres from SNE.

Yet another proposed electrospinning process necessitates the use of one or more plates held at a certain angle with respect to the horizontal and vertical oriented collector [114]. The reservoir on top of the plates drops the polymer solution onto the metal plate (which serves as a spinneret), and because of the angle and gravitational force the solution slowly flows until reaching the edge of the plate. At this point, the solution forms a drop that changes its shape to Taylor cone as a result of the electric field at the edge of the plate. More plates were used, given a 'waterfall geometry'. However, the plates resulted in an irregular spinning due to the electric field difference and the polymer solution on each of the plates. The waterfall geometry process displayed lower production rate than the SNE and single edge-plate geometry. The advantage of the single plate method lies in its simplicity and ease of operation with a large number of jets ejected from the plate edge.
The disadvantage is the inhomogeneous electric field distribution in the solution, which contributes to the nanofibre structures.

Another needleless setup involves concurrently provoking numerous jets from a sufficiently large liquid surface [115]. The electrospinning is carried out on the free liquid surface with a stainless steel cleft with a certain width. Numerous jets are generated on the surface of the conductive liquid when sufficient voltage is applied. Mathematical equations were proposed and found to be well applicable to SNE and to most of the theories based on this processing technique. The hypothesis from different parameters and dimensionless analysis created a comprehensive description which affords the opportunity for the development of the liquid surface technique.

Nanofibres were also synthesized from conical wire coils as a spinneret [94]. The technique involves a copper wire-coil nozzle with a conical shape with a certain distance between the wires connected to the voltage supply. This technique falls in between the confined and unconfined, because the dripping solution is inside the cone held upside-down, while the reservoir is not enclosed since the droplets are ejected from the solution flowing through the space (gaps) between the wires. The flowing solution is exposed to a high voltage $(40-70 \mathrm{kV})$ to produce the jets which travel towards the collector where the nanofibres are collected.

\subsection{Gas-jet electrospinning}

One of the recent advances includes new designs of the needle to fabricate the desired morphology and patterns for various applications. It necessitates a gas jet device connected to the needle and is known as the gas-jet electrospinning technique $[13,15$, 116-118]. In this technique the needle of the spinning solution is encircled by the tube of the gas jet. Lin et al. [116] studied the effect of ID and gas flow rate while keeping the other parameters fixed. They found that a smaller ID led to smaller average diameters, while the average diameter decreased monotonically as the gas flow rate increased. It was suggested that the blown gas imposes an additional drawing action on the polymer jet. Other groups used hot stream air-blowing to control the solution properties, solvent dryness and to impose additional stretching to the jet $[13,15]$. The blown air is heated by passing through heating elements offering con- 
trol over the rate and temperature of the blown air. The tip-to-collector distance is much shorter than conventional electrospinning with very high voltages $(\sim 40 \mathrm{kV})$. The method offers an opportunity to increase the processing window boundaries. Ultrahigh molecular weight polymers, and polymers that are difficult or impossible to electrospin from their aqueous solutions, can easily be electrospun through a gas jet process $[13,15,86]$. However, the throughput is still equivalent to that of SNE, while the diameters of the nanofibres range between 500 and $1000 \mathrm{~nm}$. The disadvantage of this process is the difficulty of solvent recovery. An increase in the throughput will also require an increase in the number of the needles as well as large gas volumes [118].

Another gas jet process necessitates the exploitation of the protruding jet by applying compressed air to further stretch the jet $[119,120]$. This process is known as gas jet nanofibre (GJF). The GJF consists of a syringe pump, modified nozzle, jet compressed gas (often air), and a collector. Several parameters, such as air jet pressure, feeding rate, and tip to collector distance, can be adjusted to engineer the nanofibres morphology. The mass production ranges between 0.9 and $8.6 \mathrm{~g} \cdot \mathrm{h}^{-1}$ depending on the polymer properties, solution parameters and processing parameters. However, bi-component and co-shell morphologies can easily be fabricated. Benavides et al. [120] produced nanofibres with average diameters of 280, 186 and $425 \mathrm{~nm}$ from 6\% v/v PEO, 6\% $\mathrm{v} / \mathrm{v}$ poly(vinyl pyrrolidone) (PVP) and poly(vinyl acetate) (PVAc) using a $276 \mathrm{kPa}$ compressed air jet with a feeding rate of $0.8 \mathrm{~mL} \cdot \mathrm{min}^{-1}$. They demonstrated that the nanofibre diameter can be reduced by increasing the air pressure. They also indicated that core-shell by co-axial syringe and side-by-side morphologies from immiscible polymers can easily be prepared.

\subsection{Nozzle configurations for multi- component nanofibres}

\subsubsection{Co-electrospinning}

The modifications of the standard electrospinning devices created a new avenue to combine one or more components with ease of functionalization. One of the simplest ways to fabricate one or more polymeric components is through the use of two or more needles containing different solutions (double electrospinning). This can be done by spinning both solutions, fed from different reservoirs, in a programmed way such that both solutions reach the collector at the same time [121]. Another way is the depositing of the nanofibres in a sequential way, where one polymer solution is first deposited followed by the other [122]. In these methods the syringes filled with different polymers are placed opposite each other with the collector between them, and perpendicular to the principal axis of the collector. The ejected jets are collected using the same collector (mandrel). Nanofibrous membranes containing chitosan and alginate were produced via the dual-jet system by $\mathrm{Hu}$ and $\mathrm{Yu}$ [123]. The PEO/chitosan and $\mathrm{PEO} /$ alginate were fed from two different nozzles and the jetting difference was 15 seconds [123]. X-ray photon-electron spectroscopy (XPS) confirmed the compositions of the two biopolymers, and fluorescent microscopy micrographs showed that these polymers were evenly dispersed onto each other. A hybrid of chitin and silk fibroin (SF) were also electrospun simultaneously from their solutions fed from two syringes on opposite sides facing a rotating target [124]. Chitin/SF (75/25, $50 / 50,25 / 75)$ hybrids were prepared from chitin (5 wt\% in 1.1.1.3.3.3-hexaflouro-2-propanol (HFIP)) and SF ( $7 \mathrm{wt} \%$ in HFIP) and fed to two syringe in opposite directions. The resulting bimodal type of distribution consisted of thinner chitin nanofibres and thicker SF nanofibres with each component dominant depending on their concentration in the composition.

Similarly, the two polymer solutions in the syringes can be placed on opposite sides of the collector. The voltage applied to the syringes result in ejection of the jets which come into contact (merge into single nanofibres) moving towards the collector (Figure 3) [125]. Duan et al. [126] simultaneously electrospun poly(lactide-co-glycolide) (PLGA) and chitosan/ poly(vinyl alcohol) (PVA) from different syringes and mixed them on the collector (drum). The solutions from the two syringes connected to a high voltage $(15 \mathrm{kV})$ were fed by a double-way syringe pump at a feeding rate of $0.2 \mathrm{~mL} \cdot \mathrm{h}^{-1}$ to a grounded drum $(\mathrm{TCP}=10 \mathrm{~cm})$. The composite nanofibres with a diameter of $275 \pm 175 \mathrm{~nm}$ consisted of both smooth nanofibres with large diameters and beaded nanofibres. Ji et al. [86] crosslinked hyaluronic acid (HA) hydrogel nanofibres by a primary syringe $(2.5 \% \mathrm{w} / \mathrm{v} /$ $2.5 \% \mathrm{w} / \mathrm{v} \mathrm{HA} / \mathrm{PEO}$ ) connected to a T-shaped threeway steel adapter, and the secondary syringe 


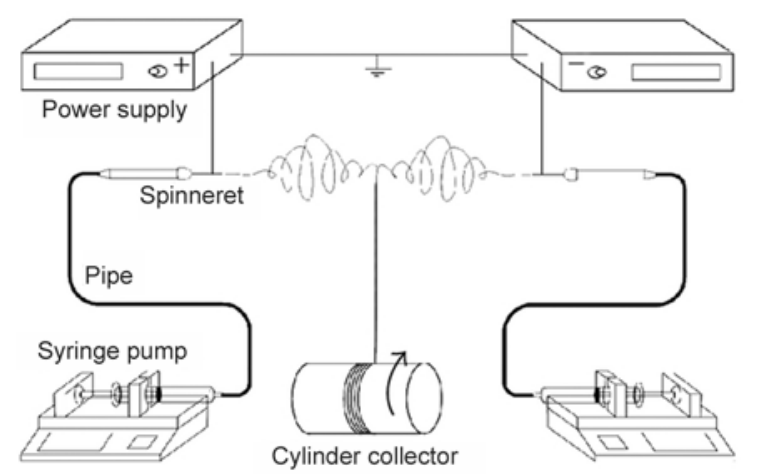

Figure 3. Schematic representation of other side-by-side electrospinning (Reprinted with permission from Xu et al. [125] Copyright (C) $2012 \mathrm{Fu} \mathrm{Xu} \mathrm{et} \mathrm{al.)}$

(9.0\% w/v PEGDA) connected by Teflon tubing. A voltage of $18 \mathrm{kV}$ was applied with a TCP of $10 \mathrm{~cm}$. The primary syringe feeding rate was $20 \mu \mathrm{L} \cdot \mathrm{min}^{-1}$ and secondary syringe feeding rate was maintained at $5 \mu \mathrm{L} \cdot \mathrm{min}^{-1}$ to yield a final 3.3'-dithiobis(propanoic dihydrazide)-modified HA (HA-DTPH) concentration of $2.0 \%(\mathrm{w} / \mathrm{v})$ in the mixture. Ultrafine nanofibres with diameters of $90 \pm 15 \mathrm{~nm}$ were obtained. The fibrous structure was maintained after dissolution of PEO in water, but the average diameter moved to $110 \pm 28 \mathrm{~nm}$.

The most convenient way to electrospin two polymers is through blending the two or more polymers in a suitable solvent [127]. In this case, the selection of the polymers and the solvent is important due to

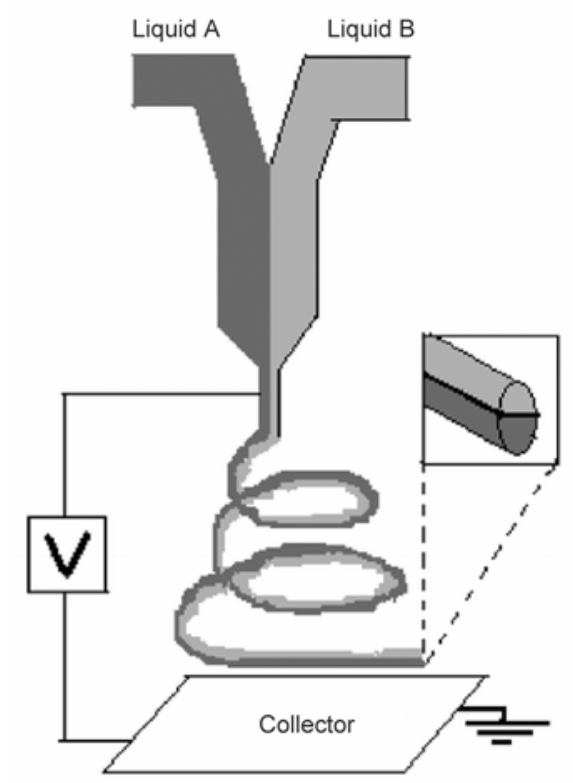

Figure 4. Schematic diagram of side-by-side dual spinneret (Reprinted with the permission from Liu et al. [128]. Copyright (2007) American Chemical Society) the fact that the interactions between the polymers must not cause phase separation during electrospinning. Nonetheless, the proposition to use a single nozzle with two polymer solutions lying in a sideby-side fashion and coming into contact at the tip of the needle and flowing towards the counter electrode overcame the complications of blending the polymers [127]. This technique is known as side-byside dual spinneret (Figure 4) [128]. These authors synthesized bicomponent nanofibres made up of two small fibres bound together and respectively containing titanium dioxide $\left(\mathrm{TiO}_{2}\right)$ and tin dioxide $\left(\mathrm{SnO}_{2}\right)$. This was confirmed by SEM-EDS results showing that $\mathrm{TiO}_{2}$ and $\mathrm{SnO}_{2}$ were on different surfaces of the fibre.

\subsubsection{Co-axial electrospinning}

Other designs include co-axial electrospinning where hollow or core-shell fibres can be produced with easy functionalization (Figure 5). Various materials such as polymers, oligomers, nanoparticles, metal salts, proteins, oils, and enzymes immobilized into the core can be produced to achieve integrated multifunctional materials [1, 129-132]. Coaxial electrospinning offers an avenue to prepare nanofibres from the materials which are difficult or impossible to be electrospun into nanofibres using conventional electrospinning processes $[129,132]$. It can be used in various applications where the stability and control release of small molecules are of significance [133136]. With appropriate choice of solvent and components a variety of functionalised hollow structures can be fabricated from blend to composite materials [134]. A core-shell of collagen-r-poly $(\varepsilon-$ caprolactone) was prepared by this technique [136]. The inner and outer solutions were - poly $(\varepsilon$-caprolactone) (PCL)/triflouroethanol (TFE) $\left(100 \mathrm{mg} \cdot \mathrm{mL}^{-1}\right)$ and collagen/TFE $\left(72 \mathrm{mg} \cdot \mathrm{mL}^{-1}\right)$, respectively. TEM revealed a core-shell structure with a dark PCL component inside with a diameter $385 \pm 82 \mathrm{~nm}$, and a lighter collagen shell with a thickness of $64 \pm 26 \mathrm{~nm}$. The variation of the concentration of the solutions for the inner and outer layers influences the overall diameters of the nanofibres, the thickness of the shell and the diameter of the core. Gulfam et al. [137] produced porous co-shell structured nanofibres by utilizing a collecting water bath. They varied the concentration of PCL (outer shell) to evaluate its effect on the overall diameter of the resulting nanofibres. The overall diameters of the gelatin- 
a)
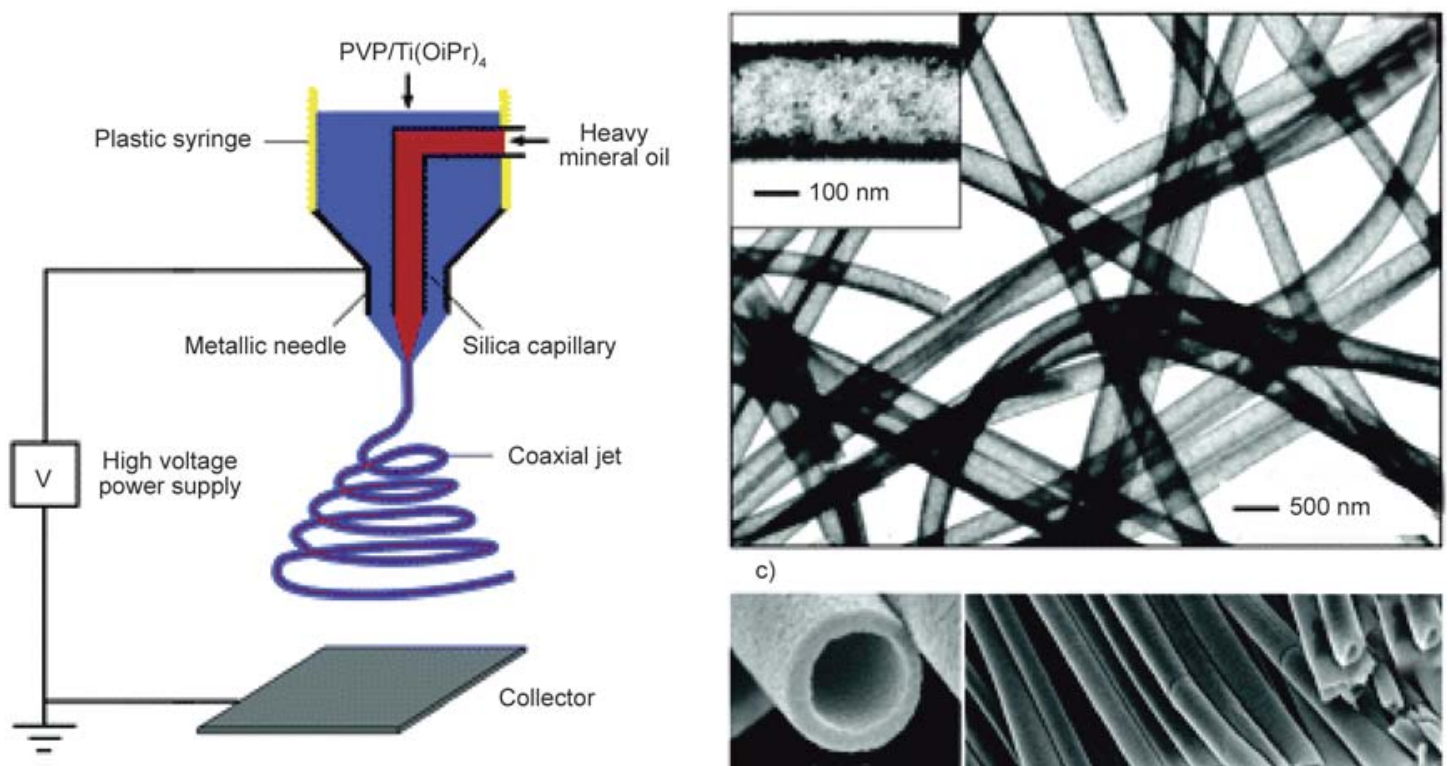

c)

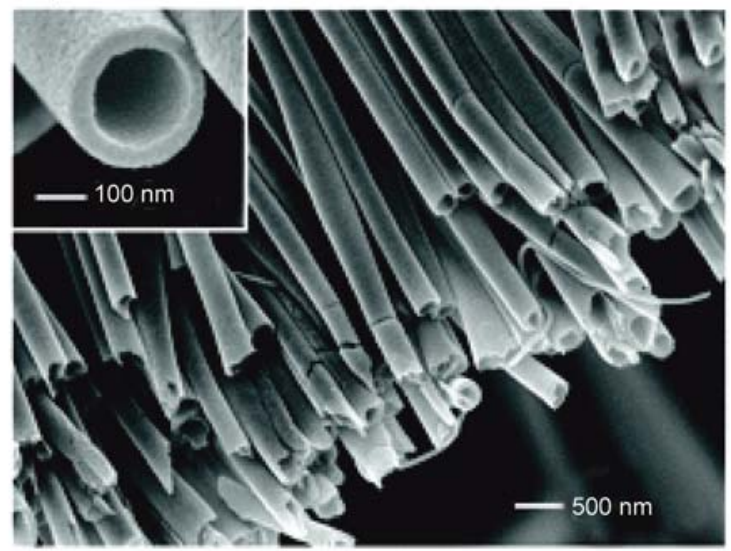

d)

b)

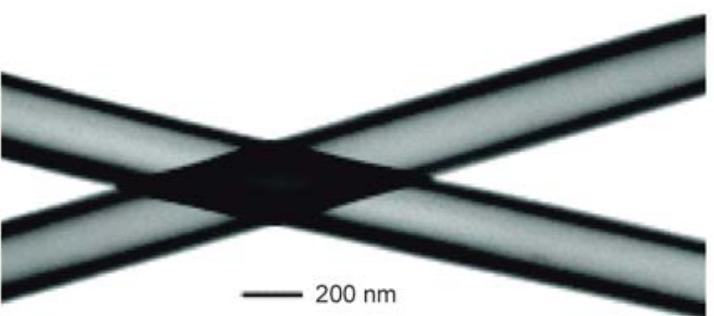

Figure 5. Schematic representations for co-axial electrospinning (a). It consists of a spinneret with two coaxial capillaries in which the polymer solution, mineral oil and functional group are ejected simultaneously to fabricate functionalized hollow fibres. TEM image of two as-spun hollow fibres (b). TEM image of $\mathrm{TiO}_{2}$ (anatase) hollow fibres (c). SEM image of a uniaxially aligned array of anatase hollow fibres (d). (Reprinted with the permission from Li and Xia [134]. Copyright (2004) American Chemical Society).

PCL core-shell nanofibres gradually increased with an increase in PCL concentration from $105 \pm 31 \mathrm{~nm}$ at $4 \%$ PCL to $210 \pm 49 \mathrm{~nm}$ at $12 \%$ PCL.

\subsubsection{Tri-axial electrospinning}

Additional to the conventional co-axial electrospinning, various researchers developed a novel triaxial electrospinning technique $[130,138,139]$. The method uses a nozzle with three concentric needles and three solutions are delivered by different pumps to meet at the tip of the nozzle. Liu et al. [140] produced multi-layered biodegradable nanofibres made of gelatin as core and sheath and PCL as middle layer by triaxial electrospinning (Figure 6). The gelatin shell $(17 \mathrm{wt} \%)$ and core $(10 \mathrm{wt} \%)$ solutions in 80/20 w/w TFE/deionized water and middle layer PCL $(11 \mathrm{wt} \%)$ solution in TFE were fed from the triaxial concentric nozzle at $1.0,0.15$, and $0.4 \mathrm{~mL} \cdot \mathrm{h}^{-} 1$, respectively. The confocal fluorescence microscopy (with the aid of dyes) and FIB-SEM images con- firmed the presence of the gelatin/PCL/gelatin layers. The thickness of the sheath was $130 \mathrm{~nm}$, that of the intermediate layer $240 \mathrm{~nm}$, and that of the core layer $230 \mathrm{~nm}$. Even miscible and immiscible polymer solutions, that were impossible to electrospin with traditional co-axial electrospinning, can be fabricated by introduction of the solvent between the two solutions and a reasonable flow rate $[130,140]$. The incorporated multilayers can perform different functions and incorporate functional groups to target specific applications of the nanofibres.

\section{Electrospinning of biopolymers}

A wide array of biopolymers have been electrospun into ultrafine fibres with some difficulty due to the rigid structure and lack of solubility in common solvents. The functional groups, biocompatibility, biodegradability and non-toxicity of biopolymers are unique properties that afford their applications in various fields. The major disadvantage of some bio- 


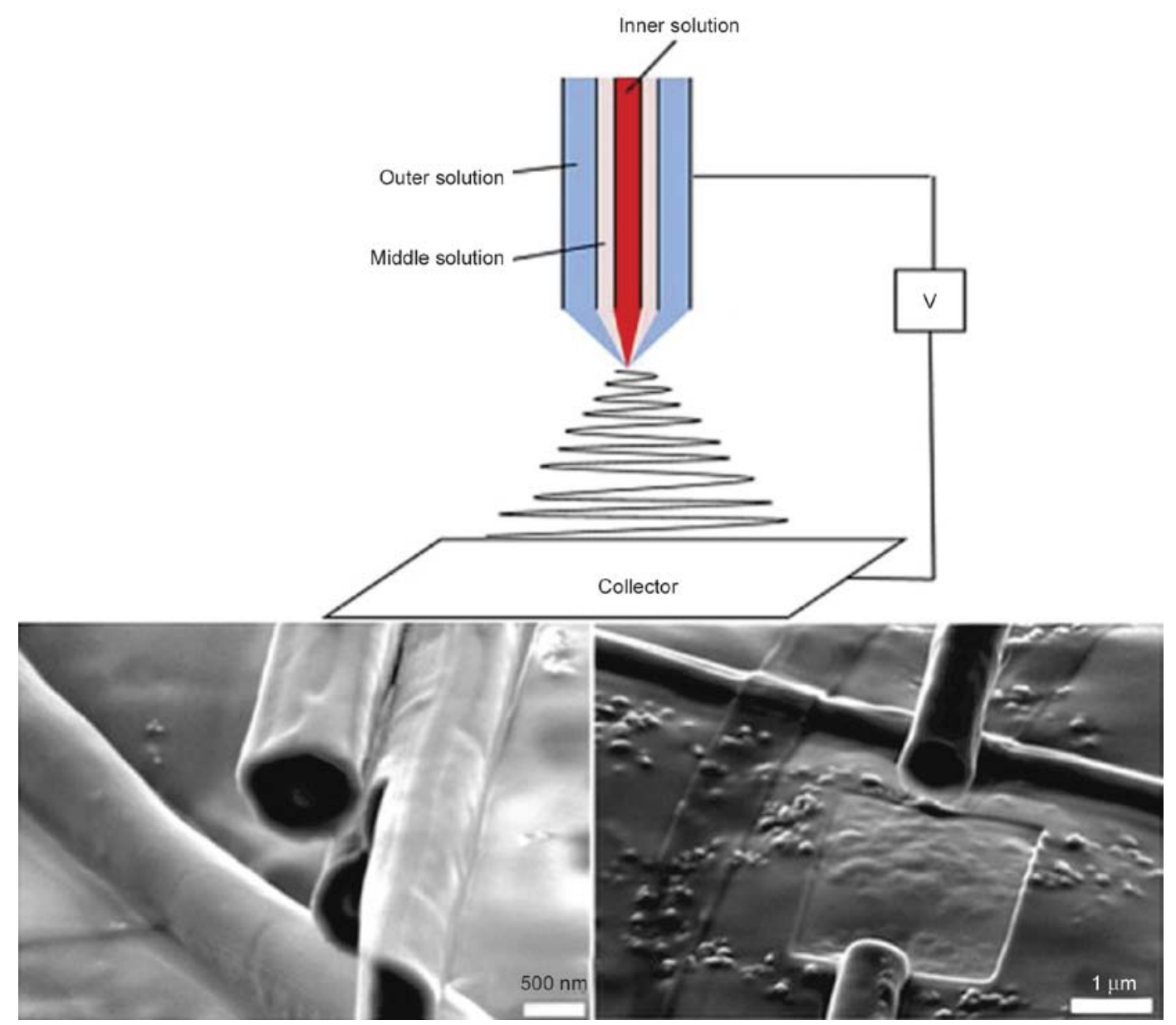

Figure 6. Schematic presentation of triaxial and FIB-FESEM images of triaxial electrospun nanofibres (Reprinted with permission from Liu et al. [140]. Copyright (2013) American Chemical Society.)

Table 4. The potential applications of electrospun biopolymer membranes in water treatment

\begin{tabular}{|c|c|c|c|}
\hline Biopolymer & Desirable properties & Current application & Potential future applications \\
\hline Cellulose and derivatives & $\begin{array}{l}\text { Easy functionalization, hydroxyl } \\
\text { groups, and functional groups } \\
\text { from derivatives }\end{array}$ & $\begin{array}{l}\text { Drug delivery, food, tissue scaf- } \\
\text { folds, personal care, detergent, } \\
\text { paper making, textile, mining flota- } \\
\text { tion, Pharmaceuticals, personal } \\
\text { care, cigarette filters }\end{array}$ & $\begin{array}{l}\text { Bioadsorbent, metal and impurities } \\
\text { separation, ultralfitration, microfil- } \\
\text { tration and bioadsorbent, trace } \\
\text { metal detection }\end{array}$ \\
\hline Cellulose nanowhiskers & $\begin{array}{l}\text { High specific area, easy function- } \\
\text { alization, high crystallinity, high } \\
\text { modulus }\end{array}$ & Polymer reinforcement & $\begin{array}{l}\text { Selective layer in ultrafiltration and } \\
\text { nanofiltration membranes, micro- } \\
\text { filtration, reinforcement }\end{array}$ \\
\hline Chitin and derivatives & $\begin{array}{l}\text { Easy functionalization, availabil- } \\
\text { ity of amino groups and other } \\
\text { functional groups from deriva- } \\
\text { tives }\end{array}$ & $\begin{array}{l}\text { Drug delivery, environmental engi- } \\
\text { neering, tissue scaffolds, food } \\
\text { wraps, flocculants in water, bioci- } \\
\text { dal membranes, tissue scaffolds }\end{array}$ & $\begin{array}{l}\text { Anti-biofouling membranes, mem- } \\
\text { brane coating, flocculation agent }\end{array}$ \\
\hline Chitin nanowhiskers & $\begin{array}{l}\text { High specific area, easy function- } \\
\text { alization, high crystallinity, high } \\
\text { modulus }\end{array}$ & Polymer reinforcement & $\begin{array}{l}\text { Barrier layer in TNFC, reinforce- } \\
\text { ment }\end{array}$ \\
\hline Alginate & $\begin{array}{l}\text { Carboxyl groups and hydroxyl } \\
\text { groups }\end{array}$ & Food texturing, tissue scaffolds & $\begin{array}{l}\text { Metal chelation, } \\
\text { membrane, heav }\end{array}$ \\
\hline Collagen & Unique triple-helical structure & Food, tissue scaffolds, cosmetics & Metal chelation \\
\hline Gelatin & $\begin{array}{l}\text { Thermoreversible viscosity, inde- } \\
\text { pendent of } \mathrm{pH}\end{array}$ & $\begin{array}{l}\text { Cosmetics, food industry, pharma- } \\
\text { ceutical, coatings }\end{array}$ & $\begin{array}{l}\text { Membrane coating, controlled } \\
\text { release and encapsulation of disin- } \\
\text { fection agents }\end{array}$ \\
\hline Hyaluronic and derivatives & Easy functionalization & Dermal fillers, tissue scaffolds & Metal chelation \\
\hline Aloe vera & Different functional groups & $\begin{array}{l}\text { Antibacterial creams, lotions, oint- } \\
\text { ment, tissue scaffolds }\end{array}$ & $\begin{array}{l}\text { Immobilizer of bacteria, enzymes } \\
\text { and other biological molecules }\end{array}$ \\
\hline
\end{tabular}


polymers in water treatment is their solubility and biodegradation in an aqueous medium, giving the edge to synthetic polymers to be the most applied in water filtration and treatment. As already mentioned earlier, different metal oxides were incorporated into the polymers to enhance their biocidal efficacy and the mechanical strength of the electrospun membranes. Most of these biopolymers bear unique functional groups that can be explored in wastewater treatment to adsorb various heavy metals via different mechanisms such as chelation, electrostatic attraction and ion-exchange. They have abundant availability, biocompatibility, large surface-to-area ratio, high porosity, and malleable mechanical properties and structure, with some unique and interesting potential applications (Table 4).

\subsection{Cellulose}

Cellulose is the most abundant natural polymer on earth derived from a wide variety of cellulose-containing sources such as plants, animals and bacteria $[26,141]$. It is composed of a linear chain of $\beta(1-4)$ linked D-glucose units as shown in Figure 7. Cellulose has interesting properties such as biocompatibility, biodegradability, and recyclability. Electrospinning of pure cellulose, from its aqueous solutions, like most biopolymers poses many challenges, where some modifications of the electrospinning setup/ devices are needed $[11,14]$. For example, Frenot et $a l$. [11] found that the collected fibre stood straight up on the collector when plastic and aluminium covered plates are used as collectors. However, the use of a rotating drum/copper or liquid bath collector in a suitable humidity resulted in smooth bead-free fibres [76, 142, 143]. Cellulose cannot melt and is insoluble in water and most of the common organic solvents because of the dense hydrogen network which limits its applications and processability. Only a few solvents such as paraformaldehyde (PF)/N.N-dimethylformamide (DMF), lithium chloride $(\mathrm{LiCl}) / \mathrm{N}$.N-dimethylacetamide (DMAc), Nmethylmorpholine-N-oxide (NMMO), urea/sodium

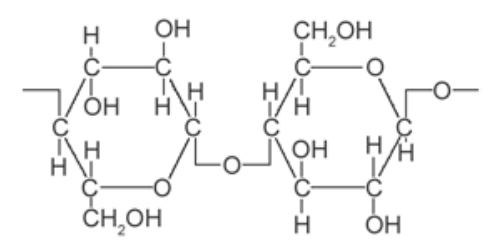

Figure 7. Structure of cellulose hydroxide $(\mathrm{NaOH})$ and ionic liquids can dissolve cellulose $[23,76]$.

The possibility to functionalize cellulose via the hydroxyl side groups on the backbone offers the opportunity to electrospin it in a derivative-form followed by its regeneration via deacetylation or hydrolysis treatments.

The cellulose derivatives through $-\mathrm{OH}$ (hydroxyl group) functionalization include cellulose acetate, hydroxyl propyl cellulose, hydroxyl propyl methyl cellulose, and methyl cellulose [11]. These derivatives are soluble in most of the common organic solvents and they can be converted to pure cellulose via hydrolysis and deacetylation. Stephen et al. [142] functionalized cellulose nanofibrous membrane with oxolane-2,5-dione to enhance their heavy metal adsorption efficiency. They first electrospun cellulose acetate, followed by deacetylation of the resulting nanofibres membrane using sodium hydroxide $(0.3 \mathrm{M} \mathrm{NaOH})$ to generate pure cellulose. The nanofibrous membrane displayed a large surface area of $13.7 \mathrm{~m}^{2} \cdot \mathrm{g}^{-1}$ compared to raw cellulose fibres membrane with a surface area of only $3.2 \mathrm{~m}^{2} \cdot \mathrm{g}^{-1}$. The adsorption capacity for lead $(\mathrm{Pb})$ and cadmium (Cd) were respectively 1.0 and $2.9 \mathrm{mmol} \cdot \mathrm{g}^{-1}$. The regeneration of the mats was done through nitric acid $\left(\mathrm{HNO}_{3}\right)$ treatment, and the regenerated mats performed quite well.

\subsubsection{Cellulose nanowhiskers}

Cellulose nanowhiskers can be extracted from their abundant source (cellulose) by mechanical and chemical means [141, 144]. The high aspect ratio, high crystallinity, easy functionalization, and large surface areas make the nanowhiskers the next generation of wastewater treatment nanomaterials. Several researchers incorporated various whiskers in different polymers such as poly(2-hydroxy ethyl methacrylate) [145], PVA [146], and PEO [147] to improve the mechanical properties of the resulting electrospun nanofibres. These researchers found that the higher modulus and stiffer nanowhiskers improved the mechanical properties of the electrospun nanofibres despite the observed agglomeration of the whiskers [147].

Oxidized jute cellulose whiskers with diameters ranging between 3 and $10 \mathrm{~nm}$ were coated onto polyacrylonitrile (PAN) nanofibres membrane (mean diameter $\sim 173 \mathrm{~nm}$ ) either once (single layer) or 
twice (double layer) by using a glass rod [148]. This method afforded pore sizes ranging between 5 and $65 \mathrm{~nm}$. The membrane was tested under both ultrafiltration (UF) and nanofiltration (NF) conditions, in which the rejection of both nanosilica (in the case of UF) and oil and water (in the case of NF) was above $99 \%$. The mechanical properties of the resulting electrospun nanofibrous membrane (ENM) were improved by the presence of the whiskers, with the tensile strength increasing from 4 to $10 \mathrm{MPa}$ (for one coating of the whiskers onto the ENM) and $14 \mathrm{MPa}$ (for double coating).

Cellulose nanowhiskers and nanofibres have also been thoroughly studied by the Chu and Hsiao group in water treatment and filtration applications [149-152]. The cellulose nanowhiskers were either employed as barrier layer of thin-film nanofibrous composite membranes (TFNC) (Figure 8), or they were infused into the electrospun membrane, depending on the intended filtration application (microfiltration (MF) or UF).

The cellulose nanowhiskers were prepared through a [2.2.6.6-tetramethylpiperidinooxy (TEMPO)/ sodium bromide $(\mathrm{NaBr})$ /sodium hypochlorite $(\mathrm{NaClO})]$ oxidation method. The length of the cellulose nanowhiskers ranged between 200 and $400 \mathrm{~nm}$ and the diameters between 5 and $10 \mathrm{~nm}$. In the case of MF, the infusion of the whiskers resulted in a reduction of the mean pore size with a narrower dis- tribution than the electrospun PAN nanofibrous membrane. In comparison with the commercial membrane GS0.22 made of nitrocellulose and acetyl cellulose ester, the water flux cellulose nanowhiskerbased membrane was better because of the difference in porosity ( $>80 \%$ versus $52 \%$ ) [144]. The mechanical properties were improved with Young's modulus and tensile strength values of $375 \pm 15$ and $14.3 \pm 0.4 \mathrm{MPa}$, respectively, compared to the unmodified membrane $(226 \pm 20$ and $8.5 \pm 0.3 \mathrm{MPa})$ which was still higher than the commercial membrane with a tensile strength of $5.6 \pm 0.3 \mathrm{MPa}$. The adsorption of crystal violet (CV) dye was better in the case of the cellulose nanowhiskers-based membrane than in GS0.22 (Figure 9a). The adsorption was two times higher at $10 \mathrm{mg} \cdot \mathrm{L}^{-1}$ of $\mathrm{CV}$ dye with a high rate of adsorption because of the hydrophilicity and large surface area. The adsorption data fitted the Langmuir isotherm showing monolayer adsorption (Figure 9b). The adsorption capacity was 16 times higher for the cellulose nanowhiskers-based membrane. The cellulose nanowhiskers as a thin barrier layer in TNFC displayed superior performance compared to the commercial known membranes [144]. The hydrophilicity, large surface area to volume ratio and the surface charges of the cellulose nanowhiskers played a significant role in improving the rejection and flux of the membrane.

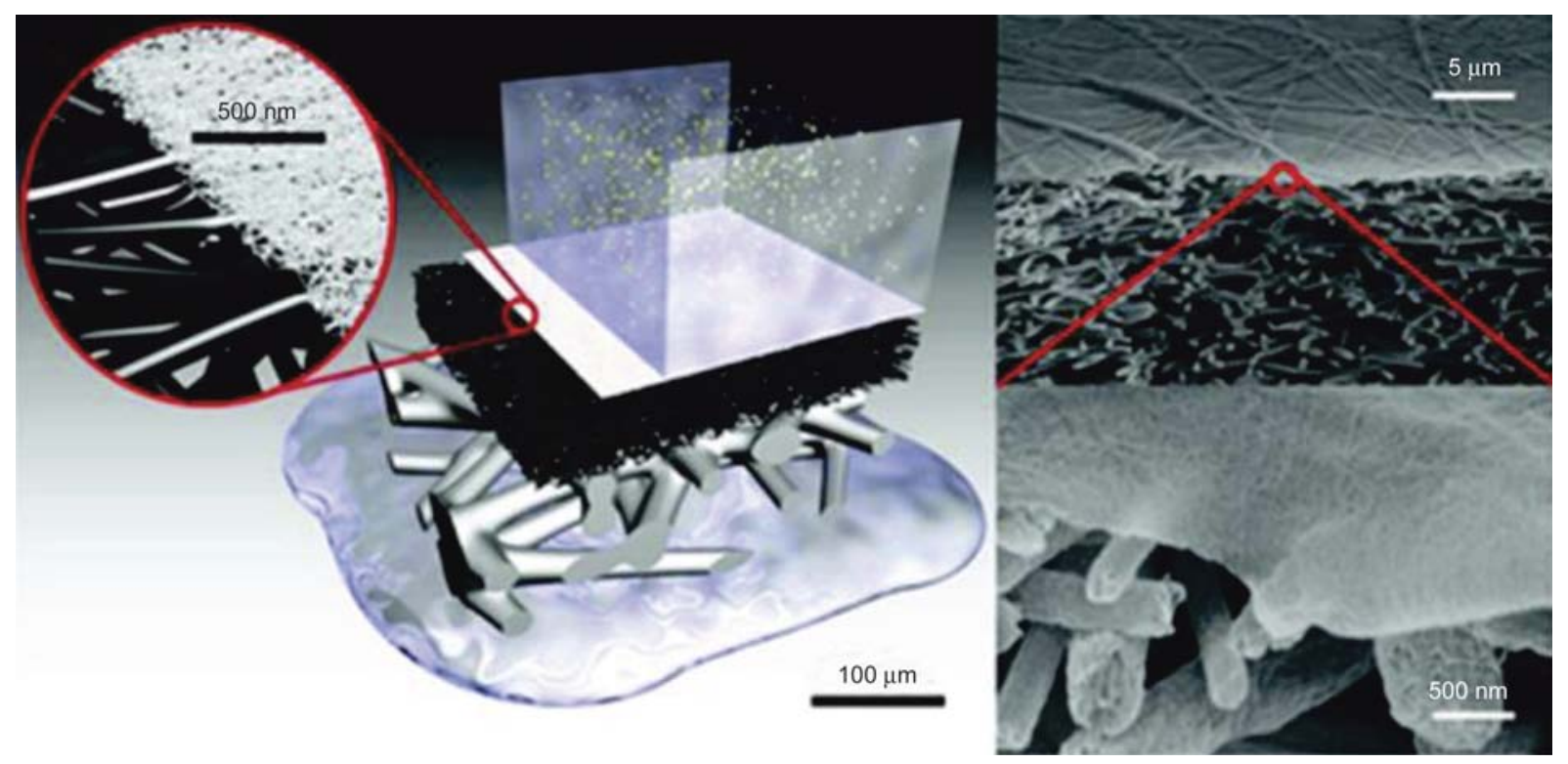

Figure 8. (Left) A schematic representation of a thin-film nanofibre composite membrane (TNFC) with three layers: selective/barrier layer, mid-layer of electrospun nanofibres, and nonwoven supporting mat (poly(ethylene terephthalate) (PET)). (Right) Cross-sectional SEM views of the barrier layer and electrospun nanofibres in a typical TNFC membrane. (Reprinted with permission from Ma et al. [150]. Copyright (2012) American Chemical Society). 


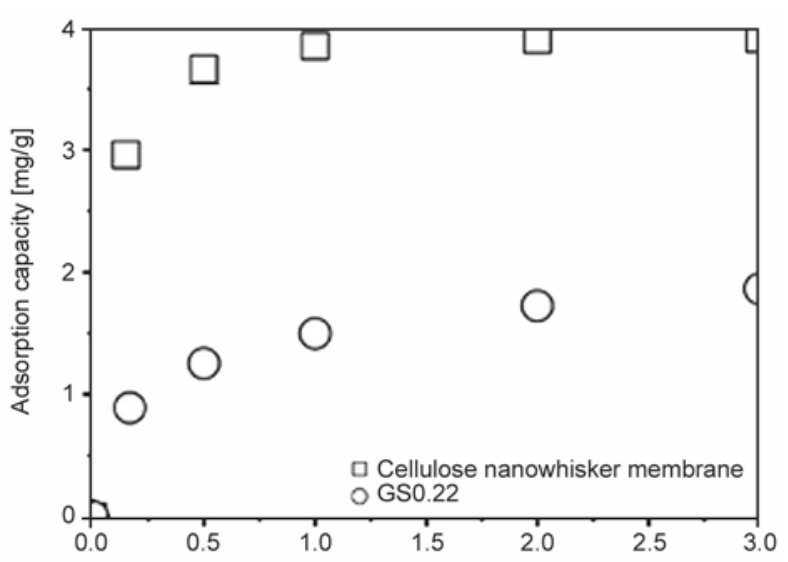

a)

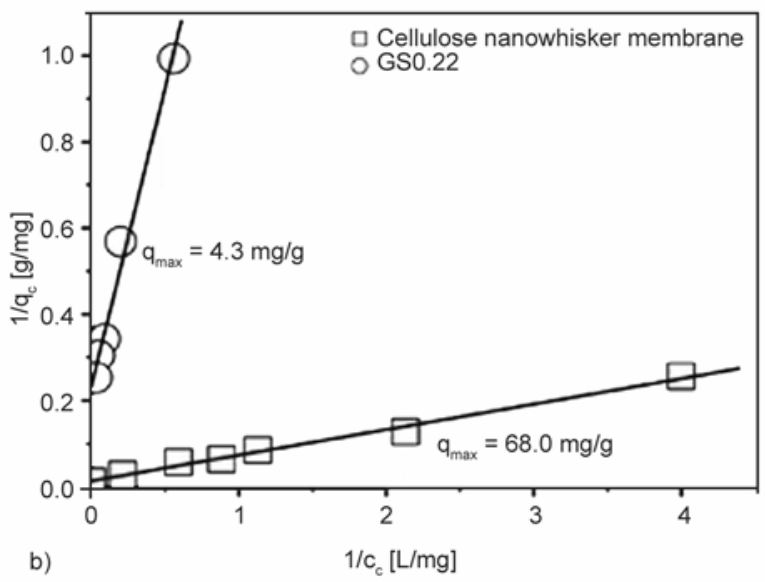

Figure 9. (a) Adsorption capacity of cellulose nanowhiskersbased nanofibrous MF membrane and GS0.22 against time; (b) respective Langmuir adsorption isotherms for the two membranes (Reprinted with permission from Ma et al. [144]. Copyright (2012) American Society.)

\subsubsection{Cellulose derivatives}

\section{Cellulose acetate}

Among the cellulose derivatives, cellulose acetate (CA) is the most studied derivative due to its potential to regenerate pure cellulose via deacetylation $[23,152]$. Cellulose acetate is synthesized by acetylation of the hydroxyl groups on cellulose with an average of 2-4 degree of substitution per glucose units (Figure 10). The CA enjoyed its success in membrane filtration for more than seven decades

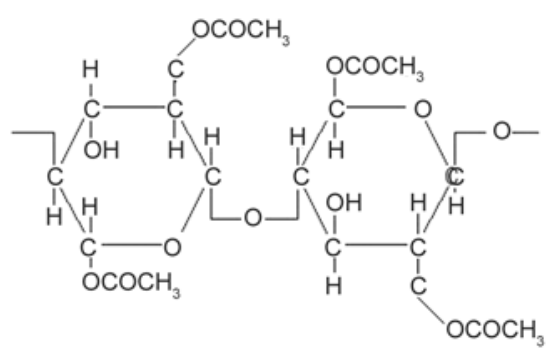

Figure 10. Structure of cellulose acetate now $[149,153,154]$. It has been widely used as a selective layer in nanofiltration and ultrafiltration. With its unique functional groups that can be modified, it is rated as one of the good metal adsorbents $[149,150]$. The functionalization of CA with $-\mathrm{COOH}$, $-\mathrm{SO}_{3} \mathrm{H}$ and $\mathrm{NH}_{2}$ offers an opportunity for the application of CA in heavy metal complexation [155158]. Some nanofillers can be added to a cellulose acetate membrane to enhance the metal adsorption capacity $[149,155,156]$.

Zhou et al. [159] prepared cellulose acetate nanofibrous membranes from various solvents (dichloromethane, formic acid, acetic acid, and triflouroacetic acid). Only trifluoroacetic acid afforded the production of smooth nanofibres with diameters ranging between 100 and $300 \mathrm{~nm}$. This membrane displayed a porosity and surface area of respectively $87 \%$ and $2.02 \cdot 10^{7} \mathrm{~m}^{-1}$ with high water permeability and hydrolytic stability. Aluigi et al. [61] studied the influence of various solvents and their mixtures on the electrospinning of CA. Using a single solvent like chloroform, N,N-dimethylformamide (DMF), dichloromethane (DCM), methanol (MeOH), formic acid, or pyridine, it was not possible to fabricate smooth nanofibres. Only discrete beads were formed, and acetone produced short beaded nanofibres. $\mathrm{CA}(5 \% \mathrm{w} / \mathrm{v})$ in a mixture of chloroform-MeOH and $\mathrm{DCM}-\mathrm{MeOH}$ produced beaded and smooth fibres, especially at $4: 1(\mathrm{v} / \mathrm{v})$. The average diameters were $0.79-1.09 \mu \mathrm{m}$ and $0.67-1.06 \mu \mathrm{m}$ respectively for the binary mixtures of chloroform- $\mathrm{MeOH}$ and DCM-MeOH. Smooth fibres were formed at solvent mixture concentrations of a $16 \%(\mathrm{w} / \mathrm{v})$ solution of CA in 1:1, 2:1 and 3:1 acetone-N,N-dimethylacetamide (DMAc), 14-20\% (w/v) solution of CA in 2:1 acetone-DMAc, and $8-12 \%(\mathrm{w} / \mathrm{v})$ solutions of CA in $4: 1$ $(\mathrm{v} / \mathrm{v}) \mathrm{DCM}-\mathrm{MeOH}$. The diameters ranged between $0.14-0.37 \mu \mathrm{m}$ and $0.48-1.58 \mu \mathrm{m}$ for fibres prepared from acetone-DMAc and DCM-MeOH, respectively.

Chen et al. [160] functionalized cellulose acetate nanofibrous membrane with chlorhexidine for their biocidal efficacy. To facilitate electrospinnability in $\mathrm{N}, \mathrm{N}$-dimethylformamide (DMF), high molecular weight PEO was added. The electrospun nanofibrous membrane was crosslinked using titanium triethanolamine in isopropanol. The biocidal efficiency against E. coli and S. epidermisidis increased with concentration of chlorohexidine. The membrane displayed biocidal efficiency above $99 \%$. Moreover, 
different drugs can be incorporated in cellulose acetate as carrier $[69,161,162]$. Suwatong et al. [162] incorporated curcumin in cellulose acetate nanofibres to investigate its releasing character. The cellulose acetate nanofibres retained their structure and morphology after the addition curcumin. A 95\% release without toxicity was established. This property can be explored in incorporating different functions/biocides for controlled release in water treatment. For example, Ma and Ramakrishna [163], covalently bond protein $\mathrm{A} / \mathrm{G}$ onto the oxidized $\mathrm{CA}$ membrane to bind IgG molecules and a capturing capacity of $18 \mu \mathrm{g} / \mathrm{mg}$ was reported. Similarly, Chen et al. [164] functionalized hydrolysed CA with cobalt tetraaminophthalocyanine $(\mathrm{CoPc})$ for the adsorption of reactive red X-3B dye and more than $95 \%$ of the dye was eliminated within 3 hours.

\section{Other cellulose derivatives}

Four different carboxymethyl cellulose sodium salts (CMC) were electrospun by Frenot et al. [11]. CMCs with different molecular weight and degree of substitution were electrospun in the presence of $\mathrm{PEO}$ as copolymer, dissolved in a water and ethanol mixture at a ratio of 1:1. The nanofibres displayed similar homogeneous structures with mean diameters of 200-250 nm, regardless of the molecular weight and degree of substitution. In the same study, two hydroxypropyl methyl cellulose (HMPC) samples with equal $M_{\mathrm{w}}$, and with varying contents of methoxy and hydroxypropoxy groups, were compared. Mean diameters of 127 and $128 \mathrm{~nm}$ were obtained for the two HMPCs, regardless of the functional group contents, but at different spinnable concentrations. Lim et al. [88] studied the effect of different parameters (concentration, voltage, flow rate and tip-to-collector distance) on the electrospinning of ethyl cellulose (EC). At a low concentration $(6 \mathrm{wt} \%)$ a mixture of smooth and beaded-fibre structures was observed, which disappeared as the concentration was increased to $8 \mathrm{wt} \%$ of the EC and above. The mean diameter of the nanofibres gradually increased with flow rate, whereas an increase in voltage reduced the mean diameter of the nanofibres.

\subsection{Chitin}

Chitin is the second most abundant natural polymer on earth after cellulose. It appears as ordered crystalline structure of microfibrils in the exoskeleton of arthropods, and the cell walls of fungi and yeast

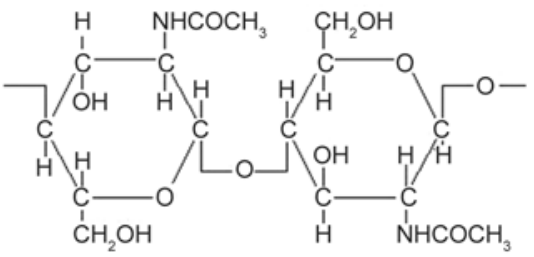

Figure 11. Structure of chitin

[165]. Chitin, the mucopolysaccharides that is made up of B-(1-4)-N-acetyl-D-glucosamine units linked by 1-4 glycosidic bonds, acts as mechanical strength and supporting structure in crustaceans, insects, etc. (Figure 11) [51, 166, 167]. Chitin with desirable properties such as good biocompatibility, biodegradability and ubiquitous availability has been used in various fields such as cosmetic, biomedical and in food additives [165].

Very few studies dealt with electrospinning chitin from its aqueous solution, because of its poor solubility $[168,169]$. In these studies the solubility of chitin was enhanced by $\mathrm{Co}^{60}$ gamma ray irradiation. Chitin nanofibres with diameters ranging between $50 \mathrm{~nm}$ and several microns were electrospun in 1.1.1.3.3.3-hexaflouro-2-propanol (HFIP), with the diameters depending on the electrospinning technique parameters such as concentration [167-169]. Min et al. [168] irradiated chitin (200 kGy) and obtain an average molecular weight of 91000 to enhance its dissolution in HFIP. They produced chitin nanofibres with a broad fiber diameter distribution (40 to $640 \mathrm{~nm}$ ) and most were less than $100 \mathrm{~nm}$.

\subsubsection{Chitin nanowhiskers}

The nanocomposites of PVA and chitin whiskers were reported for the first time by Junkasem et al. [170]. Nanowhiskers with the lengths in the range 231-969 nm and widths of 12 to $65 \mathrm{~nm}$ were produced. Nanocomposite nanofibres (prepared from water) with diameters ranging between 175 and $214 \mathrm{~nm}$, depending on the concentration of the chitin whiskers, were obtained. The thermomechanical properties of PVA were enhanced by the presence of the chitin whiskers [171]. Naseri et al. [172] reinforced a blend of chitosan and PEO with chitin nanowhiskers. The modulus and tensile strength were significantly increased from 0.4 to $4.3 \mathrm{GPa}$ and and from 4.6 to $34.9 \mathrm{MPa}$, respectively. An antibacterial TNFC membrane was developed by including chitin nanowhiskers as barrier layer onto electrospun PAN nanofibres (as a mid-layer on top of a PET nonwoven support) [144]. The flux permeation was 
217.0 $\mathrm{L} \cdot \mathrm{m}^{-2} \cdot \mathrm{h}^{-1}$ (which was $8-10$ times higher than that of commercial PAN10) for two days at $30 \mathrm{psi}$ with a rejection above $99.7 \%$.

\subsubsection{Chitin with synthetic/biopolymers}

A nanofibre blend of poly (glycolic acid) (PGA) and chitin was prepared by Park et al. [173]. The nanofibres had a broad diameter distribution in the range of 50-350 nm, with most of the nanofibres having an average diameter of $150 \mathrm{~nm}$. Chitin/silk blend nanofibres were prepared by several researchers using HFIP as a solvent $[124,173]$. The nanofibres had diameters ranging between 340 to $920 \mathrm{~nm}$ depending on the content of silk in the composite material. Irradiation and little deacetylation (8\% DD) of chitin was also adopted to reduce its molecular weight and improve its solubility.

\subsubsection{Chitin derivatives}

\section{Dibutyryl chitin}

One of the readily soluble chitin derivatives in most common organic solvents (acetone, ethanol) is dibutyryl chitin. It is synthesized from butyric anhydride and perchloric acid. Błasińsk et al. [174] electrospun an ester derivative of chitosan, dibutyrylchitin (DBC), from ethanol. $9 \mathrm{wt} / \mathrm{v}$ of DBC at $25 \mathrm{kV}$ was the optimal conditions to establish bead-free nanofibres with a transverse dimension of $0.3 \mu \mathrm{m}$. DBC and a cellulose acetate hybrid were electrospun in a 1:1 ratio of acetone and acetic acid [175]. The mixture of $\mathrm{CA} / \mathrm{DBC}$ at a concentration of $5 \%$ from $100 / 0$ to $0 / 100$ ratio compositions produced bead-free nanofibres with $30-350 \mathrm{~nm}$ diameters. Pant et al. [176] synthesized chitin butyrate from a mixture of butyric acid, trifluoro acetic anhydride and phosphoric acid, followed by the addition of ethyl alcohol and filtration. The resulting solution was washed repeatedly with diethyl ether and water, followed by drying for 3 days in a hood and then in a $60^{\circ} \mathrm{C}$ oven for 6 hours. The resulting butyric chitosan was electrospun with nylon- 6 in formic acid/acetic acid to give spider-web-like nanofibres with an average diameter of $15 \mathrm{~nm}$ at a low butyric chitosan content (90/10 nylon-6/butyric chitosan).

\section{Carboxymethyl chitin}

To circumvent the solubility issues of chitin and chitosan, some of their derivatives have been electrospun into nanofibres either from their aqueous solutions or by blending with other polymers. This not only to improved their spinnability, but also alleviated the use of a toxic solvent utilized in electrospinning both chitin and chitosan. Carbomethyl chitin (CMC) is one of the chitin derivatives that are readily soluble in water. However, the electrospinning of $\mathrm{CMC}$ from its aqueous solution results in spherical drops [177]. Nevertheless, ultrafine nanofibres from a CMC/PVA blend at a 20:80 ratio (CMC (7\%):PVA (8\%)) was reported. Sohofi et al. [178] were the first to fabricate CMC electrospun nanofibres from its aqueous solutions using binary solvents. The $6 \mathrm{wt} \%$ CMC (with degree of substitution of 0.65 ) was electrospun in a 30/70 dichloromethane/trifluoroacetic acid mixture to ultrafine nanofibres with an average diameter of $260 \pm 42 \mathrm{~nm}$. Although the carbomethylated chitosan showed a potential in metal adsorption [179], nanofiltration [180], and microfiltration [181] processes, not much has been done on electrospun CMC in wastewater treatment.

\section{Chitosan}

Chitosan results from the deacetylation of chitin under alkaline conditions, or from enzymatic hydrolysis in the presence of chitin deacetylase. It is an aminopolysacchride with unique properties and functionalities for a wide spectrum of applications from biomedical to industrial areas. Chitosan is a copolymer made up of 2-acetamido-2-deoxy- $\beta$-D-glucopyranose and 2-amino-2-deoxy- $\beta$-glycopyranose linked together through (1-4)- $\beta$-glycosidic bonds (Figure 12). Similar to alginates, different forms of chitin and chitosan such as gels, membranes, beads, microparticles, nanoparticles and nanofibres have been produced for various applications [51, 166]. Chitosan is well-known for its unique antimicrobial activity and metal adsorption [182, 183]. These result from the protonation of $\mathrm{NH}_{2}^{-}$groups on its backbone. It is capable of chelating ions from aqueous media and inhibiting the growth of a broad spectrum of fungi, yeasts and bacteria. The cations along the chitosan repeating units can be varied through deacetylation. A higher the degree of deacetylation results in a larger number of cations on the backbone of the chi-

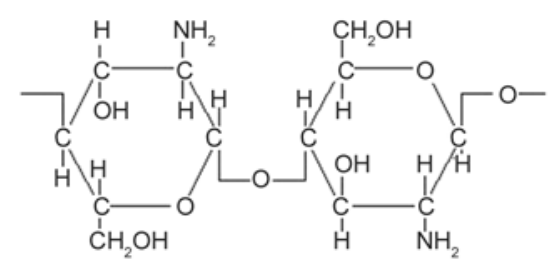

Figure 12. Structure of chitosan 
tosan. Chitosan is soluble in most acids, which protonate it into a polyelectrolyte.

Different solvents such as dilute hydrochloric acid, acetic acid, formic acid and triflouroacetic acid (TFA) were tested to envisage the electrospinnability of chitosan [184]. Only with TFA as solvent chitosan nanofibres were successfully established [184]. It was indicated that the TFA either forms amino groups on chitosan, which results in the destruction of the rigid interaction between the chitosan molecules, or that the high volatility of TFA caused rapid solidification of the electrified jet. More homogeneous nanofibres were obtained by addition of dichloromethane, due to its high volatility. Geng et al. [67] successfully electrospun chitosan from concentrated acetic acid. $30 \%$ of acetic acid in water resulted in a combination of droplets and thinner nanofibres with an average diameter of $40 \mathrm{~nm}$, whereas at $90 \%$ acid concentration the diameter of the nanofibres increased to $130 \mathrm{~nm}$ without beads.

\section{Chitosan with synthetic polymers}

Over the past decades, electrospun chitosan hybrids have been fabricated using various synthetic polymers such as polyvinyl alcohol (PVA) [126, 185], poly(lactide-co-glycolide) (PLGA) [126], polyethylene oxide (PEO) [186], polyvinyl pyrrolidone (PVP) [83], poly(lactic acid) (PLA) [80], and poly (ethylene terephthalate) (PET) [187]. Interestingly, the synthetic polymer did not only improve the electrospinnability of chitosan, but significantly enhanced the biocompatibility, antibacterial, mechanical strength and other properties of the hybrid nanofibres. These broadened the applicability of the chitosan-based nanofibres in a broad spectrum of applications. PEO is a biocompatible synthetic polymer favourable for biomedical and tissue engineering. Su et al. [186] prepared chitosan/PEO blends doped with monovalent $\left(\mathrm{Na}^{+}\right)$, divalent $\left(\mathrm{Ca}^{2+}\right)$ and trivalent $\left(\mathrm{Fe}^{3+}\right)$ metal chlorides to enhance the homogeneity of the resulting nanofibres. They found that these metal chlorides promoted the fibrous morphology of the chitosan/PEO blends, opening doors for the use of these nanofibres in various applications such wound dressing, bone regeneration, etc.

\section{Chitosan with other biopolymers}

The electrospun nanofibres of chitosan and other natural polymer blends were studied by several researchers [188, 189]. Torres-Giner et al. [188] pre- pared a bioblend of chitosan and zein for biocidal applications. Low zein content $(1 \mathrm{wt} \%)$ in the bioblend resulted in ribbon-like nanofibres with an average diameter of $320.9 \pm 92.3 \mathrm{~nm}$. An increase in the percentage of chitosan in the blend yielded beadedfibres with smaller average diameters between $161.7 \pm 39.6$ and $128.5 \pm 26.2 \mathrm{~nm}$. The electrospun bioblend inhibited bacterial growth. Bioblend electrospun nanofibrous membrane of chitosan and a type I collagen were fabricated with the aid of PEO, followed by crosslinking with glutaraldehyde [190]. The ultrafine fibres had average diameters of $134 \pm 42 \mathrm{~nm}$ before crosslinking and $98 \pm 76 \mathrm{~nm}$ after crosslinking. The difficulty of electrospinning CS/collagen, due to its high conductivity/charge density, was improved by the addition of PEO. Young modulus was improved from $0.29 \pm 0.04$ to $0.65 \pm 0.02 \mathrm{MPa}$ by crosslinking. Maeda et al. [191] electrospun chitosan with the aid of PEO, followed by coating with hyaluronic acid. The composite was made by dissolving PEO in water and coating with hyaluronic acid, and it was stable in water with an improved swelling ratio due to the increased hydrophilicity as a result of the presence of hyaluronic acid. PVA/CS was electrospun onto a PVDF micro-filter, followed by crosslinking with glutaraldehyde [192]. The membrane was immersed in glutaraldehyde $(5 \mathrm{mM})$ and an $\mathrm{HCl}(0.01 \mathrm{~N})$ solution for six hours, and the membrane shrinked by $\sim 5 \%$. Dead-end filtration was utilized to evaluate the metal adsorption capacity of the membrane. A 5\% adsorption capacity was reported.

\section{Chitosan derivatives}

Quaternized chitosan (QCh) nanofibrous membrane for antibacterial activity were electrospun by Ignatova et al. [83, 193, 194] using poly(vinyl pyrrolidone), polyvinyl alcohol, and poly(lactic acid). The addition of these synthetic polymers significantly improved the electrospinnability of quaternized chitosan. The composite nonwoven mats showed good antibacterial activity against Gram negative and Gram positive bacteria. Kangwansupamonkon et al. [195] prepared chitosan/PEO mats followed by functionalization to form N-(2-hydroxyl) propyl-3-trimethyl ammonium chitosan chloride (HTACC) and N-benzyl-N,N-dimethyl chitosan iodide (QBzCS) membranes. They prepared the nanofibres from a blend of chitosan and PEO (6.7:0.3\% w/v) in a mixture of trifluoroacetic acid/dichloromethane (70/30 $\mathrm{v} / \mathrm{v}$ ) followed by functionalization. They obtained 
ultrafine nanofibres with average diameters of $272 \pm 56 \mathrm{~nm}$. The membranes displayed good antibacterial efficiency against both $S$. aureus and E. coli. Ultrathin nanofibres of $\mathrm{N}$-[(2-hydroxy-3-trimethlammonium) propyl] chitosan chloride (HTTC) through blending with PVA was reported by Alipour et al. [196]. The HTTC was synthesized from a reaction between chitosan and glycidyl-trimethylammonium chloride. The water soluble derivative, HTTC, was electrospun through blending with PVA to give nanofibres with 200-600 nm diameters. Good antibacterial efficiency was reported for these membranes.

Chitosan can be modified by various acyl chlorides (dodecyl, hexanoyl, decanoyl, and lauronyl) in the presence of mixed pyridine and chloroform as solvents [197]. These modifications are usually adapted to improve the solubility of the chitosan. Hexanoylchitosan from chitosan modification by hexanoyl chloride in chloroform was electrospun by Neamark et al. [82]. The ribbon-like fibres with average diameter of $3.93 \pm 1.82 \mu \mathrm{m}$ at a concentration of $14 \% \mathrm{w} / \mathrm{v}$ were obtained. This was due to the rapid evaporation of the chloroform from the electrified jet. Peesan et al. [198] fabricated a blend of hexanoyl chitosan/polylactide using chloroform, dichloromethane and tetrahydrofuran as solvents. The smooth bead-free nanofibres were obtained at $50 \mathrm{wt} \%$ of chitosan in the blends using chloroform as spinning solvent. Patanaik et al. [27] electrospun lactic acid modified chitosan using TFA as solvent and MC as co-solvent. The nanofibres were stabilized using thermal treatment to convert the lactate to lactamide. The resulting nanofibres showed good nanofibrous integrity, even after exposure to a BSA medium for 72 hours.

Different molecular weights $(40-405 \mathrm{kDa})$ and degrees of substitution (DS) (0.25-1.19) carbomethyl chitosan (CMCS) were synthesized via chitosan alkalization, followed by carbomethylation with monochloroacetic acid [81]. Despite the difference in DS and $M_{\mathrm{w}}$, and with the incorporation of Triton X-100 (to reduce both solution surface tension and conductivity) into the aqueous CMCS solution, the spinning solution still led to drops (6-20\% concentration). The blending of the CMCS with hydrosoluble synthetic polymers (PVA, polyacrylic acid (PAA), polyacrylamide (PAAm) and PEO) enhanced the spinnability of CMCS into smooth nanofibres, but it depended on the polymer used. PEO (100 kDa) with
$30 \%$ CMCS gave merged non-cylindrical nanofibres mostly with $300 \mathrm{~nm}$ diameter, while PAAm at $1 / 10 \mathrm{w} / \mathrm{w}$ of $5000 \mathrm{kDa} / 10 \mathrm{kDa}(18 \mathrm{wt} \%)$ resulted into a similar structure as the PEO/CMCS blend. A $10 \mathrm{wt} \%$ binary aqueous mixture with equal mass PAA (450 kDa), produced straight cylindrical nanofibres with elongated beads (100 nm diameter). A mixture of PAAm and PAA resulted in higher CMCS content (50\%), but with a large number of beads. In the case of a PVA binary solution with a concentration of $8.5 \mathrm{wt} \%$ (CMCS $405 \mathrm{kDa}$ ), nanofibres with average diameters ranging between 210 and $170 \mathrm{~nm}$ were obtained on increasing the CMCS content from 20 to $50 \%$. The PVA/CMCS system is therefore feasible to produce bead-free nanofibres. The stability of the PVA/CMCS in water was further enhanced by heat treatment at $140^{\circ} \mathrm{C}$ for 30 minutes.

Another interesting approach to overcome the problem of solubility of chitosan is PEGylation. Du and Hsieh [84] synthesized PEG-N-chitosan and PEG$\mathrm{N}, \mathrm{O}$-chitosan via reductive amination and acylation of the chitosan. A small DS value of 0.2 for the solubility of the derivatives in water was reported. For PEG- $N, O$-chitosan a DS of 1.5 was sufficient for its solubility in $\mathrm{CHCl}_{3}$, DMF, DMSO and THF. Regardless of the degree of substitution of PEG (DS) and the derivative of chitosan, only droplets were collected due to a lack of chain entanglements. All the aqueous solutions of PEG-N-chitosan (from reductive amination) resulted in spraying (drops), regardless of the DS of PEG. Smooth nanofibres with diameters ranging between 40 and $306 \mathrm{~nm}$ (average 162) were obtained by increasing the concentration of the PEG- $N, O$-chitosan with the aid of a surfactant $\left(0.5 \%\right.$ Triton $\left.X-100^{\mathrm{TM}}\right)$ and co-solvent $(75 / 25 \mathrm{v} / \mathrm{v}$ $\mathrm{THF} / \mathrm{DMF})$.

\subsection{Alginate}

Alginate is a well-known polyelectrolyte binary copolymer derived from seaweeds/algae [199-202]. It contributes to the flexibility and strength of the seaweeds against adverse water forces. It is usually found in the cell wall matrix and intercellular material (mucilage). Alginate is a linear polysaccharide made up of D-mannuronic (M) and L-guluronic (G) units linked together by 1-4 glycosidic bond (Figure 13). These units appear in varying sequences and ratios, $\mathrm{M} / \mathrm{G}$, along the polymer chain depending on the source or specie, the growth conditions, season and depth at which is extracted. The varia- 


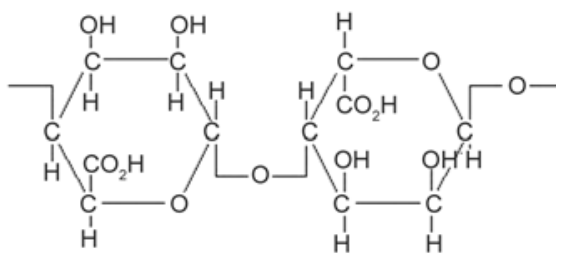

Figure 13. Structure of alginate

tion of $\mathrm{M}$ and $\mathrm{G}$ along the alginate chain determines its physical properties and reactivity. The molecular conformation and functional groups (especially carbonate ions) have been found to play a significant role in the heavy metal affinity of the alginates [202]. Alginate can gel at room temperature in the presence of polyvalent or divalent metal ions. This phenomenon has been exploited to prepare different morphologies and structures for certain applications. Beads [203], films [204, 205], hydrogels [206], as well as porous membranes and nanofibers [200] were fabricated for different applications such as wound dressings and metal adsorption. There has been significant interest in the use of alginate in biomedical applications because of its antimicrobial efficiency and structural resemblance to glycosamineglycan (GAG) (one of the significant components of natural extracellular matrices (EMCs) found in mammalian tissues). Furthermore, the good cellular compatibility, non-toxicity, biodegradability, and availability of alginate opened doors for its exploitation in various applications such as metals recovery [202, 203].

Until now the electrospinnability (in this case electrospinnability is used to describe bead-free smooth nanofibres) of sodium alginate is still impossible. In most studies carrier polymers are generally used to improve this. Alginate is readily soluble in water. However, it is still controversial on why it is not possible to electrospin alginate on its own. It has been postulated that a high conductivity, lack of entanglements, and gelation of the alginate solution at low concentration (below the concentration for the formation of entanglements) are responsible for this. The rigidity of the chains, worm-like molecular structure and high surface tension also contribute to this. Nevertheless, Nie et al. [12] managed to prepare pure alginate nanofibres using glycol as a solvent. They found that the glycol altered the chain conformation of the alginate and improved chain entanglements (viscosity and elasticity). Glycol decreased the surface tension and conductivity which contributed to the electrospinnability of pure alginate. Bonino et al.
[207] tried to electrospin pure alginate using water as a solvent, which resulted in large droplets on the collector, that were reduced by a surfactant. The production of alginate nanofibres from its aqueous solution was also reported by Fang et al. [24]. Calcium ions improved the intermolecular interaction which enhanced its electrospinnability from water. $1 \mathrm{wt} \%$ $\mathrm{Ca}^{2+}$ was sufficient to ensure continuous electrospinning and long nanofibres. The hydrolysis degradation of alginate in water via glycosidic hydrolysis after 15 days (reducing alginate solution viscosity) was exploited to electrospin alginate solution $(4 \mathrm{wt} \%)$ with the aid of a Triton X-100 surfactant and dimethyl formamide (DMF) as a cosolvent [208].

\subsubsection{Alginate with synthetic polymers}

One of the convenient ways to enhance the electrospinnability of biopolymers consists of choosing a compatible copolymer to co-spin with. Polyethylene (PEO) is a biocompatible and biodegradable synthetic polymer. It is non-ionic and hydrosoluble. Alginate is also hydrosoluble and therefore offers the opportunity to co-spin the two without difficulties [54]. The two interact with each other through hydrogen bonding which reduces the viscosity of the alginate solution. Cylindrical nanofibres from alginate/ PEO with a mean diameter of $\sim 75 \mathrm{~nm}$ were prepared by Jeong et al. [52]. Recently, Saquing et al. [54] reported that higher molecular weight PEO is required to increase the concentration of alginate in the PEO/alginate blend. They indicated that the PEOPEO interaction is responsible for the electrospinnability of alginate. Co-axial electrospinning of alginate (core) and PEO (shell) was recently reported. PEO was easily extracted by dissolving the nanofibres in water containing calcium chloride to crosslink the alginate [129]. They successfully incorporated $85 \mathrm{wt} \%$ of alginate in the blend with the aid of the surfactant. Another hydrosoluble synthetic polymer, with good mechanical properties, thermal stability, chemical stability and biocompatibility, is poly (vinyl alcohol) (PVA). A number of researchers utilized this polymer as copolymer for alginate electrospinning [208-210]. Similar to PEO, the flexible PVA interacts with the alginate via hydrogen bonding, thus improving the electrospinnability of the rigid alginate [208]. Different morphologies of PVA/ alginate were reported by Lee et al. [210]. At low alginate concentrations, ultrafine nanofibres were produced, and when the concentration was increased, 
electrospinning led to bigger beads with smaller average distances between the beads.

The solubility of alginate has been one difficulty facing its applicability in various fields. In order to improve the stability of the electrospun alginate, various crosslinking agents were investigated [211]. The electrospun nanofibrous membrane retained their fibrous structure after incubation for 7 days in aqueous medium (BSF). The morphology of the electrospun alginate/PEO blend as vitamin carrier was directly dependent on the viscosity of the alginate [212]. Higher viscosity alginate favoured beaded nanofibres with smaller average diameters, compared to low viscosity alginate-based nanofibres that were bead-free with larger diameters. The most significant part of using PEO as copolymer, beside the fact of enhancing the electrospinnability, is the opportunity to extract PEO from the nanofibres by incubation in water [53]. In this case the alginate is crosslinked through ionic bonds followed by leaching the PEO. A natural surfactant such as lecithin has been used to impart uniformity to the nanofibres [213]. The surfactant readily renders the opportunity to increase the alginate content in the blend without losing the uniformity of the nanofibres.

\subsubsection{Alginate with other biopolymers}

A blend of gelatin/sodium alginate produced smooth nanofibres in heated water $\left(45^{\circ} \mathrm{C}\right)$ [22]. A blend of chitosan and alginate was also electrospun with the aid of PEO as copolymer [214]. Because chitosan is a cationic copolymer and alginate is an anionic copolymer, they form a polyionic complex that does not need further crosslinking. Due to the gelation of these polymers, side-by-side electrospinning was used where the alginate and chitosan meet at the tip of the spinneret. The swelling of the nanofibres was reduced by the incorporation of chitosan which is not soluble in water. Core-sheath morphology of alginate and chitosan was achieved by spinning the alginate into a chitosan coagulation bath [133]. The average diameter of the nanofibres ranged between 600 and $900 \mathrm{~nm}$ coated with chitosan. This enhanced the stability of the alginate in saline solution.

\subsection{Collagen}

One of the most abundant proteins is collagen. Collagen is a kind of protein that gives strength, elasticity and structural support. The two most electrospun collagen types are collagen type I and type III [75,
215]. Collagen is soluble in a water/ethanol mixture, HIFP [216], TFE [217] and acetic acid [218]. Most research based on collagen was aimed to develop collagen nanofibrous membrane from non-toxic solvents, since collagen is usually used in biomedical applications [219]. These authors established that collagen nanofibrous membrane electrospun from fluoroalcohols lost their natural inherited properties. Matthews et al. [75] fabricated aligned collagen nanofibres using 1,1,1,3,3,3 hexafluoro-2-propanol as solvent with a rotating drum collector. The nanofibres were randomly oriented at a mandrel rotating speed of less than $500 \mathrm{rpm}$, and an increase to $4500 \mathrm{rpm}$ aligned the fibres along the rotation axis. Optimization of the collagen nanofibres was studied by Li et al. [218] . Through manipulation of the processing and solution parameters it was possible to produce smooth nanofibres with diameters below $100 \mathrm{~nm}$, but at the expense of the fibre structure. A decrease in concentration from $5 \%$ gradually reduced the fibre diameter from $\sim 500$ to $\sim 200 \mathrm{~nm}$, and a further decrease in concentration led to fibres with diameters below $100 \mathrm{~nm}$, but with significant formation of beads. It was concluded that the minimal concentration of collagen in 1,1,1,3,3,3 hexafluoro-2-propanol to produce smooth and uniform nanofibres is $5 \%$.

\subsubsection{Collagen with synthetic polymers}

Another feasible approach to avoid the use of toxic solvents is to co-spin collagen with a spinnable polymer. Chakrapani et al. [220] produced collagen nanofibrous membrane from a blend of PCL and collagen in acetic acid. The nanofabric network was made up of fibres with diameters ranging between 100 and $200 \mathrm{~nm}$ having a porosity of about $60 \%$. Dong et al. [20] prepared collagen nanofibres from phosphatebuffered saline (PBS) and ethanol in the presence of the salt $(\mathrm{NaCl})$. They found out that $16 \mathrm{wt} \%$ of collagen was readily soluble when the salt was $5 \mathrm{wt} \%$ or more. Nanofibres with diameter ranging between 210 and $540 \mathrm{~nm}$, depending on the salt concentration, were produced. A co-axial morphology of collagen (outer shell) and PCL (inner core) as structural support was produced using both TFE and 1.1.1.3.3.3-hexaflouro-2-propanol (HFP). The coaxial structure was fabricated by using a co-axial nozzle or by coating the electrospun membrane by immersion into a collagen solution [217]. The coaxially electrospun nanofibres displayed a similar morphology as pure PCL nanofibres, with an aver- 
age diameter of $385 \pm 82 \mathrm{~nm}$, and a coating thickness of $64 \pm 26 \mathrm{~nm}$. Another copolymer often used to enhance the spinnability of collagen without toxic solvents is poly(L-lactide-co-e-caprolactone) [221]. Zhong et al. [222] prepared collagen-glycosaminoglycan scaffolds through electrospinning in a mixture of TFE and water, followed by glutaraldehyde vapour crosslinking. The biostability of the smooth nanofibres with a mean diameter of $260 \mathrm{~nm}$ was improved. Although much work has been done on collagen in clinical applications, not much has been done on the application of the collagen in water treatment [219, 223]. However, Davis and Maffia [224] successfully prepared collagen from type 1 bovine for water treatment and sludge dewatering. The collagen showed good potential as a coagulant of colloidal solids.

\subsection{Gelatin}

Gelatin, similar to other naturally occurring polymers, is biocompatible, biodegradable and nontoxic [12]. It is derived from animal tissue such as skin, muscle and bone. Gelatin is subdivided into Type A and Type B, depending on the extraction and chemical treatment. Gelatin type A is obtained from the acidic pre-treatment of collagen, whereas Type $B$ is from alkali pre-treatment. The glutamine and asparagine are converted into glutamic and aspartic acid during alkali pre-treatment, yielding a high carboxylic acid content in gelatin Type B. Gelatin has been processed into various forms for a wide spectrum of applications such as food products, cosmetics and pharmaceuticals [225]. Although gelatin is readily soluble in water and polar solvents, the electrospinnability of gelatin is still a challenge. However, some reports indicated the possibility of electrospinning gelatin using solvents such as using 2.2.2trifluoroethanol TFE [226], formic acid [66], and 1.1.1.3.3.3-hexaflouro-2-propanol (HIFP) [85]. Electrospinning gelatin in water can be done by applying heat above $37^{\circ} \mathrm{C}[220]$.

The use of copolymers is another conducive route, not only to electrospin gelatin, but also to improve the mechanical and chemical stability [85, 136]. Huang et al. [227] indicated that gelatin can be electrospun into smooth nanofibres with a diameter of $140 \mathrm{~nm}$ using 2,2,2-trifluoroethanol (TFE) as a solvent. With a concentration of $7.5 \mathrm{wt} \%$ of gelatin, the modulus was $117 \mathrm{MPa}$ and the ultimate strength $4.9 \mathrm{MPa}$. Similar to collagen the gelation of gelatin and its sol-

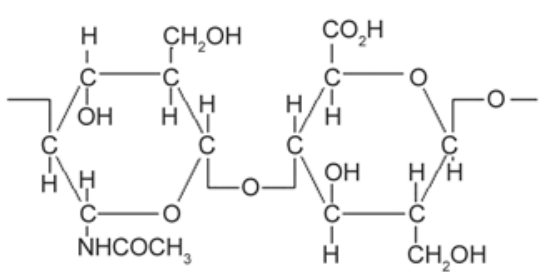

Figure 14. Structure of hyaluronic acid

ubility in water is the reason why it cannot be used in water treatment applications. The limitations of the application of gelatin are its weak mechanical strength and its ready solubility in water. The crosslinking of electrospun gelatin nanofibrous membrane is the most convenient way to improve the stability and mechanical strength [227].

\subsection{Hyaluronic acid}

Hyaluronic acid (HA), a natural polysaccharide, is often found in connective tissues in the body, such as the vitreous humour, the umbilical cord, and the joint fluid. It is a polyanionic acid made-up of Nacetyl-D-glucosamine and D-glucuronic repeating units as shown in Figure 14.

Thanks to the advancements in electrospinning, pure hyaluronic has been successfully electrospun into nanofibrous membrane from its solution $[13,15]$. The electro-blowing of hyaluronic acid affords the preparation of its nanofibres with diameters ranging from 49 to $83 \mathrm{~nm}$ depending on the preparation and solution properties used. HA mats with an average fibre diameter of $39 \pm 12 \mathrm{~nm}$ were produced from $\mathrm{NH}_{4} \mathrm{OH}: \mathrm{DMF}$ at ratio 2:1 [228]. Many researchers studied the application of the hyaluronic acid in biomedical applications. The hyalorunic was immobilized on the surface of silica microspheres to fabricate a magnetic adsorbent. This shows the possibility to develop new adsorbents for wastewater treatment [229].

\subsubsection{Hyaluronic acid with other biopolymers}

Hyaluronic acid/chitosan electrospun bioblend nanofibres were prepared by Ma et al. [230] in a mixture of formic acid and water. Smooth fibres with smaller average diameters $(83 \mathrm{~nm})$ were obtained at higher contents of hyaluronic acid (hyaluronic/chitosan at 9/1), while at low contents beaded-fibres (7/3) and drops (6/4) formed.

\subsubsection{Hyaluronic acid derivatives}

A thiolated HA derivative, 3,3'-dithiobis(propanoic dihydrazide)-modified HA (HA-DTPH), was syn- 
thesized and electrospun into nanofibrous membrane by Ji et al. [86]. The dithiobis(propanoic dihydrazine) was synthesized and coupled to the carboxylic groups of HA via carbodiimide chemistry. The thiolated bond formed were reduced using dithiothreitol to produce thiolated HA-DTPH. HA-DTPH $(2 \% \mathrm{w} / \mathrm{v}) / \mathrm{PEO}(2 \% \mathrm{w} / \mathrm{v})$ resulting in uniform nanofibres with diameters ranging from 70 to $110 \mathrm{~nm}$. The resulting fibres were crosslinked with PGEDA $(9 \mathrm{w} / \mathrm{v})$, followed by the dissolution of PEO in deionized water for 48 hours. After the extraction of PEO the fibre diameter distribution became much wider (with $85 \%$ of the fibre diameters ranging between 50 and $300 \mathrm{~nm}$ ). The crosslinking of the nanofibres reduced the swelling ratio of the mats. Another group investigated a similar system, but they used dualsyringe reactive electrospinning with thiolated HA/ PEO into contact with PEGDA before electrospinning to induce crosslinking [86].

\subsection{Aloe vera}

Aloe vera is one of the oldest herbal products used for medicinal purposes. It contains more than 200 nutrients which include amino acids, saliycilic acid, absorbic acid, enzymes and lots of minerals and vitamins [231, 232]. It is largely made up of water with long chain polysaccharides of acetylated glucomannan and carbohydrates. So far there is no work based on the electrospinning of aloe vera alone, but blends of synthetic and biopolymers were used to facilitate its electrospinnability. We included aloe vera as biopolymer because of its biocidal efficacy (towards different pathogenic organisms), and the possibility to functionalize electrospun mats in water filtration and treatment to reduce the biofouling of the electrospun membrane. Nonetheless, aloe vera enjoyed its success over a wide array of medical applications [233].

\subsubsection{Aloe Vera with synthetic/biopolymers}

A hybrid of hydroxypropyl methylcellulose (HPMC), poly(vinyl alcohol) PVA, poly(vinyl pyrrolidone), iodine PVP and poly(ethylene glycol) (PEG) were doped with aloe vera to investigate the effect of aloe vera on the properties of the resulting nanofibrous membrane. Like any biopolymer, aloe vera influenced the solution properties such as viscosity and conductivity. The addition of aloe vera increased both the viscosity and conductivity of the spinning solution, and decreased the mean diameter of the ensuing nanofibres from 660 to $596 \mathrm{~nm}$ at $1 \%$ of aloe vera. SEM showed an interfuse with each other when the content of aloe vera increased in the composition. In another study the addition of aloe vera (at 6\%) resulted in finer and more homogeneous nanofibres with mean diameters of 150 to $350 \mathrm{~nm}$ [232]. A similar study on the hybrid of biodegradable PCL and aloe vera to prepare transdermal biomaterial showed homogeneity and small average diameters of the nanofibres in the presence of aloe vera $(519 \pm 28$ versus $215 \pm 63 \mathrm{~nm}$ at $10 \%$ aloe vera), and greatly improved mechanical properties and hydrophilicity [234].

\section{Electrospun biopolymers with nanomaterials}

In the past few years there has been an ever increasing interest in incorporating different nanoparticles in biopolymers for a broad range of applications [26, 235]. Nanoparticles have a promising potential in wastewater/water treatment as biocidal agents, sensors, and adsorbents. If these nanoparticles are used alone for water/wastewater treatment there are some limitations such as their recovery and reuse, cost and their long-term effect on health and/or the environment. The biocidal activities of these nanoparticles are depicted in Table 5. A possible solution is to immobilize and control their release to overcome these complications/limitations [236, 237]. Electrospinning these nanomaterials (with known content) with biopolymers offers the possibility to retain their nanosize and their release into streams without any harmful by-products, thus reducing the overall cost.

\subsection{Silver nanoparticles}

Silver is well-known for centuries for its attractive antimicrobial, antiviral and fungicidal activity [236, 238]. The metal enjoyed its success in a broad spectrum of consumer products, such as plastics, soaps, pastes, food and textiles. The antimicrobial and antifungal activity of silver nanoparticles (AgNP) makes it the most studied metal nanoparticle for different applications [234-236]. There are several ways by which ionic silver can be reduced into silver nanoparticles $[26,238]$. There is still a lot of controversy on the mechanism behind the antibacterial, fungicidal, and antiviral activity displayed by silver nanoparticles. Three mechanisms were postulated, namely i) attachment of the silver nanoparticles on the surface of the cell membrane and disturbing its permeability and respiration, ii) penetrating the cell and 
Table 5. Summary of common antibacterial nanomaterials and applications

\begin{tabular}{|l|l|l|}
\hline \multicolumn{1}{|c|}{ Nanomaterial } & \multicolumn{1}{|c|}{ Proposed antimicrobial mechanism } & \multicolumn{1}{c|}{ Potential water treatment applications } \\
\hline Silver (AgNP) & $\begin{array}{l}\text { Release of } \mathrm{Ag}^{+} \text {ions, disruption of cell membrane and } \\
\text { electron transport, DNA damage }\end{array}$ & $\begin{array}{l}\text { Surface coatings, membranes, membrane reinforce- } \\
\text { ment }\end{array}$ \\
\hline Carbon nanotube (CNT) & $\begin{array}{l}\text { Disruption of intracellular metabolic pathways, oxida- } \\
\text { tive stress, physical membrane damage }\end{array}$ & $\begin{array}{l}\text { Biofouling resistance membranes, carbon hollow } \\
\text { fibres, membrane reinforcement }\end{array}$ \\
\hline Hydroxyapatite (Hap) & $\begin{array}{l}\text { Easy functionalization with different biocidal metal } \\
\text { oxide }\end{array}$ & Membrane reinforcement \\
\hline Zinc (ZnO) & $\begin{array}{l}\text { Intracellular accumulation of nanoparticles, disruption of } \\
\text { cell membrane, } \mathrm{H}_{2} \mathrm{O}_{2} \text { production, release of } \mathrm{Zn}^{+} \text {ions }\end{array}$ & $\begin{array}{l}\text { Surface coating, membranes, membrane reinforce- } \\
\text { ment }\end{array}$ \\
\hline
\end{tabular}

reacting with some compounds containing sulphur and phosphorus such as DNA and proteins, and iii) releasing silver ions which contributes to its activity towards pathogens [236]. These mechanisms depend on the distribution, shape and size of the silver nanoparticles.

Formic acid was used as solvent to prepare chitosan/PVA nanofibres with optimal conditions of $0.5 \mathrm{~mL} \cdot \mathrm{h}^{-1}$ flow rate, $18 \mathrm{kV}$ voltage and a TCD of $7.5 \mathrm{~cm}$. Chitosan/PVA was doped with silver oxides and titanium oxides to significantly improve the antibacterial activity of the ensuing nanofibres [26]. The prepared nanofibres with mean diameters ranging between 270 and $360 \mathrm{~nm}$ were cultured to find their antibacterial activity against both Gram negative and Gram positive bacteria. The antibacterial activity of $\mathrm{AgNO}_{3}$ loaded composite nanofibres increased with an increase in $\mathrm{AgNO} 3$ content with $99 \%$ bacteria eradicated for S. aures and 98\% for Escherichia coli at only $0.04 \mathrm{wt} \%$ of $\mathrm{AgNO}_{3}$. $\mathrm{TiO}_{2}$ loaded composite nanofibres showed a maximum of $90 \%$ bacteria for S. aures and $85 \%$ bacteria for Escherichia coli eradicated at concentrations above $0.03 \mathrm{wt} \%$ of $\mathrm{TiO}_{2}$.

The diameter of the nanofibres also influenced the antibacterial activity, with smaller diameters showing better efficiency because of the large surface to volume ratio giving more contact with the bacteria. A similar blend of chitosan and PVA was doped with AgNPs [239]. A $12 \mathrm{wt} \%$ PVA solution containing $\mathrm{AgNO}_{3}$ blended with a $6 \mathrm{wt} \%$ chitosan solution (15 wt $\%$ in acetic acid) was electrospun, followed by either refluxing for 48 hours or annealing at $130^{\circ} \mathrm{C}$ for 16 hours (to reduce $\mathrm{Ag}$ ions of the nanofibres). The intensities of surface plasmon resonance (SPR) of AgNPs increased in the presence of chitosan compared to that of PVA and $\mathrm{AgNO}_{3}$ only, indicating that chitosan can act as a stabilizer as well as a reducing agent for the formation of AgNPs. The spherical AgNPs on the surface of the electrospun nanofibrous membranes were fairly uniform and smaller in size when refluxed, while larger particles were asso- ciated with diffusion and agglomeration of residual $\mathrm{Ag}$ ions and AgNPs formed in the solid during heating were formed when annealed. This resulted in a lower killing efficiency of the annealed samples due to the surface area of the AgNPs coming into contact with the bacteria.

An et al. [240] prepared chitosan (CS)/polyethylene oxide (PEO) containing AgNPs nanofibres by means of in situ chemical reduction of Ag ions. The average diameter of the nanofibres decreased with an increase in AgNPs because of the increased charge density in the spinning solution, imparting stretching of the electrified jet under the electrical field. The cubic crystal AgNPs were fairly well dispersed in the CS/PEO ultrafine nanofibres with average diameter of less than $5 \mathrm{~nm}$. The tensile modulus and tensile strength of the CS/PEO/AgNP nanofibres were better than that of the CS/PEO nanofibres. The CS/PEO/ AgNP nanofibrous membrane exhibited higher antibacterial activity than the CS/PEO nanofibres towards E. coli. Silver nanoparticles were also incorporated into PVA/CS blends for their antibacterial activity [241]. The electrospinnability of the PVA/CS was enhanced by the AgNPs, and the size of the AgNPs varied between 2.4 to $10.7 \mathrm{~nm}$ depending on the CS concentration in the blends. A biopolymer blend of CS/gelatin containing AgNPs was successfully electrospun by Zhuang et al. [242]. The study indicates that the microcrystalline chitosan was used as reducing agent and stabilizer to synthesize the AgNPs at room temperature. Using a noniogenic polymer (PEO), a natural polymer (N-carboxyethylchitosan), and silver nanoparticles, Penchev et al. [87] observed a complete killing of the bacteria (Staphylococcus aureus) within an hour of contact at higher concentrations of silver nanoparticles, whereas at low concentrations the nanoparticles only inhibits bacterial growth. They used a one pot system to fabricate the nanofibre in which all the components were added into the spinning solution. Formic acid was again used as reducing agent and solvent, and the 
sizes of the NPs were $4 \pm 0.5$ and $6 \pm 1.5 \mathrm{~nm}$ respectively for 5 and $10 \mathrm{wt} \%$ of the $\mathrm{AgNO}_{3}$. Yang et al. [31] fabricated antimicrobial membrane using cellulose acetate and $\mathrm{AgNO}_{3}$ by slow and fast photoreduction. The mats were tested against Staphylococcus aureus, Escherilia coli, Klebsiella pneumonia, and Pseudomonas aeruginosa by an attachment method. The mean diameter of the ultrafine nanofibres ranged between 680 and $610 \mathrm{~nm}$ for 0.05 and $0.5 \mathrm{wt} \%$ of $\mathrm{AgNO}_{3}$, respectively. Most of the nanoparticles had a mean diameter between 3 and $16 \mathrm{~nm}$, whereas $15.4 \mathrm{~nm}$ resulted after rapid photoreduction. The killing efficiency for all the bacteria was $99.9 \%$ at a very low concentration of $0.05 \mathrm{wt} \%$. Lee et al. [243] produced electrospun chitosan nanofibres with chemically reduced AgNPs via electrospinning. The resulting spherical nanoparticles with sizes ranging between 10 and $11 \mathrm{~nm}$ (average diameter of $10 \pm 2 \mathrm{~nm}$ ) were evenly distributed in the chitosan nanofibres. The growth inhibition of Pseudomonas aeruginosa (gram negative) and Staphylococcus aureus (gram positive) increased with an increase in AgNPs in the composite materials.

\subsection{Hydroxyapatite (HAp) nanoparticles}

Celebi et al. [244] produced electrospun chitosan/ PVA nanofibrous membrane containing silver ionincorporated hydroxyapatite (HAp) nanoparticles. A mean diameter of $\sim 70 \mathrm{~nm}$ of silver ions-incorporated HAp particles were obtained with good antibacterial efficiency against Escherichia coli. Hydroxyapatite (HAp)/chitosan was synthesized by co-precipitation synthesis followed by electrospinning of $10 \mathrm{wt} \%$ UHMPEO in aqueous solution with the solvent composed of acetic acid (HAc) and dimethyl sulphoxide (DMSO). The X-ray diffraction (XRD) and selected area electron diffraction (SAED) spectra confirmed that the crystalline structure of HAp was retained in the nanofibres [217]. The electrospun nanocomposite nanofibrous membrane were finer and more homogeneous with diameters of $214 \pm 25 \mathrm{~nm}$ with spindle-like HAp parallel to the nanofibres direction. A similar dispersion of HAp and structure were reported using gelatin as matrix [245]. The mechanical properties were also improved in the presence of HAp.

\subsection{Carbon nanotubes}

Carbon nanotubes have excellent antimicrobial activity and mechanical strength. Similar to Ag nanopar- ticles, the mechanism of the carbon nanotubes against pathogenic organisms is still controversial [236]. The proposed mechanisms include physical membrane perturbation and oxidative stress. Their antimicrobial activity is also influenced by their distribution, diameter, length, and electronic structure. Most of the carbon nanotubes exhibit good cytotoxicity towards pathogenic organisms, with single-walled carbon nanotubes reported to be the most efficient. Well-aligned single walled carbon nanotube (SWNT) along the fibre axis of the bombyx mori silk nanofibre were produced by Ayutsede et al. [246]. A very low concentration of SWNT (1 wt \%) was enough to increase the crystallinity and mechanical properties. Multiwalled carbon nanotubes (MWNTs) were also incorporated in electrospun cellulose acetate (CA) nanofibres to investigate the effect of these nanoparticles on biopolymers [247]. The mean diameter of the nanofibres reduced from $267 \mathrm{~nm}$ for pure CA to $193 \mathrm{~nm}$ with MWNTs at only $0.55 \mathrm{wt} \%$. The MWNTs impart significant water wetting, surface area (from 4.3 to $7.7 \mathrm{~m} \cdot \mathrm{g}^{-1}$ ), Young's modulus (doubled from 553 to $1144 \mathrm{MPa}$ ), tensile strength (from 21.9 to $40.7 \mathrm{MPa}$ ) and elongation at break (from 8.0 to $10.5 \%$ ). A core-sheath structure of PVA/CS-MWNT with outer and inner sheath-core nanofibres of 200 and $100 \mathrm{~nm}$ respectively was reported by Feng et al. [248]. The composite nanofibres showed fast transfer kinetics and good electrochemical properties. In one of their recent studies on electrospun silk fibroin (B. mori)/multiwalled carbon nanotubes they reported that MWNTs induced crystallization of silk and significantly improved the mechanical properties [249].

\subsection{Zinc nanoparticles}

Zinc nanoparticles $(\mathrm{ZnO})$ antibacterial activity is still not clear, but several mechanisms were proposed. It was suggested that the lethal effect of $\mathrm{ZnO}$ results from disruption of the cell membrane activity and induction of intercellular reactive oxygen species, such as $\mathrm{H}_{2} \mathrm{O}_{2}$, a strong oxidizing agent harmful to bacterial cells [236]. Zinc oxide was produced by mixing the precursor (zinc acetate) in $0.1 \mathrm{M}$ sodium hydroxide in methanol [250]. The prepared $\mathrm{ZnO}$ was introduced in an alginate/PVA blend dissolved in distilled water. With a large contact area the composite exhibited high toxicity to both gram-negative and gram-positive bacteria. Taha et al. [156] functionalized a cellulose acetate/silica composite with $\mathrm{NH}_{2}$ to enhance its affinity towards $\mathrm{Cr}(\mathrm{IV})$ ions. They used 
tetraethoxysilane (TEOS) as silica source, cellulose acetate as precursor and 3-ureidoptopyltriethoxysilane as a compatibilizer. They produced $\mathrm{NH}_{2}$ functionalized nanofibres with a mean diameter of 100 $500 \mathrm{~nm}$ and a porosity and surface area of $73 \%$ and $126.5 \mathrm{~m}^{2} \cdot \mathrm{g}^{-1}$. Using static and dynamic experiments the membrane showed adsorption of $98 \%$. $\mathrm{ZnO}$ nanoparticles were impregnated into the electrospun cellulose acetate nanofibre membrane by Anitha et al. [251]. The membrane displayed a superhydrophobic nature (water contact angle of $124^{\circ}$ ) and antibacterial property against well-known bacteria.

\section{Applications of electrospun biopolymers in water treatment}

Electrospun nanofibres afford the opportunity to be applied in various fields such as biosensors, and filtration because of their unique properties such as large surface area and engineered porosity, and physico-mechanical properties. The manipulation of the solution properties and technique advancement rendered the opportunity to produce the desired morphology and structure of the resulting nanofibres for specific applications.

\subsection{Bioremediation}

Heavy metals in wastewater is still a big problem, and a challenge to researchers to come up with reliable solutions without leaving by-products. Cellulose acetate has been functionalized to increase its adsorption efficiency which depends mostly on the functional groups found on the main chain. Poly(methacrylic acid) (PMAA) with additional carboxyl groups was used to functionalize cellulose acetate to increase the number of metal binding sites [252]. The efficiency was enhanced by the presence of PMAA on the cellulose acetate fibres, but the adsorption was more effective for the removal of mercury ( $\mathrm{Hg}(\mathrm{II})$ ) with an adsorption capacity of $4.8 \mathrm{mg} \cdot \mathrm{g}^{-1}$. The efficiency may, however, depend on the metal ion type and the $\mathrm{pH}$. The de-adsorption of the metals is possible with an appropriate solvent such as ethylenedinitrilotetraacetic acid (EDTA). Cellulose acetate/ silica composites were tested for $\mathrm{Cr}(\mathrm{VI})$ adsorption [156]. In this case the $\mathrm{CA} / \mathrm{SiO}_{2}$ was functionalized with $\mathrm{NH} 2$ to enhance the adsorption of the resulting fibre membranes. The membranes displayed a good adsorption, and desorption after washing five times with an aqueous solution of sodium hydroxide $(\mathrm{NaOH})$. The adsorption data of $\mathrm{Cr}(\mathrm{VI})$ fitted well with the Langmuir isotherm with an adsorption capacity of $19.5 \mathrm{mg} \cdot \mathrm{g}^{-1}$.

Although various mechanisms were proposed to describe the metal ions adsorption of chitosan, the electrostatic attraction on the protonated amine groups is the accepted mechanism [253]. The heavy metal adsorption efficiency of an electrospun chitosan membrane was studied by several researchers $[10,254]$. It was found to depend on several aspects such as the degree of deacetylation [254], $\mathrm{pH}$, fibre structure and morphology [181, 254]. Desai et al. [254] studied the adsorption efficiency of PEO/chitosan nanofibres electrospun towards chromium using simulated flow conditions at a $\mathrm{pH}$ of 7.3. The chromium solution (prepared from $5 \mathrm{mg} \cdot \mathrm{L}^{-1} \mathrm{~K}_{2} \mathrm{CrO}_{4}$ ) was passed ten consecutive times through the chitosan nanofibrous filter. The binding efficiency of the membrane decreased with an increase in nanofibre diameter (81-131 nm). However, the heavy metal adsorption efficiency increased with an increase in the degree of deacetylation. Using static conditions, the same group found that the metal adsorption depends on the molecular weight of chitosan, the degree of deacetylation, the percentage of chitosan in the blend, and the surface area to mass ratio. The molecular weight is related to the length of the chains and therefore to the number of cations on the backbone of the chitosan acting as active binding sites.

Cho et al. [10] neutralized the nanofibres with $\mathrm{K}_{2} \mathrm{CO}_{3}$ to obtain an $-\mathrm{NH}_{2}$ group on the backbone of the chitosan membrane. This improved the stability of the electrospun membrane in water, with negligible weight reduction after 24 hours. The adsorption of the metals $\left(\mathrm{Cu}\right.$ (II), $419.2 \mathrm{mg} \cdot \mathrm{g}^{-1}$ and $\mathrm{Pb}(\mathrm{II})$, $202.8 \mathrm{mg} \cdot \mathrm{g}^{-1}$ ) increased significantly for the first $15 \mathrm{~min}$ to 4 hours and levelled off after 8 hours, due to the unavailability of binding sites (amine, primary and secondary hydroxyl groups), large surface area, and inter- and intrafibrous pores in the fibrous membrane. The Langmuir isotherm data showed that the equilibrium adsorption capacities for $\mathrm{Cu}$ (II) and $\mathrm{Pb}$ (II) were respectively $485.4 \mathrm{mg} \cdot \mathrm{g}^{-1}\left(2.85 \mathrm{mmol} \mathrm{g}^{-1}\right)$ and $263.2 \mathrm{mg} \cdot \mathrm{g}^{-1}\left(0.79 \mathrm{mmol} \cdot \mathrm{g}^{-1}\right)$. The difference between the values for the two metals was attributed to the differences in their atomic radii. It was suggested that the chitosan' adsorption followed a monolayer mechanism.

A nanofibrous membrane of pure silk fibroin (SF), and a blend of wool keratose and silk fibroin 
(WK/SF), were compared with pure silver wool and filter paper for their $\mathrm{Cu}$ (II) adsorption capacity [255]. The nanofibrous membranes displayed a significant $\mathrm{Cu}$ (II) adsorption capacity compared to silver wool and filter paper because of the large specific area which is $\sim 50$ times larger than those of filter paper and silver wool. The blend membrane showed a higher capacity than the SF membrane. The difference in $\mathrm{Cu}$ (II) adsorption capacity was related to the different chemical compositions (especially amino acids compositions). Both membranes displayed good desorption percentages. Desorption and readsorption was repeated six times, but the membrane kept $90 \%$ of its adsorption capacity. The Langmuir isotherm fits the experimental results better than the Freudlinch model. The $\mathrm{Cu}(\mathrm{II})$ adsorption followed a monolayer adsorption model.

Yang et al. [256] functionalized oxidized cellulose nanofibres embedded in an electrospun polyacrylonitrile (PAN) nanofibrous membrane with thiol groups to evaluate the metal adsorption capacity. Besides the increased stiffness due to the functionalization, the functionalized composite membrane displayed an adsorption of $76.5 \pm 2.0 \mathrm{Cr}_{2} \mathrm{O}_{7}^{2-}$ metal ions per gram of cellulose nanofibre at $\mathrm{pH}=4.0$, while the adsorption of $\mathrm{Pb}$ (II) was $133 \pm 2.5 \mathrm{mg} \cdot \mathrm{g}^{-1}$ at $\mathrm{pH}=5$ in static conditions. The membrane also reached $80.0 \mathrm{mg} \cdot \mathrm{g}^{-1}$ of $\mathrm{Pb}(\mathrm{II})$ within 15 minutes, and $125 \mathrm{mg} \cdot \mathrm{g}^{-1}$ within 20 minutes. Under dynamic conditions the membrane showed $60 \mathrm{mg} \mathrm{Cr}(\mathrm{VI}) \mathrm{g}^{-1}$ $(\mathrm{pH}=4)$ and $115 \mathrm{mg} \mathrm{Pb}$ (II) $\mathrm{g}^{-1}$ were adsorbed. Wang et al. [257] grafted cellulose nanowhiskers with amine groups using polyvinylamine (PVAm). The membrane displayed a maximum dynamic adsorption of $100 \mathrm{mg} \mathrm{Cr}(\mathrm{VI})($ at $\mathrm{pH}=4$ ) and $260 \mathrm{mg} \mathrm{Pb}$ (II) (at a $\mathrm{pH}$ of 6) per gram of cellulose nanofibre.

\subsection{Filtration membrane}

Even though electrospun nanofibrous membranes were successful in air filtration, much work was still needed for water filtration. The breakthrough came when the electrospun nanofibres were spun onto more rigid nonwoven polyesters to improve handling issues and their mechanical properties [29]. The thin composite membrane (TNFC) significantly enhanced the rejection and flux permeation of the membranes, because of the nanofibres with high porosity and controllable pore size for specific filtration processes. TNFC membranes have been one of the growing subjects in water filtration, because of the performance displayed by these materials since the introduction of electrospun nanofibres as one of the sub-layers.

Several researchers found that the coating of these TNFC with cellulose nanowhiskers imparts significant hydrophilicity and mechanical properties to the membrane [144, 149-152]. The thin top-layer coating enhanced the rejection and flux. Wang et al. [258] found that the interfacial polymerization of polyamide around the ultrafine cellulose nanofibres layer in TFNC showed a good rejection of $\mathrm{MgCl}$ and $\mathrm{MgSO}_{4}$, depending on the adapted interfacial polymerization (i.e. IP, the organic phase on top of the aqueous phase, or IP-R, the aqueous phase on top of the organic phase). The IP based membrane showed a rejection of $67.6 \%$ at $1 \%$ of piperazine (PIP), while the IP-R showed a rejection of $91.6 \%$ of $\mathrm{MgSO}_{4}$. However, both membranes displayed similar rejection percentages for both $\mathrm{MgSO}_{4}$ and $\mathrm{MgCl}$ at higher PIP concentrations. The same group electrospun PAN onto PET and infused cellulose nanowhiskers (diameter $5 \mathrm{~nm}$ ) for the microfiltration process [257]. The cellulose nanowhiskers were functionalized with different amines such as polyethyleneimine (PEI), ethylenediamine (EA), and polyvinylamine (PVAm) by using N-(3-Dimethylaminopropyl)-N'ethylcarbodiimide hydrochloride (EDC) and NHydroxysuccinimide (NHS) as catalysts. The resulting cellulose-based membrane had a mean pore size of $0.38 \mu \mathrm{m}$ with a maximum pore size of $0.78 \mu \mathrm{m}$, and the water permeation was about $1300 \mathrm{~L} \cdot \mathrm{m}^{-2} \cdot \mathrm{h}^{-1} \cdot \mathrm{psi}^{-1}$. All the membranes showed complete removal of the bacteria by size exclusion. The coating of chitosan on electrospun PAN enhanced the filtration efficiency and rejection for both ultrafiltration and nanofiltration processes [259]. The membrane displayed a rejection of $99 \%$ due to the inherited hydrophilicity of chitosan.

\subsection{Biocidal membrane}

Biofouling is a major problem for most membranes, because it results in the accumulation and biological growth of pathogenic organisms, and the deterioration of the membrane performance. A variety of metal oxides have been added to the electrospun biopolymer nanofibres to impart biocidal activity to the resulting nanofibres. Most of the diseases in developing countries are caused by pathogenic organisms. There has been an escalation of research in incorporating silver nanoparticles in the electro- 
spun membrane to impart biocidal activity [156, 239, 240, 243, 244]. Even though there is still much controversy over the biocidal activity of the silver nanoparticles, electrospun nanofibres displayed enhanced antibacterial efficiency when the membranes contained silver. $\mathrm{ZnO}$ particles were introduced in an alginate/PVA blend dissolved in distilled water, followed by electrospinning [250]. With the high contact area the electrospun composite displayed toxicity to both negative and positive bacteria. $\mathrm{ZnO}$ nanoparticles were also incorporated in a cellulose acetate membrane to enhance the antibacterial efficiency against Staphylococcus aureus, E. coli, and Citrobacter freundii. [251]. The impregnated $\mathrm{ZnO}$ nanoparticles significantly inhibited the growth of the bacteria and the inhibition zone diameters were 27, 22, and $14 \mathrm{~mm}$ for Staphylococcus aureus, Escherichia coli, and Citrobacter freundii. The functionalization of the electrospun membrane also enhanced the biocidal efficiency [83, 193, 195]. A quaternized chitosan membrane displayed inhibition of bacterial growth on the mat. Blending biopolymers with good antibacterial efficiency was also significantly reduced the biocidal activity of the resulting membrane [83].

\subsection{Chemosensors}

Chemosensors are detectors to selectively identify and recognize ions and molecules. A number of studies have been done on implanting the chemosensing agent onto solid matrices to improve the sensitivity, robustness, and lifetime [260]. A variety of polymers and nanomaterials were used as supporting materials in solid-state sensors. The sensitivity detection and exposure of the chemosensors was found to be directly dependent on the structure of the supporting material [261].

The sensing agent embedded onto electrospun nanofibres (with large surface areas) improves the detection sensitivity and response time, and reduces the concentration detection value (lowest detection value (LOD)) compared to commonly used films. The presence and concentration of the heavy metals can therefore be traced and removed at fairly low concentrations. Several biobased nanofibres such as ethyl acetate, cellulose acetate and cellulose have been functionalized with different fluorescent compounds to detect $\mathrm{Cu}$ [260-262]; $\mathrm{Cr}$ [260], $\mathrm{Fe}$ [263] and $\mathrm{Hg}$ ions [261,264]. Due to the large surface areas of the electrospun nanofibres, the sensitivity, selectivity, response time, and stability were enhanced. Kacmaz et al. [263] produced electrospun EC doped with dye to detect $\mathrm{Fe}^{3+}$ ions. The membrane sensed $\mathrm{Fe}^{3+}$ ions over a concentration range of $10^{-12}-10^{-6} \mathrm{M}$ (with an LOD of $0.07 \mathrm{pM}$ ), with a sensitivity response time of less than $30 \mathrm{~s}$ and sensor regeneration within $60 \mathrm{~s}$.

Zdyrko [265] developed a self-deployable colorimetric sensor by taking advantage of the superabsorbency of alginate, and functionalizing it with a heavy metal sensitive compound/dye. A blend of alginate and PEO electrospun onto rigid nonwoven (PET) absorbed metal ions from contaminated water.

\section{Limitations of electrospun biopolymers in water treatment}

Besides the hurdles based on the production scaleup of biopolymers, properties from the same source differ and the growth conditions influence the resulting properties. The harsh chemical treatment used to extract some biopolymers put an additional burden onto the water and the environment. It is important to do a lot of research on genetically engineering organisms and novel designed productions to scale up the production of biopolymers with high purity/ quality and having identical properties. Electrospun nanofibrous membranes have limited mechanical strength to withstand the pressures involved in water filtration, thus they are only applicable in membrane technologies were low pressures are involved (MF, UF and NF). Even though the work done on electrospun biopolymers shows potential to use ecofriendlier solvents, their application in water/wastewater treatment is still in its infancy. Most of these polymers are naturally prone to biodegradation and some are readily soluble in water, hence their lifetime is too short and they will need to be regularly replaced over time. This results in increasing the price of the membrane. The enhancement of the stability via either chemical or physical treatment without altering the unique valuable properties of the biobased membranes is important for their application in water/wastewater treatment. The dispersion of the nanomaterials in electrospun nanofibres (without agglomeration to retain their nanosize), and their exposure and release into the stream requires a lot of understanding. Most methods used to prepare the electrospun composite materials revolve around coating the mat (immersing the mat in a metal oxide 
solution) or adding the nanomaterial into the spinning solution. Nanomaterials from these methods have different release rates and exposure to the water stream. In the near future, investigation of the controlled release and exposure of the nanomaterials is required to understand and control their disinfection efficiency.

\section{Conclusions}

In the past decades, electrospinning has been highly recognized as a new class of nanotechnology providing access to a range of nanomaterials with unique properties. Significant progress has been made on the fundamental understanding of the mechanism, and the modelling of the envisaged processes governing the fibre formation. This was proven by advanced developments to engineer desired nanostructured materials through electric field manipulation, solution properties and new designs. Control over their deposition, dimensions and assemblies created new avenues to generate desired configurations for specific applications. There is currently a big paradigm shift towards the industrialization and commercialization of the electrospun nanofibres. The new technical advances (fibre collections strategies, needle shapes, and high throughput production) proved to be successful in the synthesis of these fascinating nanostructured materials. A fair amount of work has been done on electrospinning biopolymers for a broad array of applications, especially in the biomedical field. Much of this work was based on electrospinning of biopolymers with and without copolymers and using non-toxic solvents. Water filtration and wastewater treatment received little attention, despite the unique properties of biopolymers that are important in addressing environmental concerns. The biodegradation and mechanical strength of the electrospun mats are critical limitations in water filtration and wastewater treatment. In future the mutual relation to protect and improve the strength of the electrospun biopolymers by blending, chemical and physical treatment, and the addition of metal oxides and their controlled release into water streams will revolutionize wastewater treatment and water filtration. Through further research it will be possible to bridge the gap to enable the application of biopolymers in water filtration and treatment.

\section{Acknowledgements}

The authors would like to thank the National Research Foundation of South Africa (NRF), Professional Development Programme (PDP: UID-86101) for their financial support.

\section{Abbreviations}

\begin{tabular}{|l|l|}
\hline 3D & three dimensional \\
\hline AgNP & silver nanoparticles \\
\hline C & concentration \\
\hline CA & cellulose acetate \\
\hline CMC & carbomethyl chitin \\
\hline CMCs & carboxymethyl cellulose sodium salt \\
\hline CoPc & cobalt tetraaminophthalocyanine \\
\hline CV & crystal violet \\
\hline D & diameter \\
\hline DCM & dichloromethane \\
\hline DD & deacetylation degree \\
\hline DMAc & N,N-dimethylacetamide \\
\hline DMF & N,N-dimethylformamide \\
\hline DNA & deoxyribonucleic acid \\
\hline DOSE & dual-opposite-spinneret electrospinning \\
\hline DS & Degree of substitution \\
\hline EA & ethylenediamine \\
\hline EC & ethyl cellulose \\
\hline EDC & $\begin{array}{l}\text { N-(3-Dimethylaminopropyl)-N'-ethylcarbodiimide } \\
\text { hydrochloride }\end{array}$ \\
\hline EDS & energy-dispersive X-ray spectroscopy \\
\hline EDTA & ethylenediaminetetraacetic acid \\
\hline ENM & electrospun nanofibrous membrane \\
\hline GAG & glycosaminoglycan \\
\hline GJF & gas jet nanofibre \\
\hline
\end{tabular}

\begin{tabular}{|l|l|}
\hline HA & hyaluronic acid \\
\hline HA-DTPH & $\begin{array}{l}3.3^{\prime} \text {-dithiobis(propanoic dihydrazide)-modified } \\
\text { hyaluronic acid }\end{array}$ \\
\hline HAp & hydroxyapatite \\
\hline HPMC & hydroxypropyl methyl cellulose \\
\hline HTACC & $\begin{array}{l}\text { N-(2-hydroxlpropyl-3-trimethyl ammonium chi- } \\
\text { tosan chloride) }\end{array}$ \\
\hline LOD & lowest detection value \\
\hline MeOH & methanol \\
\hline MF & microfiltration \\
\hline Mw & molecular weight \\
\hline MWNT & multiwalled carbon nanotube \\
\hline NHS & N-Hydroxysuccinimide \\
\hline NMMO & N-methylmorpholine-N-oxide \\
\hline NP & nanoparticles \\
\hline P(CLLA) & poly(L-lactide-co-caprolactome) \\
\hline P(LLA-CL) & poly (L-lactide-co-caprolactone) \\
\hline PAA & polyacrylic acid \\
\hline PAAm & poly(acrylamide) \\
\hline PAN & poly(acrylonitrile) \\
\hline PBS & phosphate buffered saline \\
\hline PCL & polycaprolactone \\
\hline PCLDLLA & poly(e-caprolectome-co-D-L-lactide) \\
\hline PEG & poly(ethylene glycol) \\
\hline
\end{tabular}




\begin{tabular}{|c|c|}
\hline PEGDA & poly(ethylene glycol) diacrylate \\
\hline PEI & polyethyleneimine \\
\hline PEO & poly(ethylene oxide) \\
\hline PES & poly(ether sulphone) \\
\hline PET & poly(ethylene terephthalate) \\
\hline $\mathrm{PF}$ & paraformaldehyde \\
\hline PGA & poly(glycolic acid) \\
\hline PIP & piperazine \\
\hline PLA & poly(lactic acid) \\
\hline PMAA & poly(methacrylic acid) \\
\hline PS & polystyrene \\
\hline $\mathrm{PU}$ & poly urethane \\
\hline PVA & poly(vinyl alcohol) \\
\hline PVAc & poly(vinyl acetate) \\
\hline PVAm & polyvinylamine \\
\hline PVDF & poly(vinylidene flouride) \\
\hline PVP & poly(vinyl pyrrolidone) \\
\hline QBzCSN & N-benzyl-N,N-dimethyl chitosan iodide \\
\hline QCh & quaternized chitosan \\
\hline RJS & rotary-jet spinning \\
\hline RNA & ribonucleic acid \\
\hline SEM & scanning electron microscopy \\
\hline SF & silk fibroin \\
\hline SNE & standard electrospinning \\
\hline $\mathrm{SO} 3 \mathrm{H}$ & sulphonate groups \\
\hline SWNT & single walled carbon nanotube \\
\hline TCD & tip-to-collector distance \\
\hline TEM & transmission electron microscopy \\
\hline TEMPO & 2,2,6,6-tetramethylpiperidiooxy \\
\hline TFA & trifluoroacetic acid \\
\hline TFE & triflouroethanol \\
\hline $\mathrm{Tg}$ & glass transition temperature \\
\hline $\operatorname{Tm}$ & melting temperature \\
\hline TMP & trans-membrane pressure \\
\hline TNFC & thin film composite membrane \\
\hline TPU & thermoplastic polyurethane \\
\hline UF & ultrafiltration \\
\hline WK & wool keratose \\
\hline XPS & X-ray photoelectron spectroscopy \\
\hline
\end{tabular}

\section{References}

[1] Pendergast M. M., Hoek E. M.: A review of water treatment membrane nanotechnologies. Energy and Enviromental Science, 4, 1946-1971 (2011). DOI: $10.1039 / \mathrm{C} 0 \mathrm{EE} 00541 \mathrm{~J}$

[2] Progress on sanitation and drinking water, 2013 update, WHO and UNICEF report (2013).

[3] Ahmad S., Martens P. N., Pateiro F. J., Fuchsschwanz M.: Mine waste dumping and corresponding enviromental impacts at Chihn Bac waste dump in Vietnam. in 'Securing the Future and 8th ICARD. Skellefttes, Sweden’ p.6 (2009).

[4] Binns J., Illgner P., Nel E.: Water shortage, deforestation and development: South Africa's working for water programme. Land Degradation and Development, 12, 341-355 (2001).

DOI: $10.1002 / 1 \mathrm{dr} .455$
[5] Balamurugan R., Sundarrajan S., Ramakrishna S.: Recent trends in nanofibrous membranes and their suitability for air and water filtrations. Membranes, 1, 232-248 (2011).

DOI: $10.3390 /$ membranes 1030232

[6] Ramakrishna S., Fujihara K., Teo W-E., Yong T., Ma Z., Ramaseshan R.: Electrospun nanofibers: Solving global issues. Materials Today, 9, 40-50 (2006).

DOI: 10.1016/S1369-7021(06)71389-X

[7] Haider S., Park S-Y.: Preparation of the electrospun chitosan nanofibers and their applications to the adsorption of $\mathrm{Cu}(\mathrm{II})$ and $\mathrm{Pb}(\mathrm{II})$ ions from an aqueous solution. Journal of Membrane Science, 328, 90-96 (2009). DOI: $10.1016 /$ j.memsci.2008.11.046

[8] Greiner A., Wendorff J. H.: Electrospinning: A fascinating method for the preparation of ultrathin fibers. Angewandte Chemie International Edition, 46, 56705703 (2007).

DOI: $10.1002 /$ anie. 200604646

[9] Andrady A. L.: Science and technology of polymer nanofibers. Wiley, Hoboken (2008).

[10] Cho H., Min S-Y., Lee T-W.: Electrospun organic nanofiber electronics and photonics. Macromolecular Materials and Engineering, 298, 475-486 (2013).

DOI: 10.1002/mame.201200364

[11] Frenot A., Henriksson M. W., Walkenström P.: Electrospinning of cellulose-based nanofibers. Journal of Applied Polymer Science, 103, 1473-1482 (2007). DOI: $10.1002 /$ app. 24912

[12] Nie H., He A., Zheng J., Xu S., Li J., Han C. C.: Effects of chain conformation and entanglement on the electrospinning of pure alginate. Biomacromolecules, 9, 1362-1365 (2008).

DOI: $10.1021 / \mathrm{bm} 701349 \mathrm{j}$

[13] Um I. C., Fang D., Hsiao B. S., Okamoto A., Chu B.: Electro-spinning and electro-blowing of hyaluronic acid. Biomacromolecules, 5, 1428-1436 (2004).

DOI: $10.1021 / \mathrm{bm} 034539 \mathrm{~b}$

[14] Viswanathan G., Murugesan S., Pushparaj V., Nalamasu O., Ajayan P. M., Linhardt R. J.: Preparation of biopolymer fibers by electrospinning from room temperature ionic liquids. Biomacromolecules, 7, 415-418 (2006). DOI: $10.1021 / \mathrm{bm} 050837 \mathrm{~s}$

[15] Wang X., Um I. C., Fang D., Okamoto A., Hsiao B. S., Chu B.: Formation of water-resistant hyaluronic acid nanofibers by blowing-assisted electro-spinning and non-toxic post treatments. Polymer, 46, 4853-4867 (2005).

DOI: 10.1016/j.polymer.2005.03.058

[16] Safi S., Morshed M., Hosseini Ravandi S., Ghiaci M.: Study of electrospinning of sodium alginate, blended solutions of sodium alginate/poly(vinyl alcohol) and sodium alginate/poly(ethylene oxide). Journal of Applied Polymer Science, 104, 3245-3255 (2007). DOI: 10.1002/app.25696 
[17] Fang X., Reneker D. H.: DNA fibers by electrospinning. Journal of Macromolecular Science Part B: Physics, 36, 169-173 (1997).

DOI: $10.1080 / 00222349708220422$

[18] Buchko C. J., Chen L. C., Shen Y., Martin D. C.: Processing and microstructural characterization of porous biocompatible protein polymer thin films. Polymer, 40, 7397-7407 (1999).

DOI: $10.1016 / \mathrm{S} 0032-3861(98) 00866-0$

[19] Jacobs V., Patanaik A., Anandjiwala R. D., Maaza M.: Optimization of electrospinning parameters for chitosan nanofibres. Current Nanoscience, 7, 396-401 (2011).

DOI: $10.2174 / 157341311795542570$

[20] Dong B., Arnoult O., Smith M. E., Wnek G. E.: Electrospinning of collagen nanofiber scaffolds from benign solvents. Macromolecular Rapid Communications, 30, 539-542 (2009).

DOI: $10.1002 /$ marc.200800634

[21] Wnek G. E., Carr M. E., Simpson D. G., Bowlin G. L.: Electrospinning of nanofiber fibrinogen structures. Nano Letters, 3, 213-216 (2003). DOI: $10.1021 / \mathrm{n} 1025866 \mathrm{c}$

[22] Moon S., Farris R. J.: Electrospinning of heated gelatinsodium alginate-water solutions. Polymer Engineering and Science, 49, 1616-1620 (2009).

DOI: $10.1002 /$ pen.21355

[23] Frey M. W.: Electrospinning cellulose and cellulose derivatives. Polymer Reviews, 48, 378-391 (2008). DOI: $10.1080 / 15583720802022281$

[24] Fang D., Liu Y., Jiang S., Nie J., Ma G.: Effect of intermolecular interaction on electrospinning of sodium alginate. Carbohydrate Polymers, 85, 276-279 (2011). DOI: $10.1016 /$ j.carbpol.2011.01.054

[25] Barhate R. S., Ramakrishna S.: Nanofibrous filtering media: Filtration problems and solutions from tiny materials. Journal of Membrane Science, 296, 1-8 (2007). DOI: $10.1016 /$ j.memsci.2007.03.038

[26] Gopal R., Kaur S., Ma Z., Chan C., Ramakrishna S., Matsuura T.: Electrospun nanofibrous filtration membrane. Journal of Membrane Science, 281, 581-586 (2006).

DOI: $10.1016 /$ j.memsci.2006.04.026

[27] Patanaik A., Jacobs V., Anandjiwala R. D.: Performance evaluation of electrospun nanofibrous membrane. Journal of Membrane Science, 352, 136-142 (2010). DOI: $10.1016 /$ j.memsci.2010.02.009

[28] Son W. K., Youk J. H., Lee T. S., Park W. H.: Preparation of antimicrobial ultrafine cellulose acetate fibers with silver nanoparticles. Macromolecular Rapid Communications, 25, 1632-1637 (2004).

DOI: $10.1002 /$ marc. 200400323

[29] Son B., Yeom B-Y., Song S-H., Lee C-S., Hwang T. S.: Antibacterial electrospun chitosan/poly(vinyl alcohol) nanofibers containing silver nitrate and titanium dioxide. Journal of Applied Polymer Science, 111, 28922899 (2009).

DOI: $10.1002 / a p p .29233$
[30] Cooper A., Oldinski R., Ma H., Bryers J. D., Zhang M.: Chitosan-based nanofibrous membranes for antibacterial filter applications. Carbohydrate Polymers, 92, 254-259 (2013).

DOI: $10.1016 /$ j.carbpol.2012.08.114

[31] Yang R., He J., Xu L., Yu J.: Bubble-electrospinning for fabricating nanofibers. Polymer, 50, 5846-5850 (2009). DOI: $10.1016 /$ j.polymer.2009.10.021

[32] Ding B., Kimura E., Sato T., Fujita S., Shiratori S.: Fabrication of blend biodegradable nanofibrous nonwoven mats via multi-jet electrospinning. Polymer, 45, 1895-1902 (2004).

DOI: $10.1016 /$ j.polymer.2004.01.026

[33] Thoppey N., Bochinski J., Clarke L. I., Gorga R. E.: Edge electrospinning for high throughput production of quality nanofibers. Nanotechnology, 22, 345301/1345301/11 (2011).

DOI: $10.1088 / 0957-4484 / 22 / 34 / 345301$

[34] Bhardwaj N., Kundu S. C.: Electrospinning: A fascinating fiber fabrication technique. Biotechnology Advances, 28, 325-347 (2010). DOI: $10.1016 /$ j.biotechadv.2010.01.004

[35] Zeleny J.: The electrical discharge from liquid points, and a hydrostatic method of measuring the electric intensity at their surfaces. Physical Review, 3, 69-91 (1914). DOI: 10.1103/PhysRev.3.69

[36] Cooley J. F.: Apparatus for electrically dispersing fluids. U.S. Patent 692631 A, USA (1902).

[37] Formhals A.: Process and apparatus for preparing artificial threads. U.S. Patent 1975504, USA (1934).

[38] Formhals A.: Method and apparatus for the production of fibers. U.S. Patent 2116942, USA (1938).

[39] Formhals A.: Artificial thread and method of producing same. U.S. Patent 2187306, USA (1940).

[40] Ramakrishna S., Fujihara K., Teo W-E., Lim T-C., Ma Z.: An introduction to electrospinning and nanofibers. World Scientific, Singapore (2005).

[41] Thoppey N. M., Gorga R. E., Bochinski J. R., Clarke L. I.: Effect of solution parameters on spontaneous jet formation and throughput in edge electrospinning from a fluid-filled bowl. Macromolecules, 45, 6527-6537 (2012).

DOI: $10.1021 / \mathrm{ma3} 01207 \mathrm{t}$

[42] Masilela N., Kleyi P., Tshentu Z., Priniotakis G., Westbroek P., Nyokong T.: Photodynamic inactivation of Staphylococcus aureus using low symmetrically substituted phthalocyanines supported on a polystyrene polymer fiber. Dyes and Pigments, 96, 500-508 (2013). DOI: $10.1016 /$ j.dyepig.2012.10.001

[43] Huang Z-M., Zhang Y-Z., Kotaki M., Ramakrishna S.: A review on polymer nanofibers by electrospinning and their applications in nanocomposites. Composites Science and Technology, 63, 2223-2253 (2003). DOI: $10.1016 / \mathrm{S} 0266-3538(03) 00178-7$

[44] Abdel-Hady F., Alzahrany A., Hamed M.: Experimental validation of upward electrospinning process. ISRN Nanotechnology, 2011, 851317/1-851317/14 (2011). DOI: $\underline{10.5402 / 2011 / 851317}$ 
[45] Subbiah T., Bhat G., Tock R., Parameswaran S., Ramkumar S.: Electrospinning of nanofibers. Journal of Applied Polymer Science, 96, 557-569 (2005).

DOI: 10.1002/app.21481

[46] Teo W-E., Inai R., Ramakrishna S.: Technological advances in electrospinning of nanofibers. Science and Technology of Advanced Materials, 12, 013002/1031002/19 (2011).

DOI: $10.1088 / 1468-6996 / 12 / 1 / 013002$

[47] Haghi A., Akbari M.: Trends in electrospinning of natural nanofibers. Physica Status Solidi (a), 204, 18301834 (2007).

DOI: $10.1002 /$ pssa.200675301

[48] Deitzel J. M., Kleinmeyer J., Harris D., Beck T. N.: The effect of processing variables on the morphology of electrospun nanofibers and textiles. Polymer, 42, 261272 (2001).

DOI: $10.1016 / \mathrm{S} 0032-3861(00) 00250-0$

[49] Eda G., Shivkumar S.: Bead-to-fiber transition in electrospun polystyrene. Journal of Applied Polymer Science, 106, 475-587 (2007).

DOI: $10.1002 /$ app. 25907

[50] Pawlowski K. J., Belvin H. L., Raney D. L., Su J., Harrison J. S., Siochi E. J.: Electrospinning of a micro-air vehicle wing skin. Polymer, 44, 1309-1314 (2003). DOI: 10.1016/S0032-3861(02)00859-5

[51] Schiffman J. D., Schauer C. L.: A review: Electrospinning of biopolymer nanofibers and their applications. Polymer Reviews, 48, 317-352 (2008). DOI: $10.1080 / 15583720802022182$

[52] Bhattarai N., Li Z., Edmondson D., Zhang M.: Alginate-based nanofibrous scaffolds: Structural, mechanical, and biological properties. Advanced Materials, 18, 1463-1467 (2006).

DOI: $10.1002 /$ adma.200502537

[53] Jeong S. I., Krebs M. D., Bonino C. A., Khan S. A., Alsberg E.: Electrospun alginate nanofibers with controlled cell adhesion for tissue engineering. Macromolecular Bioscience, 10, 934-943 (2010). DOI: $10.1002 /$ mabi.201000046

[54] Saquing C. D., Tang C., Monian B., Bonino C. A., Manasco J. L., Alsberg E., Khan S. A.: Alginate-polyethylene oxide blend nanofibers and the role of the carrier polymer in electrospinning. Industrial and Engineering Chemistry Research, 52, 8692-8704 (2013). DOI: $10.1021 /$ ie $302385 b$

[55] Jacobs V., Anandjiwala R. D., Maaza M.: The influence of electrospinning parameters on the structural morphology and diameter of electrospun nanofibers. Journal of Applied Polymer Science, 115, 3130-3136 (2010). DOI: $10.1002 / a p p .31396$

[56] Lee K. H., Kim H. Y., Khil M. S., Ra Y. M., Lee D. R.: Characterization of nano-structured poly( $\varepsilon$-caprolactone) nonwoven mats via electrospinning. Polymer, 44, 1287-1294 (2003). DOI: $10.1016 / \mathrm{S} 0032-3861(02) 00820-0$
[57] Choktaweesap N., Arayanarakul K., Aht-ong D., Meechaisue C., Supaphol P.: Electrospun gelatin fibers: Effect of solvent system on morphology and fiber diameters. Polymer Journal, 39, 622-631 (2007). DOI: 10.1295/polymj.PJ2006190

[58] Fryczkowski R., Gorczowska M., Fryczkowska B., Janicki J.: The effect of solvent on the properties of nanofibres obtained by electrospinning from a mixture of poly(3-hydroxybutyrate) and polyaniline. Synthetic Metals, 166, 14-21 (2013). DOI: 10.1016/j.synthmet.2013.01.011

[59] Uyar T., Besenbacher F.: Electrospinning of uniform polystyrene fibers: The effect of solvent conductivity. Polymer, 49, 5336-5343 (2008).

DOI: $10.1016 /$ j.polymer.2008.09.025

[60] Sun Z., Deitzel J. M., Knopf J., Chen X., Gillespie J. W.: The effect of solvent dielectric properties on the collection of oriented electrospun fibers. Journal of Applied Polymer Science, 125, 2585-2594 (2012).

DOI: $10.1002 / a p p .35454$

[61] Tungprapa S., Puangparn T., Weerasombut M., Jangchud I., Fakum P., Semongkhol S., Meechaisue C., Supaphol P.: Electrospun cellulose acetate fibers: Effect of solvent system on morphology and fiber diameter. Cellulose, 14, 563-575 (2007).

DOI: $10.1007 / \mathrm{s} 10570-007-9113-4$

[62] Yuan X., Zhang Y., Dong C., Sheng J.: Morphology of ultrafine polysulfone fibers prepared by electrospinning. Polymer International, 53, 1704-1710 (2004). DOI: $10.1002 /$ pi.1538

[63] Aluigi A., Varesano A., Montarsolo A., Vineis C., Ferrero F., Mazzuchetti G., Tonin C.: Electrospinning of keratin/poly(ethylene oxide)blend nanofibers. Journal of Applied Polymer Science, 104, 863-870 (2007). DOI: 10.1002/app.25623

[64] Katti D. S., Robinson K. W., Ko F. K., Laurencin C. T.: Bioresorbable nanofiber-based systems for wound healing and drug delivery: Optimization of fabrication parameters. Journal of Biomedical Materials Research Part B: Applied Biomaterials, 70, 286-296 (2004). DOI: $10.1002 / \mathrm{jbm} . b .30041$

[65] Arayanarakul K., Choktaweesap N., Aht-ong D., Meechaisue C., Supaphol P.: Effects of poly(ethylene glycol), inorganic salt, sodium dodecyl sulfate, and solvent system on electrospinning of poly(ethylene oxide). Macromolecular Materials and Engineering, 291, 581591 (2006).

DOI: $10.1002 / \mathrm{mame} .200500419$

[66] Ki C. S., Baek D. H., Gang K. D., Lee K. H., Um I. C., Park Y. H.: Characterization of gelatin nanofiber prepared from gelatin-formic acid solution. Polymer, 46, 5094-5102 (2005).

DOI: $10.1016 /$ j.polymer.2005.04.040

[67] Geng X., Kwon O-H., Jang J.: Electrospinning of chitosan dissolved in concentrated acetic acid solution. Biomaterials, 26, 5427-5432 (2005). DOI: $10.1016 /$ j.biomaterials.2005.01.066 
[68] Ki C. S., Kim J. W., Hyun J. H., Lee K. H., Hattori M., Rah D. K., Park Y. H.: Electrospun three-dimensional silk fibroin nanofibrous scaffold. Journal of Applied Polymer Science, 106, 3922-3998 (2007).

DOI: $10.1002 / a p p .26914$

[69] Tungprapa S., Jangchud I., Supaphol P.: Release characteristics of four model drugs from drug-loaded electrospun cellulose acetate fiber mats. Polymer, 48, 50305041 (2007).

DOI: $10.1016 /$ j.polymer.2007.06.061

[70] Heikkilä P., Harlin A.: Electrospinning of polyacrylonitrile (PAN) solution: Effect of conductive additive and filler on the process. Express Polymer Letter, 3, 437-445 (2009).

DOI: $10.3144 /$ expresspolymlett.2009.53

[71] Li D., Wang Y., Xia Y.: Electrospinning of polymeric and ceramic nanofibers as uniaxially aligned arrays. Nano Letters, 3, 1167-1171 (2003).

DOI: $10.1021 / \mathrm{n} 10344256$

[72] Li D., Wang Y., Xia Y.: Electrospinning nanofibers as uniaxially aligned arrays and layer-by-layer stacked films. Advanced Materials, 16, 361-366 (2004). DOI: 10.1002/adma.200306226

[73] Theron A., Zussman E., Yarin A. L.: Electrostatic fieldassisted alignment of electrospun nanofibres. Nanotechnology, 12, 384-390 (2001).

DOI: $10.1088 / 0957-4484 / 12 / 3 / 329$

[74] Errico C., Detta N., Puppi D., Piras A. M., Chiellini F., Chiellini E.: Polymeric nanostructured items electrospun on a cylindrical template: A simple procedure for their removal. Polymer International, 60, 1162-1166 (2011).

DOI: $10.1002 /$ pi.3060

[75] Matthews J. A., Wnek G. E., Simpson D. G., Bowlin G. L.: Electrospinning of collagen nanofibers. Biomacromolecules, 3, 232-238 (2002).

DOI: $10.1021 / \mathrm{bm} 015533 \mathrm{u}$

[76] Kim C-W., Kim D-S., Kang S-Y., Marquez M., Joo Y. L.: Structural studies of electrospun cellulose nanofibers. Polymer, 47, 5097-6107 (2006). DOI: $10.1016 /$ j.polymer.2006.05.033

[77] Bonino C. A., Efimenko K., Jeong S. I., Krebs M. D., Alsberg E., Khan S. A.: Three-dimensional electrospun alginate nanofiber mats via tailored charge repulsions. Small, 8, 1928-1936 (2012).

DOI: $10.1002 /$ smll.201101791

[78] Homayoni H., Ravandi S. A. H., Valizadeh M.: Electrospinning of chitosan nanofibers: Processing optimization. Carbohydrate Polymers, 77, 656-661 (2009).

DOI: $10.1016 /$ j.carbpol.2009.02.008

[79] Teng S-H., Wang P., Kim H-E.: Blend fibers of chitosan-agarose by electrospinning. Materials Letters, 63, 2510-2512 (2009).

DOI: $10.1016 /$ j.matlet.2009.08.051

[80] Xu J., Zhang J., Gao W., Liang H., Wang H., Li J.: Preparation of chitosan/PLA blend micro/nanofibers by electrospinning. Materials Letters, 63, 658-660 (2009). DOI: $10.1016 /$ j.matlet.2008.12.014
[81] Du J., Hsieh Y-L.: Nanofibrous membranes from aqueous electrospinning of carboxymethyl chitosan. Nanotechnology, 19, 125707/1-125707/9 (2008).

DOI: $10.1088 / 0957-4484 / 19 / 12 / 125707$

[82] Neamnark A., Rujiravanit R., Supaphol P.: Electrospinning of hexanoyl chitosan. Carbohydrate Polymers, 66, 298-305 (2006).

DOI: $10.1016 /$ j.carbpol.2006.03.015

[83] Ignatova M., Manolova N., Rashkov I.: Novel antibacterial fibers of quaternized chitosan and poly(vinyl pyrrolidone) prepared by electrospinning. European Polymer Journal, 43, 1112-1122 (2007).

DOI: $10.1016 /$ j.eurpolymj.2007.01.012

[84] Du J., Hsieh Y-L.: PEGylation of chitosan for improved solubility and fiber formation via electrospinning. Cellulose, 14, 543-552 (2007). DOI: $10.1007 / \mathrm{s} 10570-007-9122-3$

[85] Li M., Guo Y., Wei Y., MacDiarmid A. G., Lelkes P. I.: Electrospinning polyaniline-contained gelatin nanofibers for tissue engineering applications. Biomaterials, 27, 2705-2715 (2006).

DOI: 10.1016/j.biomaterials.2005.11.037

[86] Ji Y., Ghosh K., Li B., Sokolov J. C., Clark R. A., Rafailovich M. H.: Dual-syringe reactive electrospinning of cross-linked hyaluronic acid hydrogel nanofibers for tissue engineering applications. Macromolecular Bioscience, 6, 811-817 (2006).

DOI: $10.1002 /$ mabi.200600132

[87] Penchev H., Paneva D., Manolova N., Rashkov I.: Hybrid nanofibrous yarns based on $N$-carboxyethylchitosan and silver nanoparticles with antibacterial activity prepared by self-bundling electrospinning. Carbohydrate Research, 345, 2374-2380 (2010). DOI: $10.1016 /$ j.carres.2010.08.014

[88] Lim Y-M., Gwon H-J., Jeun J. P., Nho Y-C.: Preparation of cellulose-based nanofibers using electrospinning. in 'Nanofibers' (ed.: Kumar A.), InTech, Rijeka 179188 (2010). DOI: $10.5772 / 8153$

[89] Wang C., Chien H-S., Hsu C-H., Wang Y-C., Wang CT., Lu H-A.: Electrospinning of polyacrylonitrile solutions at elevated temperatures. Macromolecules, 40, 7973-7983 (2007).

DOI: $10.1021 / \mathrm{ma} 070508 \mathrm{n}$

[90] De Vrieze S., Van Camp T., Nelvig A., Hagström B., Westbroek P., De Clerck K.: The effect of temperature and humidity on electrospinning. Journal of Materials Science, 44, 1357-1362 (2009).

DOI: $10.1007 / \mathrm{s} 10853-008-3010-6$

[91] Tripatanasuwan S., Zhong Z., Reneker D. H.: Effect of evaporation and solidification of the charged jet in electrospinning of poly(ethylene oxide) aqueous solution. Polymer, 48, 5742-5746 (2007).

DOI: $10.1016 /$ j.polymer.2007.07.045 
[92] Casper C. L., Stephens J. S., Tassi N. G., Chase D. B., Rabolt J. F.: Controlling surface morphology of electrospun polystyrene fibers: Effect of humidity and molecular weight in the electrospinning process. Macromolecules, 37, 573-578 (2004).

DOI: $10.1021 / \mathrm{ma} 0351975$

[93] Wang X., Niu H., Lin T., Wang X.: Needleless electrospinning of nanofibers with a conical wire coil. Polymer Engineering and Science, 49, 1582-1586 (2009).

DOI: $10.1002 /$ pen.21377

[94] Wang X., Niu H., Wang X., Lin T.: Needleless electrospinning of uniform nanofibers using spiral coil spinnerets. Journal of Nanomaterials, 2012, 785920/1785920/9 (2012).

DOI: $10.1155 / 2012 / 785920$

[95] Liu W., Yao Y., Lin Y., Wang B., Luo Y., Li N., Zhang Q., Wu Y., Niu A.: Electrospinning assisted by gas jet for preparing ultrafine poly(vinyl alcohol) fibres. Iran Polymer Journal, 18, 89-96 (2009).

[96] Tomaszewski W., Szadkowski M.: Investigation of electrospinning with the use of a multi-jet electrospinning head. Fibres and Textiles in Eastern Europe, 13, 22 26 (2005).

[97] Cengiz F., Jirsak O.: The effect of salt on the roller electrospinning of polyurethane nanofibers. Fibers and Polymers, 10, 177-184 (2009).

DOI: $10.1007 / \mathrm{s} 12221-009-0177-7$

[98] Dosunmu O. O., Chase G. G., Kataphinan W., Reneker D. H.: Electrospinning of polymer nanofibres from multiple jets on a porous tubular surface. Nanotechnology, 17, 1123-1127 (2006).

DOI: $10.1088 / 0957-4484 / 17 / 4 / 046$

[99] Nurwaha D., Han W., Wang X.: Investigation of a new needleless electrospinning method for the production of nanofibers. Journal of Engineered Fibers and Fabrics, 8, 42-49 (2013).

[100] Theron S., Yarin A., Zussman E., Kroll E.: Multiple jets in electrospinning: Experiment and modeling. Polymer, 46, 2889-2899 (2005).

DOI: 10.1016/j.polymer.2005.01.054

[101] Yamashita Y., Ko F., Miyake H., Higashiyama A.: Establishment of nanofiber preparation technique by electrospinning. Sen'i Gakkaishi, 64, 24-28 (2008). DOI: $10.2115 /$ fiber.64.24

[102] Varesano A., Carletto R. A., Mazzuchetti G.: Experimental investigations on the multi-jet electrospinning process. Journal of Materials Processing Technology, 209, 5178-5185 (2009).

DOI: 10.1016/j.jmatprotec.2009.03.003

[103] Kim G., Park K-E.: Alginate-nanofibers fabricated by an electrohydrodynamic process. Polymer Engineering and Science, 49, 2242-2248 (2009).

DOI: $10.1002 /$ pen.21472

[104] Varabhas J. S., Chase G. G., Reneker D. H.: Electrospun nanofibers from a porous hollow tube. Polymer, 49, 4226-4229 (2008).

DOI: $10.1016 /$ j.polymer.2008.07.043
[105] Kumar A., Wei M., Barry C., Chen J., Mead J.: Controlling fiber repulsion in multijet electrospinning for higher throughput. Macromolecular Materials and Engineering, 295, 701-708 (2010).

DOI: $10.1002 /$ mame.200900425

[106] Badrossamay M. R., Mcllwee H. A., Goss J. A., Parker K. K.: Nanofiber assembly by rotary jet-spinning. Nano Letters, 10, 2257-2261 (2010).

DOI: $10.1021 / \mathrm{nl} 101355 \mathrm{x}$

[107] Yarin A., Zussman E.: Upward needleless electrospinning of multiple nanofibers. Polymer, 45, 2977-2980 (2004).

DOI: 10.1016/j.polymer.2004.02.066

[108] Huang X., Wu D., Zhu Y., Sun D.: Needleless electrospinning of multiple nanofibers. in 'Poceedings of the $7^{\text {th }}$ IEEE International Conference on Nanotechnology. Hong Kong, China' 823-826 (2007).

DOI: $10.1109 /$ NANO.2007.4601311

[109] Kostakova E., Meszaros L., Gregr J.: Composite nanofibers produced by modified needleless electrospinning. Materials Letters, 63, 2419-2422 (2009). DOI: $10.1016 /$ j.matlet.2009.08.014

[110] Niu H., Lin T., Wang X.: Needleless electrospinning. I. A comparison of cylinder and disk nozzles. Journal of Applied Polymer Science, 114, 3524-3230 (2009). DOI: 10.1002/app.30891

[111] Tang S., Zeng Y., Wang X.: Splashing needleless electrospinning of nanofibers. Polymer Engineering and Science, 50, 2252-2257 (2010).

DOI: $10.1002 /$ pen. 21767

[112] Weitz R., Harnau L., Rauschenbach S., Burghard M., Kern K.: Polymer nanofibers via nozzle-free centrifugal spinning. Nano Letters, 8, 1187-1191 (2008).

DOI: $10.1021 / \mathrm{nl} 080124 \mathrm{q}$

[113] Dabirian F., Hosseini Ravandi S. A., Pishevar A. R., Abuzade R. A.: A comparative study of jet formation and nanofiber alignment in electrospinning and electrocentrifugal spinning systems. Journal of Electrostatics, 69, 540-546 (2011). DOI: $10.1016 /$ j.elstat.2011.07.006

[114] Thoppey N. M., Bochinski J. R., Clarke L. I., Gorga R. E.: Unconfined fluid electrospun into high quality nanofibers from a plate edge. Polymer, 51, 4928-4936 (2010). DOI: $10.1016 /$ j.polymer.2010.07.046

[115] Lukas D., Sarkar A., Pokorny P.: Self-organization of jets in electrospinning from free liquid surface: A generalized approach. Journal of Applied Physics, 103, 084309/1-084309/7 (2008).

DOI: $10.1063 / 1.2907967$

[116] Lin Y., Yao Y., Yang X., Wei N., Li X., Gong P., Li R., Wu D.: Preparation of poly(ether sulfone) nanofibers by gas-jet/electrospinning. Journal of Applied Polymer Science, 107, 909-917 (2008). DOI: $10.1002 / a p p .26445$ 
[117] Wang B., Yao Y., Peng J., Lin Y., Liu W., Luo Y., Xiang R., Li R., Wu D.: Preparation of poly(ester imide) ultrafine fibers by gas-jet/electrospinning. Journal of Applied Polymer Science, 114, 883-891 (2009). DOI: 10.1002/app.30505

[118] Zhmayev E., Cho D., Joo Y. L.: Nanofibers from gasassisted polymer melt electrospinning. Polymer, 51, 4140-4144 (2010).

DOI: $10.1016 /$ j.polymer.2010.06.058

[119] Benavides R. E., Jana S. C., Reneker D. H.: Role of liquid jet stretching and bending instability in nanofiber formation by gas jet method. Macromolecules, 46, 6081-6090 (2013).

DOI: $10.1021 / \mathrm{ma} 400900 \mathrm{~s}$

[120] Benavides R. E., Jana S. C., Reneker D. H.: Nanofibers from scalable gas jet process. ACS Macro Letters, 1, 1032-1036 (2012).

DOI: $10.1021 / \mathrm{mz} 300297 \mathrm{~g}$

[121] Bonani W., Maniglio D., Motta A., Tan W., Migliaresi C.: Biohybrid nanofiber constructs with anisotropic biomechanical properties. Journal of Biomedical Materials Research Part B: Applied Biomaterials, 96, 276286 (2011).

DOI: $10.1002 / \mathrm{jbm} . b .31763$

[122] Bonani W., Motta A., Migliaresi C., Tan W.: Biomolecule gradient in micropatterned nanofibrous scaffold for spatiotemporal release. Langmuir, 28, 13675-13687 (2012).

DOI: $10.1021 / 1 \mathrm{a} 302386 \mathrm{u}$

[123] Hu W-W., Yu H-N.: Coelectrospinning of chitosan/alginate fibers by dual-jet system for modulating material surfaces. Carbohydrate Polymers, 95, 716-727 (2013). DOI: $10.1016 /$ j.carbpol.2013.02.083

[124] Yoo C. R., Yeo I-S., Park K. E., Park J. H., Lee S. J., Park W. H., Min B-M.: Effect of chitin/silk fibroin nanofibrous bicomponent structures on interaction with human epidermal keratinocytes. International Journal of Biological Macromolecules, 42, 324-334 (2008). DOI: $10.1016 /$ j.ijbiomac.2007.12.004

[125] Xu F., Li L., Cui X.: Fabrication of aligned side-by-side $\mathrm{TiO}_{2} / \mathrm{SnO}_{2}$ nanofibers via dual-opposite-spinneret electrospinning. Journal of Nanomaterials, 2012, 575926/1-575926/5 (2012). DOI: $10.1155 / 2012 / 575926$

[126] Duan B., Yuan X., Zhu Y., Zhang Y., Li X., Zhang Y., Yao K.: A nanofibrous composite membrane of PLGAchitosan/PVA prepared by electrospinning. European Polymer Journal, 42, 2013-2022 (2006).

DOI: 10.1016/j.eurpolymj.2006.04.021

[127] Bazilevsky A. V., Yarin A. L., Megaridis C. M.: Co-electrospinning of core-shell fibers using a single-nozzle technique. Langmuir, 23, 2311-2314 (2007). DOI: $10.1021 / 1 a 063194 q$

[128] Liu Z., Sun D. D., Guo P., Leckie J. O.: An efficient bicomponent $\mathrm{TiO}_{2} / \mathrm{SnO}_{2}$ nanofiber photocatalyst fabricated by electrospinning with a side-by-side dual spinneret method. Nano Letters, 7, 1081-1085 (2007). DOI: $10.1021 / \mathrm{n} 1061898 \mathrm{e}$
[129] Díaz J. E., Fernández-Nieves A., Barrero A., Márquez M., Loscertales I. G.: Fabrication of structured micro and nanofibers by coaxial electrospinning. Journal of Physics: Conference Series, 127, 1-8 (2008).

DOI: $10.1088 / 1742-6596 / 127 / 1 / 012008$

[130] Jiang S., Duan G., Zussman E., Greiner A., Agarwal S.: Highly flexible and tough concentric triaxial polystyrene fibers. ACS Applied Materials and Interfaces, 6, 5918-5923 (2014). DOI: $10.1021 / \mathrm{am} 500837 \mathrm{~s}$

[131] Pakravan M., Heuzey M-C., Ajji A.: Core-shell structured PEO-chitosan nanofibers by coaxial electrospinning. Biomacromolecules, 13, 412-421 (2012).

DOI: $10.1021 / \mathrm{bm} 201444 \mathrm{v}$

[132] Tong H-W., Zhang X., Wang M.: A new nanofiber fabrication technique based on coaxial electrospinning. Materials Letters, 66, 257-260 (2012).

DOI: $10.1016 /$ j.matlet.2011.08.095

[133] Chang J-J., Lee Y-H., Wu M-H., Yang M-C., Chien CT.: Preparation of electrospun alginate fibers with chitosan sheath. Carbohydrate Polymers, 87, 2357-2361 (2012). DOI: $10.1016 /$ j.carbpol.2011.10.054

[134]Li D., Xia Y.: Direct fabrication of composite and ceramic hollow nanofibers by electrospinning. Nano Letters, 4, 933-938 (2004). DOI: $10.1021 / \mathrm{nl} 049590 \mathrm{f}$

[135] Sakuldao S., Yoovidhya T., Wongsasulak S.: Coaxial electrospinning and sustained release properties of gelatin-cellulose acetate core-shell ultrafine fibres. ScienceAsia, 37, 335-343 (2011). DOI: $10.2306 /$ scienceasia1513-1874.2011.37.335

[136]Zhang Y., Huang Z-M., Xu X., Lim C. T., Ramakrishna S.: Preparation of core-shell structured PCL-rgelatin Bi-component nanofibers by coaxial electrospinning. Chemistry of Materials, 16, 3406-3409 (2004).

DOI: $10.1021 / \mathrm{cm} 049580 \mathrm{f}$

[137] Gulfam M., Lee J. M., Kim J-E., Lim D. W., Lee E. K., Chung B. G.: Highly porous core-shell polymeric fiber network. Langmuir, 27, 10993-10999 (2011). DOI: $10.1021 / 1 \mathrm{a} 201253 \mathrm{z}$

[138] Chen H., Wang N., Di J., Zhao Y., Song Y., Jiang L.: Nanowire-in-microtube structured core/shell fibers via multifluidic coaxial electrospinning. Langmuir, 26, 11291-11296 (2010).

DOI: $10.1021 / 1 \mathrm{a} 100611 \mathrm{f}$

[139] Kim W., Kim S. S.: Synthesis of biodegradable triplelayered capsules using a triaxial electrospray method. Polymer, 52, 3325-3336 (2011). DOI: $10.1016 /$ j.polymer.2011.05.033

[140] Liu W., Ni C., Chase D. B., Rabolt J. F.: Preparation of multilayer biodegradable nanofibers by triaxial electrospinning. ACS Macro Letters, 2, 466-468 (2013). DOI: $10.1021 / \mathrm{mz} 4000688$ 
[141] Mokhena T. C., Luyt A. S.: Investigation of polyethylene/sisal whiskers nanocomposites prepared under different conditions. Polymer Composites, 35, 2221-2233 (2014). DOI: $10.1002 / p c .22887$

[142] Stephen M., Catherine N., Brenda M., Andrew K., Leslie P., Corrine G.: Oxolane-2,5-dione modified electrospun cellulose nanofibers for heavy metals adsorption. Journal of Hazardous Materials, 192, 922-927 (2011).

DOI: 10.1016/j.jhazmat.2011.06.001

[143] Xu S., Zhang J., He A., Li J., Zhang H., Han C. C.: Electrospinning of native cellulose from nonvolatile solvent system. Polymer, 49, 2911-2917 (2008).

DOI: 10.1016/j.polymer.2008.04.046

[144] Ma H., Burger C., Hsiao B. S., Chu B.: Nanofibrous microfiltration membrane based on cellulose nanowhiskers. Biomacromolecules, 13, 180-186 (2011). DOI: $10.1021 / \mathrm{bm} 201421 \mathrm{~g}$

[145] Rao S. S., Jeyapal S. G., Rajiv S.: Biodegradable electrospun nanocomposite fibers based on poly(2-hydroxy ethyl methacrylate) and bamboo cellulose. Composites Part B: Engineering, 60, 43-48 (2014).

DOI: $10.1016 /$ j.compositesb.2013.12.068

[146] Peresin M. S., Habibi Y., Vesterinen A-H., Rojas O. J., Pawlak J. J., Seppälä J. V.: Effect of moisture on electrospun nanofiber composites of poly(vinyl alcohol) and cellulose nanocrystals. Biomacromolecules, 11, 24712477 (2010).

DOI: 10.1021/bm1006689

[147] Park W-I., Kang M., Kim H-S., Jin H-J.: Electrospinning of poly(ethylene oxide) with bacterial cellulose whiskers. Macromolecular Symposia, 249-250, 289294 (2007).

DOI: $10.1002 /$ masy.200750347

[148] Cao X., Huang M., Ding B., Yu J., Sun G.: Robust polyacrylonitrile nanofibrous membrane reinforced with jute cellulose nanowhiskers for water purification. Desalination, 316, 120-126 (2013).

DOI: $10.1016 /$ j.desal.2013.01.031

[149] Chu B., Hsiao B. S., Ma H.: High flux high efficiency nanofiber membranes and methods of production thereof. U.S. Patent 20110198282 A1, USA (2009).

[150] Ma H., Burger C., Hsiao B. S., Chu B.: Highly permeable polymer membranes containing directed channels for water purification. ACS Macro Letters, 1, 723726 (2012).

DOI: $10.1021 / \mathrm{mz} 300163 \mathrm{~h}$

[151] Ma H., Burger C., Hsiao B. S., Chu B.: Ultrafine polysaccharide nanofibrous membranes for water purification. Biomacromolecules, 12, 970--976 (2011). DOI: $10.1021 / \mathrm{bm} 1013316$

[152] Sato A., Wang R., Ma H., Hsiao B. S., Chu B.: Novel nanofibrous scaffolds for water filtration with bacteria and virus removal capability. Journal of Electron Microscopy, 60, 201-209 (2011).

DOI: $10.1093 /$ jmicro/dfr019
[153] Ma Z., Kotaki M., Ramakrishna S.: Electrospun cellulose nanofiber as affinity membrane. Journal of Membrane Science, 265, 115-123 (2005).

DOI: $10.1016 /$ j.memsci.2005.04.044

[154] Wenten I. G.: Recent development in membrane science and its industrial applications. Membrane Science Technology, 24, 1009-1024 (2002).

[155] Ji F., Li C., Tang B., Xu J., Lu G., Liu P.: Preparation of cellulose acetate/zeolite composite fiber and its adsorption behavior for heavy metal ions in aqueous solution. Chemical Engineering Journal, 209, 325-333 (2012).

DOI: $10.1016 /$ j.cej.2012.08.014

[156] Taha A. A., Wu Y-N., Wang H., Li F.: Preparation and application of functionalized cellulose acetate/silica composite nanofibrous membrane via electrospinning for $\mathrm{Cr}(\mathrm{VI})$ ion removal from aqueous solution. Journal of Environmental Management, 112, 10-16 (2012). DOI: $10.1016 /$ j.jenvman.2012.05.031

[157] Bódalo A., Gómez J-L., Gómez E., León G., Tejera M.: Ammonium removal from aqueous solutions by reverse osmosis using cellulose acetate membranes. Desalination, 184, 149-155 (2005).

DOI: $10.1016 /$ j.desal.2005.03.062

[158] Konwarh R., Karak N., Misra M.: Electrospun cellulose acetate nanofibers: The present status and gamut of biotechnological applications. Biotechnology Advances, 31, 421-437 (2013).

DOI: $10.1016 /$ j.biotechadv.2013.01.002

[159] Zhou W., He J., Cui S., Gao W.: Studies of electrospun cellulose acetate nanofibrous membranes. The Open Materials Science Journal, 5, 51-55 (2011).

DOI: $10.2174 / 1874088 X 01105010051$

[160] Chen L., Bromberg L., Hatton T. A., Rutledge G. C.: Electrospun cellulose acetate fibers containing chlorhexidine as a bactericide. Polymer, 49, 1266-1275 (2008).

DOI: $10.1016 /$ j.polymer.2008.01.003

[161] Taepaiboon P., Rungsardthong U., Supaphol P.: Vitamin-loaded electrospun cellulose acetate nanofiber mats as transdermal and dermal therapeutic agents of vitamin A acid and vitamin E. European Journal of Pharmaceutics and Biopharmaceutics, 67, 387-397 (2007). DOI: $10.1016 /$ j.ejpb.2007.03.018

[162] Suwantong O., Opanasopit P., Ruktanonchai U., Supaphol P.: Electrospun cellulose acetate fiber mats containing curcumin and release characteristic of the herbal substance. Polymer, 48, 7546-7557 (2007). DOI: $10.1016 /$ j.polymer.2007.11.019

[163] Ma Z., Ramakrishna S.: Electrospun regenerated cellulose nanofiber affinity membrane functionalized with protein $\mathrm{A} / \mathrm{G}$ for $\mathrm{IgG}$ purification. Journal of Membrane Science, 319, 23-28 (2008). DOI: $\underline{10.1016 / \mathrm{j} . \mathrm{memsci} .2008 .03 .045}$ 
[164] Chen S-L., Huang X-J., Xu Z-K.: Functionalization of cellulose nanofiber mats with phthalocyanine for decoloration of reactive dye wastewater. Cellulose, 18, 1295 1303 (2011).

DOI: $10.1007 / \mathrm{s} 10570-011-9572-5$

[165] Muzzarelli R. A.: Chitins and chitosans as immunoadjuvants and non-allergenic drug carriers. Marine Drugs, 8, 292-312 (2010).

DOI: $10.3390 / \mathrm{md} 8020292$

[166] Jayakumar R., Menon D., Manzoor K., Nair S., Tamura H.: Biomedical applications of chitin and chitosan based nanomaterials - A short review. Carbohydrate Polymers, 82, 227-232 (2010).

DOI: 10.1016/j.carbpol.2010.04.074

[167] Sun K., Li Z.: Preparations, properties and applications of chitosan based nanofibers fabricated by electrospinning. Express Polymer Letters, 5, 342-361 (2011). DOI: $10.3144 /$ expresspolymlett.2011.34

[168] Min B-M., Lee S. W., Lim J. N., You Y., Lee T. S., Kang P. H., Park W. H.: Chitin and chitosan nanofibers: Electrospinning of chitin and deacetylation of chitin nanofibers. Polymer, 45, 7137-7142 (2004). DOI: $10.1016 /$ j.polymer.2004.08.048

[169] Noh H. K., Lee S. W., Kim J-M., Oh J-E., Kim K-H., Chung C-P., Choi S-C., Park W. H., Min B-M.: Electrospinning of chitin nanofibers: Degradation behavior and cellular response to normal human keratinocytes and fibroblasts. Biomaterials, 27, 3934-3944 (2006). DOI: 10.1016/j.biomaterials.2006.03.016

[170] Junkasem J., Rujiravanit R., Supaphol P.: Fabrication of $\alpha$-chitin whisker-reinforced poly(vinyl alcohol) nanocomposite nanofibres by electrospinning. Nanotechnology, 17, 4519-4528 (2006).

DOI: $10.1088 / 0957-4484 / 17 / 17 / 039$

[171] Junkasem J., Rujiravanit R., Grady B. P., Supaphol P.: $\mathrm{X}$-ray diffraction and dynamic mechanical analyses of $\alpha$-chitin whisker-reinforced poly(vinyl alcohol) nanocomposite nanofibers. Polymer International, 59, 8591 (2010).

DOI: $10.1002 /$ pi.2693

[172] Naseri N., Algan C., Jacobs V., John M., Oksman K., Mathew A. P.: Electrospun chitosan-based nanocomposite mats reinforced with chitin nanocrystals for wound dressing. Carbohydrate Polymers, 109, 7-15 (2014). DOI: $10.1016 /$ j.carbpol.2014.03.031

[173] Park K. E., Kang H. K., Lee S. J., Min B-M., Park W. H.: Biomimetic nanofibrous scaffolds: Preparation and characterization of PGA/chitin blend nanofibers. Biomacromolecules, 7, 635-643 (2006).

DOI: $10.1021 / \mathrm{bm} 0509265$

[174] Błasińska A., Krucińska I., Chrzanowski M.: Dibutyrylchitin nonwoven biomaterials manufactured using electrospinning method. Fibres and Textiles in Eastern Europe, 12, 51-55 (2004).

[175] Du J., Hsieh Y-L.: Cellulose/chitosan hybrid nanofibers from electrospinning of their ester derivatives. Cellulose, 16, 247-260 (2009). DOI: $10.1007 / \mathrm{s} 10570-008-9266-9$
[176] Pant H. R., Kim H. J., Bhatt L. R., Joshi M. K., Kim E. K., Kim J. I., Abdal-hay A., Hui K., Kim C. S.: Chitin butyrate coated electrospun nylon-6 fibers for biomedical applications. Applied Surface Science, 285, 538-544 (2013).

DOI: $10.1016 /$ j.apsusc.2013.08.089

[177] Shalumon K., Binulal N., Selvamurugan N., Nair S., Menon D., Furuike T., Tamura H., Jayakumar R.: Electrospinning of carboxymethyl chitin/poly(vinyl alcohol) nanofibrous scaffolds for tissue engineering applications. Carbohydrate Polymers, 77, 863-869 (2009). DOI: 10.1016/j.carbpol.2009.03.009

[178] Sohofi N., Tavanai H., Morshed M., Abdolmaleki A.: Electrospinning of $100 \%$ carboxymethyl chitosan nanofibers. Journal of Engineered Fibers and Fabrics, 1, 87-92 (2014).

[179] Qin Y., Hu H., Luo A., Wang Y., Huang X., Song P.: Effect of carboxymethylation on the absorption and chelating properties of chitosan fibers. Journal of Applied Polymer Science, 99, 3110-3115 (2006). DOI: $10.1002 /$ app.22917

[180] Miao J., Li L., Chen G., Gao C., Dong S.: Preparation of $N, O$-carboxymethyl chitosan composite nanofiltration membrane and its rejection performance for the fermentation effluent from a wine factory. Chinese Journal of Chemical Engineering, 16, 209-213 (2008). DOI: $10.1016 / \mathrm{S} 1004-9541(08) 60064-6$

[181] Zhao Z-P., Wang Z., Wang S-C.: Formation, charged characteristic and BSA adsorption behavior of carboxymethyl chitosan/PES composite MF membrane. Journal of Membrane Science, 217, 151-158 (2003). DOI: 10.1016/S0376-7388(03)00105-4

[182] Muzzarelli R. A. A.: Potential of chitin/chitosan-bearing materials for uranium recovery: An interdisciplinary review. Carbohydrate Polymers, 84, 54-63 (2011). DOI: 10.1016/j.carbpol.2010.12.025

[183] Wan Ngah W. S., Teong L. C., Hanafiah M. A. K. M.: Adsorption of dyes and heavy metal ions by chitosan composites: A review. Carbohydrate Polymers, 83, 1446-1456 (2011).

DOI: 10.1016/j.carbpol.2010.11.004

[184] Ohkawa K., Cha D., Kim H., Nishida A., Yamamoto H.: Electrospinning of chitosan. Macromolecular Rapid Communications, 25, 1600-1605 (2004). DOI: $10.1002 /$ marc. 200400253

[185] Jia Y-T., Gong J., Gu X-H., Kim H-Y., Dong J., Shen $\mathrm{X}-\mathrm{Y}$.: Fabrication and characterization of poly (vinyl alcohol)/chitosan blend nanofibers produced by electrospinning method. Carbohydrate Polymers, 67, 403409 (2007). DOI: $10.1016 /$ j.carbpol.2006.06.010

[186] Su P., Wang C., Yang X., Chen X., Gao C., Feng X-X., Chen J-Y., Ye J., Gou Z.: Electrospinning of chitosan nanofibers: The favorable effect of metal ions. Carbohydrate Polymers, 84, 239-246 (2011). DOI: $10.1016 /$ j.carbpol.2010.11.031 
[187] Jung K-H., Huh M-W., Meng W., Yuan J., Hyun S. H., Bae J-S., Hudson S. M., Kang I-K.: Preparation and antibacterial activity of PET/chitosan nanofibrous mats using an electrospinning technique. Journal of Applied Polymer Science, 105, 2816-2823 (2007).

DOI: 10.1002/app.25594

[188] Torres-Giner S., Ocio M. J., Lagaron J. M.: Novel antimicrobial ultrathin structures of zein/chitosan blends obtained by electrospinning. Carbohydrate Polymers, 77, 261-266 (2009).

DOI: $10.1016 /$ j.carbpol.2008.12.035

[189] Chen Z., Mo X., Qing F.: Electrospinning of collagen-chitosan complex. Materials Letters, 61, 34903494 (2007).

DOI: 10.1016/j.matlet.2006.11.104

[190] Chen J-P., Chang G-Y., Chen J-K.: Electrospun collagen/chitosan nanofibrous membrane as wound dressing. Colloids and Surfaces A: Physicochemical and Engineering Aspects, 313-314, 183-188 (2008).

DOI: $10.1016 /$ j.colsurfa.2007.04.129

[191] Maeda N., Miao J., Simmons T. J., Dordick J. S., Linhardt R.: Composite polysaccharide fibers prepared by electrospinning and coating. Carbohydrate Polymers, 102, 950-955 (2014).

DOI: $10.1016 /$ j.carbpol.2013.10.038

[192] Santos C., Silva C. J., Büttel Zs., Guimarães R., Pereira S. B., Tamagnini P., Zille A.: Preparation and characterization of polysaccharides/PVA blend nanofibrous membranes by electrospinning method. Carbohydrate Polymers, 99, 584-592 (2014).

DOI: 10.1016/j.carbpol.2013.09.008

[193] Ignatova M., Starbova K., Markova N., Manolova N., Rashkov I.: Electrospun nano-fibre mats with antibacterial properties from quaternised chitosan and poly (vinyl alcohol). Carbohydrate Research, 341, 20982107 (2006).

DOI: 10.1016/j.carres.2006.05.006

[194] Ignatova M., Manolova N., Markova N., Rashkov I.: Electrospun non-woven nanofibrous hybrid mats based on chitosan and PLA for wound-dressing applications. Macromolecular Bioscience, 9, 102-111 (2009). DOI: 10.1002/mabi.200800189

[195] Kangwansupamonkon W., Tiewtrakoonwat W., Supaphol P., Kiatkamjornwong S.: Surface modification of electrospun chitosan nanofibrous mats for antibacterial activity. Journal of Applied Polymer Science, 131, 1-9 (2014).

DOI: 10.1002/app.40981

[196] Alipour S. M., Nouri M., Mokhtari J., Bahrami S. H.: Electrospinning of poly(vinyl alcohol)-water-soluble quaternized chitosan derivative blend. Carbohydrate Research, 344, 2496-2501 (2009).

DOI: $10.1016 /$ j.carres.2009.10.004

[197]Zong Z., Kimura Y., Takahashi M., Yamane H.: Characterization of chemical and solid state structures of acylated chitosans. Polymer, 41, 899-906 (2000). DOI: 10.1016/S0032-3861(99)00270-0
[198] Peesan M., Rujiravanit R., Supaphol P.: Electrospinning of hexanoyl chitosan/polylactide blends. Journal of Biomaterials Science, Polymer Edition, 17, 547-565 (2006). DOI: $10.1163 / 156856206776986251$

[199] Alsberg E., Anderson K. W., Albeiruti A., Franceschi R. T., Mooney D. J.: Cell-interactive alginate hydrogels for bone tissue engineering. Journal of Dental Research, 80, 2025-2029 (2001). DOI: $10.1177 / 00220345010800111501$

[200] Dar A., Shachar M., Leor J., Cohen S.: Optimization of cardiac cell seeding and distribution in $3 \mathrm{D}$ porous alginate scaffolds. Biotechnology and Bioengineering, 80, 305-312 (2002).

DOI: $10.1002 /$ bit.10372

[201] Hashimoto T., Suzuki Y., Tanihara M., Kakimaru Y., Suzuki K.: Development of alginate wound dressings linked with hybrid peptides derived from laminin and elastin. Biomaterials, 25, 1407-1414 (2004).

DOI: $10.1016 /$ j.biomaterials.2003.07.004

[202] Davis T. A., Volesky B., Mucci A.: A review of the biochemistry of heavy metal biosorption by brown algae. Water Research, 37, 4311-4330 (2003).

DOI: $10.1016 / \mathrm{S} 0043-1354(03) 00293-8$

[203] Papageorgiou S. K., Katsaros F. K., Kouvelos E. P., Kanellopoulos N. K.: Prediction of binary adsorption isotherms of $\mathrm{Cu}^{2+}, \mathrm{Cd}^{2+}$ and $\mathrm{Pb}^{2+}$ on calcium alginate beads from single adsorption data. Journal of Hazardous Materials, 162, 1347-1354 (2009).

DOI: $10.1016 /$ j.jhazmat.2008.06.022

[204] Xiao C., Lu Y., Liu H., Zhang L.: Preparation and physical properties of blend films from sodium alginate and polyacrylamide solutions. Journal of Macromolecular Science Part A: Pure and Applied Chemistry, 37, 1663-1675 (2000).

DOI: $10.1081 / \mathrm{MA}-100102332$

[205] Caykara T., Demirci S., Eroğlu M. S., Güven O.: Poly (ethylene oxide) and its blends with sodium alginate. Polymer, 46, 10750-10757 (2005). DOI: $10.1016 /$ j.polymer.2005.09.041

[206] Omidian H., Rocca J. G., Park K.: Elastic, superporous hydrogel hybrids of polyacrylamide and sodium alginate. Macromolecular Bioscience, 6, 703-710 (2006). DOI: 10.1002/mabi.200600062

[207] Bonino C. A., Krebs M. D., Saquing C. D., Jeong S. I., Shearer K. L., Alsberg E., Khan S. A.: Electrospinning alginate-based nanofibers: From blends to crosslinked low molecular weight alginate-only systems. Carbohydrate Polymers, 85, 111-119 (2011). DOI: $10.1016 /$ j.carbpol.2011.02.002

[208] Islam M. S., Ashaduzzaman M., Masum S. M., Yeum J. H.: Mechanical and electrical properties: Electrospun alginate/carbon nanotube composite nanofiber. Dhaka University Journal of Science, 60, 125-128 (2012). DOI: $10.3329 /$ dujs.v60i1.10350 
[209] Tarun K., Gobi N.: Calcium alginate/PVA blended nano fibre matrix for wound dressing. Indian Journal of Fibre and Textile Research, 37, 127-132 (2012).

[210] Lee Y. J., Shin D. S., Kwon O. W., Park W. H., Choi H. G., Lee Y. R., Han S. S., Noh S. K., Lyoo W. S.: Preparation of atactic poly(vinyl alcohol)/sodium alginate blend nanowebs by electrospinning. Journal of Applied Polymer Science, 106, 1337-1342 (2007).

DOI: 10.1002/app.26568

[211] Bhattarai N., Zhang M.: Controlled synthesis and structural stability of alginate-based nanofibers. Nanotechnology, 18, 455601/1-455601/10 (2007). DOI: $10.1088 / 0957-4484 / 18 / 45 / 455601$

[212] Alborzi S., Lim L. T., Kakuda Y.: Electrospinning of sodium alginate-pectin ultrafine fibers. Journal of Food Science, 75, C100-C107 (2010). DOI: $10.1111 / j .1750-3841.2009 .01437 . x$

[213] Park S. A., Park K. E., Kim W.: Preparation of sodium alginate/poly(ethylene oxide) blend nanofibers with lecithin. Macromolecular Research, 18, 891-896 (2010). DOI: $10.1007 / \mathrm{s} 13233-010-0909-\mathrm{y}$

[214] Jeong S. I., Krebs M. D., Bonino C. A., Samorezov J. E., Khan S. A., Alsberg E.: Electrospun chitosan-alginate nanofibers with in situ polyelectrolyte complexation for use as tissue engineering scaffolds. Tissue Engineering Part A, 17, 59-70 (2010).

DOI: $10.1089 /$ ten.tea.2010.0086

[215] Buttafoco L., Kolkman N. G., Engbers-Buijtenhuijs P., Poot A. A., Dijkstra P. J., Vermes I., Feijen J.: Electrospinning of collagen and elastin for tissue engineering applications. Biomaterials, 27, 724-734 (2006).

DOI: 10.1016/j.biomaterials.2005.06.024

[216] Telemeco T., Ayres C., Bowlin L. G., Wnek G. E., Boland E. D., Cohen N., Baumgarten C. M., Mathews J., Simpson D. G.: Regulation of cellular infiltration into tissue engineering scaffolds composed of submicron diameter fibrils produced by electrospinning. Acta Biomaterialia, 1, 377-385 (2005).

DOI: $10.1016 /$ j.actbio.2005.04.006

[217] Zhang Y. Z., Venugopal J., Huang Z-M., Lim C. T., Ramakrishna S.: Characterization of the surface biocompatibility of the electrospun PCL-collagen nanofibers using fibroblasts. Biomacromolecules, 6, 25832589 (2005).

DOI: $10.1021 / \mathrm{bm} 050314 \mathrm{k}$

[218] Li M., Mondrinos M. J., Gandhi M. R., Ko F. K., Weiss A. S., Lelkes P. I.: Electrospun protein fibers as matrices for tissue engineering. Biomaterials, 26, 59996008 (2005).

DOI: 10.1016/j.biomaterials.2005.03.030

[219] Zeugolis D. I., Khew S. T., Yew E. S., Ekaputra A. K., Tong Y. W., Yung L-Y. L., Hutmacher D.W., Sheppard C., Raghunath M.: Electro-spinning of pure collagen nano-fibres - Just an expensive way to make gelatin? Biomaterials, 29, 2293-2305 (2008). DOI: $10.1016 /$ j.biomaterials.2008.02.009
[220] Chakrapani V. Y., Gnanamani A., Giridev V. R., Madhusoothanan M., Sekaran G.: Electrospinning of type I collagen and PCL nanofibers using acetic acid. Journal of Applied Polymer Science, 125, 3221-3227 (2012). DOI: 10.1002/app.36504

[221] Kwon I. K., Matsuda T.: Co-electrospun nanofiber fabrics of poly(l-lactide-co-e-caprolactone) with type I collagen or heparin. Biomacromolecules, 6, 20962105 (2005). DOI: $10.1021 / \mathrm{bm} 050086 \mathrm{u}$

[222] Zhong S., Teo W. E., Zhu X., Beuerman R., Ramakrishna S., Yung L. Y. L.: Formation of collagen-glycosaminoglycan blended nanofibrous scaffolds and their biological properties. Biomacromolecules, 6, 2998-3004 (2005). DOI: $10.1021 / \mathrm{bm} 050318 \mathrm{p}$

[223] Haugh M. G., Jaasma M. J., O’Brien F. J.: The effect of dehydrothermal treatment on the mechanical and structural properties of collagen-GAG scaffolds. Journal of Biomedical Materials Research Part A, 89, 363-369 (2009).

DOI: $10.1002 / \mathrm{jbm} . a .31955$

[224] Davis J. F., Maffia G. J.: Collagen dispersions for liquid-solid separations in water treatment and sludge dewatering. Separations Technology, 5, 147-152 (1995). DOI: 10.1016/0956-9618(94)00120-H

[225] Zhang Y., Ouyang H., Lim C. T., Ramakrishna S., Huang Z-M.: Electrospinning of gelatin fibers and gelatin/PCL composite fibrous scaffolds. Journal of Biomedical Materials Research Part B: Applied Biomaterials, 72, 156-165 (2005).

DOI: $10.1002 / \mathrm{jbm} . \mathrm{b} .30128$

[226] Elliott D. E., Davis F. J., Mitchell G. R., Olley R. H.: Structure development in electrospun fibres of gelatin. Journal of Physics: Conference Series, 183, 012021/1012021/4 (2009).

DOI: $10.1088 / 1742-6596 / 183 / 1 / 012021$

[227] Huang Z-M., Zhang Y., Ramakrishna S., Lim C. T.: Electrospinning and mechanical characterization of gelatin nanofibers. Polymer, 45, 5361-5368 (2004). DOI: $10.1016 /$ j.polymer.2004.04.005

[228] Brenner E. K., Schiffman J. D., Thompson E. A., Toth L. J., Schauer C. L.: Electrospinning of hyaluronic acid nanofibers from aqueous ammonium solutions. Carbohydrate Polymers, 87, 926-929 (2012).

DOI: $10.1016 /$ j.carbpol.2011.07.033

[229] Lan S., Wu X., Li L., Li M., Guo F., Gan S.: Synthesis and characterization of hyaluronic acid-supported magnetic microspheres for copper ions removal. Colloids and Surfaces A: Physicochemical and Engineering Aspects, 425, 42-50 (2013).

DOI: $10.1016 /$ j.colsurfa.2013.02.059

[230] Ma G., Liu Y., Fang D., Chen J., Peng C., Fei X., Nie J.: Hyaluronic acid/chitosan polyelectrolyte complexes nanofibers prepared by electrospinning. Materials Letters, 74, 78-80 (2012). DOI: $10.1016 /$ j.matlet.2012.01.012 
[231] Uslu İ., Aytimur A.: Production and characterization of poly(vinyl alcohol)/poly(vinylpyrrolidone) iodine/ poly(ethylene glycol) electrospun fibers with (hydroxypropyl)methyl cellulose and aloe vera as promising material for wound dressing. Journal of Applied Polymer Science, 124, 3520-3524 (2012).

DOI: $10.1002 /$ app. 35525

[232] Uslu I., Keskin S., Gül A., Karabulut T. C., Aksu M. L.: Preparation and properties of electrospun poly (vinyl alcohol) blended hybrid polymer with aloe vera and HPMC as wound dressing. Hacettepe Journal of Biology and Chemistry, 38, 19-25 (2010).

[233] Surjushe A., Vasani R., Saple D. G.: Aloe vera: A short review. Indian Journal of Dermatology, 53, 163-166 (2008).

DOI: 10.4103/0019-5154.44785

[234] Suganya S., Venugopal J., Mary S. A., Ramakrishna S., Lakshmi B., Dev V. G.: Aloe vera incorporated biomimetic nanofibrous scaffold: A regenerative approach for skin tissue engineering. Iranian Polymer Journal, 23, 237-248 (2014). DOI: $10.1007 / \mathrm{s} 13726-013-0219-2$

[235] Abdelgawad A. M., Hudson S. M., Rojas O. J.: Antimicrobial wound dressing nanofiber mats from multicomponent (chitosan/silver-NPs/polyvinyl alcohol) systems. Carbohydrate Polymers, 100, 166-178 (2014). DOI: 10.1016/j.carbpol.2012.12.043

[236] Li Q., Mahendra S., Lyon D. Y., Brunet L., Liga M. V., Li D., Alvarez P. J.: Antimicrobial nanomaterials for water disinfection and microbial control: Potential applications and implications. Water Research, 42, 4591-4602 (2008).

DOI: 10.1016/j.watres.2008.08.015

[237] Qu X., Alvarez P. J. J., Li Q.: Applications of nanotechnology in water and wastewater treatment. Water Research, 47, 3931-3946 (2013).

DOI: $10.1016 /$ j.watres.2012.09.058

[238] Tran Q. H., Nguyen V. Q., Le A-T.: Silver nanoparticles: Synthesis, properties, toxicology, applications and perspectives. Advances in Natural Sciences: Nanoscience and Nanotechnology, 4, 033001/1-033001/20 (2013).

DOI: $10.1088 / 2043-6262 / 4 / 3 / 033001$

[239] Nguyen T. T. T., Tae B., Park J. S.: Synthesis and characterization of nanofiber webs of chitosan/poly(vinyl alcohol) blends incorporated with silver nanoparticles. Journal of Materials Science, 46, 6528-6537 (2011).

DOI: $10.1007 / \mathrm{s} 10853-011-5599-0$

[240] An J., Zhang H., Zhang J., Zhao Y., Yuan X.: Preparation and antibacterial activity of electrospun chitosan/ poly(ethylene oxide) membranes containing silver nanoparticles. Colloid and Polymer Science, 287, 1425-1434 (2009).

DOI: $10.1007 / \mathrm{s} 00396-009-2108-y$
[241] Hang A. T., Tae B., Park J. S.: Non-woven mats of poly(vinyl alcohol)/chitosan blends containing silver nanoparticles: Fabrication and characterization. Carbohydrate Polymers, 82, 472-479 (2010).

DOI: $10.1016 /$ j.carbpol.2010.05.016

[242] Zhuang X., Cheng B., Kang W., Xu X.: Electrospun chitosan/gelatin nanofibers containing silver nanoparticles. Carbohydrate Polymers, 82, 524-527 (2010). DOI: 10.1016/j.carbpol.2010.04.085

[243] Lee S. J., Heo D. N., Moon J-H., Ko W-K., Lee J. B., Bae M. S., Park S. W., Kim J. E., Lee D. H., Kim E-C., Lee C. H., Kwon I. K.: Electrospun chitosan nanofibers with controlled levels of silver nanoparticles. Preparation, characterization and antibacterial activity. Carbohydrate Polymers, 111, 530-537 (2014).

DOI: $10.1016 /$ j.carbpol.2014.04.026

[244] Celebi H., Gurbuz M., Koparal S., Dogan A.: Development of antibacterial electrospun chitosan/poly(vinyl alcohol) nanofibers containing silver ion-incorporated HAP nanoparticles. Composite Interfaces, 20, 799812 (2013). DOI: $10.1080 / 15685543.2013 .819700$

[245] Kim H-W., Song J-H., Kim H-E.: Nanofiber generation of gelatin-hydroxyapatite biomimetics for guided tissue regeneration. Advanced Functional Materials, 15, 1988-1994 (2005). DOI: $10.1002 / \mathrm{adfm} .200500116$

[246] Ayutsede J., Gandhi M., Sukigara S., Ye H., Hsu C-M., Gogotsi Y., Ko F.: Carbon nanotube reinforced Bombyx mori silk nanofibers by the electrospinning process. Biomacromolecules, 7, 208-214 (2006).

DOI: $10.1021 / \mathrm{bm} 0505888$

[247] Lu P., Hsieh Y-L.: Multiwalled carbon nanotube (MWCNT) reinforced cellulose fibers by electrospinning. ACS Applied Materials and Interfaces, 2, 24132420 (2010).

DOI: $10.1021 / \mathrm{am} 1004128$

[248] Feng W., Wu Z., Li Y., Feng Y., Yuan X.: The fabrication and electrochemical properties of electrospun nanofibers of a multiwalled carbon nanotube grafted by chitosan. Nanotechnology, 19, 105707/1-105707/6 (2008).

DOI: 10.1088/0957-4484/19/10/105707

[249] Pan H., Zhang Y., Hang Y., Shao H., Hu X., Xu Y., Feng C.: Significantly reinforced composite fibers electrospun from silk fibroin/carbon nanotube aqueous solutions. Biomacromolecules, 13, 2859-2867 (2012). DOI: $10.1021 / \mathrm{bm} 300877 \mathrm{~d}$

[250] Shalumon K. T., Anulekha K. H., Nair S. V., Nair S. V., Chennazhi K. P., Jayakumar R.: Sodium alginate/ poly(vinyl alcohol)/nano $\mathrm{ZnO}$ composite nanofibers for antibacterial wound dressings. International Journal of Biological Macromolecules, 49, 247-254 (2011). DOI: $10.1016 /$ j.ijbiomac.2011.04.005 
[251] Anitha S., Brabu B., Thiruvadigal D. J., Gopalakrishnan C., Natarajan T. S.: Optical, bactericidal and water repellent properties of electrospun nano-composite membranes of cellulose acetate and $\mathrm{ZnO}$. Carbohydrate Polymers, 87, 1065-1072 (2012).

DOI: $10.1016 /$ j.carbpol.2011.08.030

[252] Tian Y., Wu M., Liu R., Li Y., Wang D., Tan J., Wu R., Huang Y.: Electrospun membrane of cellulose acetate for heavy metal ion adsorption in water treatment. Carbohydrate Polymers, 83, 743-748 (2011).

DOI: $10.1016 /$ j.carbpol.2010.08.054

[253] Guibal E.: Interactions of metal ions with chitosanbased sorbents: A review. Separation and Purification Technology, 38, 43-74 (2004). DOI: 10.1016/j.seppur.2003.10.004

[254] Desai K., Kit K., Li J., Davidson P. M., Zivanovic S., Meyer H.: Nanofibrous chitosan non-wovens for filtration applications. Polymer, 50, 3661-3669 (2009). DOI: $10.1016 /$ j.polymer.2009.05.058

[255] Ki C. S., Gang E. H., Um I. C., Park Y. H.: Nanofibrous membrane of wool keratose/silk fibroin blend for heavy metal ion adsorption. Journal of Membrane Science, 302, 20-26 (2007).

DOI: $10.1016 /$ j.memsci.2007.06.003

[256] Yang R., Aubrecht K. B., Ma H., Wang R., Grubbs R. B., Hsiao B. S., Chu B.: Thiol-modified cellulose nanofibrous composite membranes for chromium (VI) and lead (II) adsorption. Polymer, 55, 1167-1176 (2014).

DOI: 10.1016/j.polymer.2014.01.043

[257] Wang R., Guan S., Sato A., Wang X., Wang Z., Yang R., Hsiao B. S., Chu B.: Nanofibrous microfiltration membranes capable of removing bacteria, viruses and heavy metal ions. Journal of Membrane Science, 446, 376382 (2013).

DOI: $10.1016 /$ j.memsci.2013.06.020

[258] Wang X., Yeh T-M., Wang Z., Yang R., Wang R., Ma H., Hsiao B. S., Chu B.: Nanofiltration membranes prepared by interfacial polymerization on thin-film nanofibrous composite scaffold. Polymer, 55, 1358-1366 (2014).

DOI: $\underline{10.1016 / j . p o l y m e r .2013 .12 .007 ~}$
[259] Yoon K., Kim K., Wang X., Fang D., Hsiao B. S., Chu B.: High flux ultrafiltration membranes based on electrospun nanofibrous PAN scaffolds and chitosan coating. Polymer, 47, 2434-2441 (2006). DOI: $10.1016 /$ j.polymer.2006.01.042

[260] Wang M., Meng G., Huang Q., Qian Y.: Electrospun 1,4-DHAQ-doped cellulose nanofiber films for reusable fluorescence detection of trace $\mathrm{Cu}^{2+}$ and further for $\mathrm{Cr}^{3+}$. Environmental Science and Technology, 46, 367373 (2011). DOI: $10.1021 / \mathrm{es} 202137 \mathrm{c}$

[261] Kacmaz S., Ertekin K., Suslu A., Ergun Y., Celik E., Cocen U.: Sub-nanomolar sensing of ionic mercury with polymeric electrospun nanofibers. Materials Chemistry and Physics, 133, 547-552 (2012). DOI: $10.1016 /$ j.matchemphys.2012.01.081

[262] Ongun M. Z., Ertekin K., Gocmenturk M., Ergun Y., Suslu A.: Copper ion sensing with fluorescent electrospun nanofibers. Spectrochimica Acta Part A: Molecular and Biomolecular Spectroscopy, 90, 177-185 (2012). DOI: $10.1016 /$ j.saa.2012.01.042

[263] Kacmaz S., Ertekin K., Gocmenturk M., Suslu A., Ergun Y., Celik E.: Selective sensing of $\mathrm{Fe}^{3+}$ at picomolar level with ethyl cellulose based electrospun nanofibers. Reactive and Functional Polymers, 73, 674-682 (2013). DOI: $10.1016 /$ j.reactfunctpolym.2013.02.003

[264] Ongun M. Z., Ertekin K., Hizliates C. G., Oter O., Ergun Y., Celik E.: Determination of $\mathrm{Hg}(\mathrm{II})$ at subnanomolar levels: A comparative study with nanofibrous materials and continuous thin films. Sensors and Actuators B: Chemical, 181, 244-250 (2013). DOI: $10.1016 /$ j.snb.2013.01.055

[265]Zdyrko B.: Nanofibrous materials as sensors for heavy metals. NTC Project: M10-CL03 report (2011). 